\title{
WestVirginiaUniversity
}

THE RESEARCH REPOSITORY @ WVU

Graduate Theses, Dissertations, and Problem Reports

2006

\section{Dynamic model of circulating fluidized bed}

\author{
Yue Huang \\ West Virginia University
}

Follow this and additional works at: https://researchrepository.wvu.edu/etd

\section{Recommended Citation}

Huang, Yue, "Dynamic model of circulating fluidized bed" (2006). Graduate Theses, Dissertations, and Problem Reports. 2749.

https://researchrepository.wvu.edu/etd/2749

This Dissertation is protected by copyright and/or related rights. It has been brought to you by the The Research Repository @ WVU with permission from the rights-holder(s). You are free to use this Dissertation in any way that is permitted by the copyright and related rights legislation that applies to your use. For other uses you must obtain permission from the rights-holder(s) directly, unless additional rights are indicated by a Creative Commons license in the record and/ or on the work itself. This Dissertation has been accepted for inclusion in WVU Graduate Theses, Dissertations, and Problem Reports collection by an authorized administrator of The Research Repository @ WVU.

For more information, please contact researchrepository@mail.wvu.edu. 


\title{
Dynamic Model of Circulating Fluidized Bed
}

\author{
Yue Huang \\ Dissertation submitted to the \\ College of Engineering and Mineral Resources \\ at West Virginia University \\ in partial fulfillment of the requirements \\ for the degree of \\ Doctor of Philosophy \\ in \\ Chemical Engineering \\ Richard Turton, Ph.D., Chair \\ Parviz Famouri, Ph.D. \\ Edward J. Boyle, Ph.D. \\ John W. Zondlo, Ph.D. \\ Charter D. Stinespring, Ph.D. \\ Department of Chemical Engineering \\ Morgantown, West Virginia \\ 2006
}

Keywords: Circulating fluidized bed; Dynamic model; Riser; Standpipe; Real time 


\title{
Dynamic Model of Circulating Fluidized Bed
}

\author{
Yue Huang
}

\begin{abstract}
Circulating fluidized beds (CFBs) are used in many processes in the chemical industry to reduce pollution and increase efficiency. Optimization and control of CFBs are very important and require an accurate, real time, dynamic model to describe and quantify the process.

The present work focuses on modeling the transient behavior of large CFB units, whose flow characteristics were shown to yield C-shaped voidage profiles using cork as the fluidized material and air at ambient conditions.

The riser is modeled in two ways: 1) as a set of well-mixed tanks connected in series; 2) as a 1-D axisymetric cluster flow. The tanks-in-series model visualizes the riser as consisting of a series of well-mixed vessels. Using this method, the dynamic response time at different locations along the riser was estimated successfully. The cluster flow model assumes that gas and solids flows are unidirectional with no mixing in the axial direction, and the solids move upward in the riser as clusters. This model can be used to predict the smooth changes in voidage profiles for transient processes. The influence of exit is also considered and a modified cluster model can be extended to the entire riser which includes an acceleration region, developed flow region and exit region. It can also be applied to a reacting system

A model based on the Ergun equation is developed to predict the solids flow rate and voidage in the dense phase of the standpipe. The profile of solids flow rate under unsteady state is also presented. Using this method, the dynamic response time at different locations along the standpipe is estimated successfully.

Using the pressure balance analysis, the above models are combined into an integrated CFB model. It can be applied to CFB real-time simulation under transient conditions.
\end{abstract}




\section{Acknowledgements}

I want to thank my wife, Huifang Shao, for supporting my work and life in a great and colorful manner, and also my daughter Cynthia who was born on May 2004 in Morgantown. She kept me awake while finishing my dissertation acknowledgements. I want to express our gratitude to our parents for their emotional and economic support. They have always trusted and given me unquestioning support.

I want to express my deepest gratitude to my research advisor, Dr. R. Turton, for his guidance, encouragement and support with great expertise during its different phases. I would like to thank Dr. P. Famouri and Dr. E. J. Boyle for working very closely with me and supporting my work. I also would like to express my appreciation to the other two committee members, Dr. J. W. Zondlo and Dr. C. D. Stinespring for their extended support. Their suggestions, comments and critique are gratefully acknowledged.

I am greatly indebted to Dr L. Shadle and his research team from NETL who gave invaluable support and guidance for this work. The financial support provided by DOE-EPSCoR is also gratefully acknowledged.

I am grateful to my colleagues at West Virginia University who have directly or indirectly supported my work. 


\section{Table of Contents}

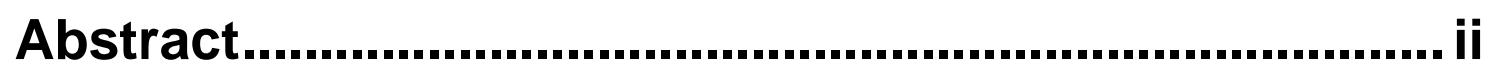

Acknowledgements .................................................... ii

List of Figures ............................................................... vii

List of Tables ................................................................... ix

Chapter 1 Introduction.............................................. 1

1.1. Background of the research............................................................. 1

1.2. Current problems and future objectives ............................................

\section{Chapter 2 Literature Review........................................ 4}

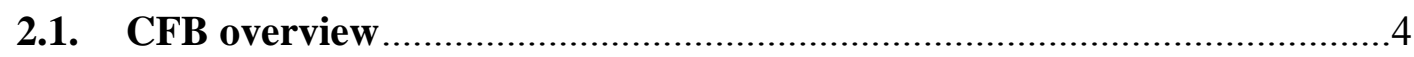

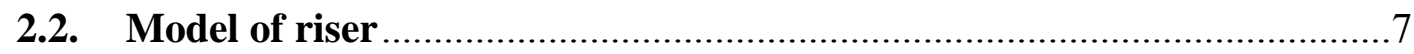

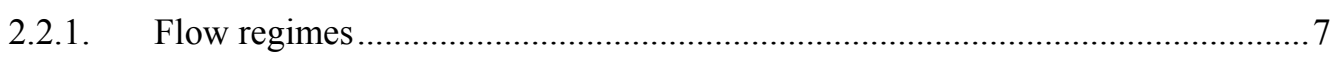

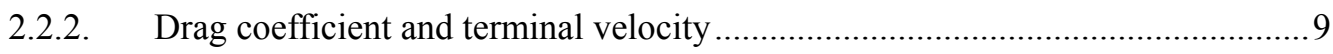

2.2.3. Voidage distribution in the riser (Empirical models) ........................................ 13

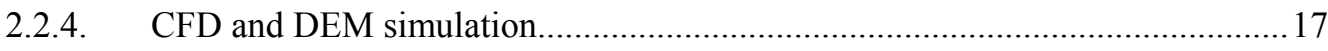

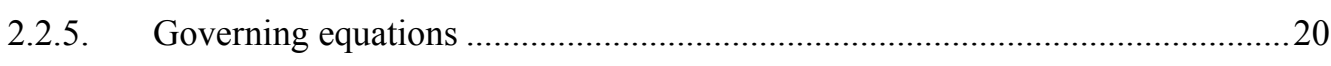

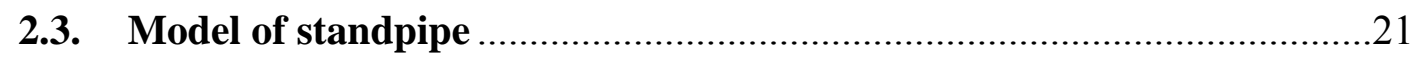

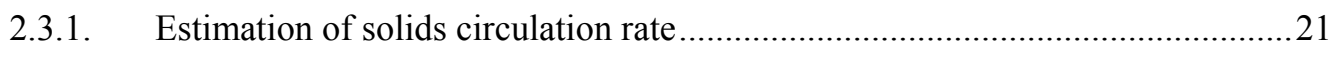

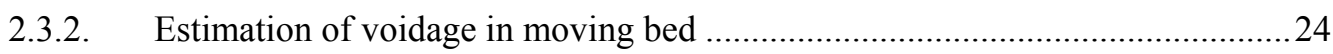

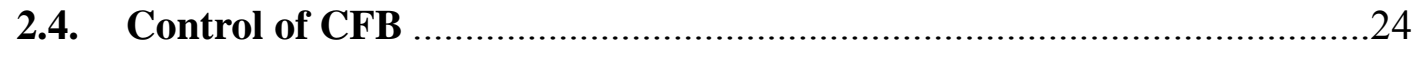

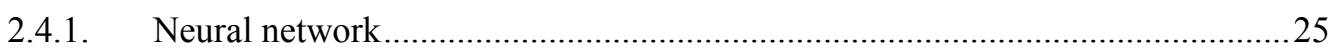

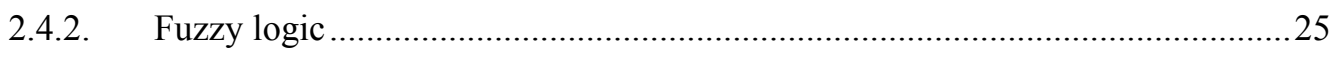

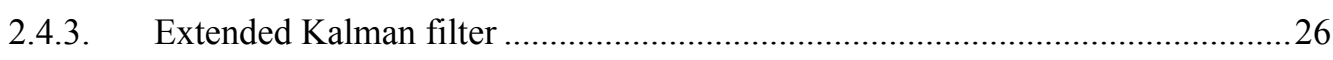

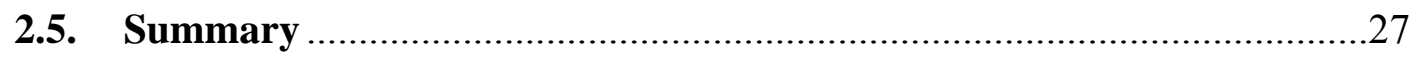




\section{Chapter 3 System Configuration}

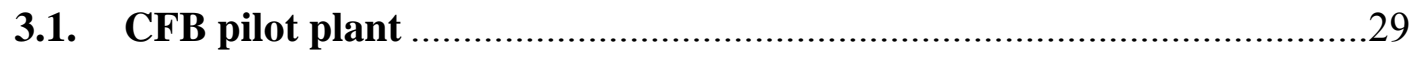

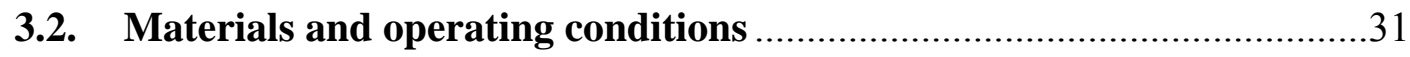

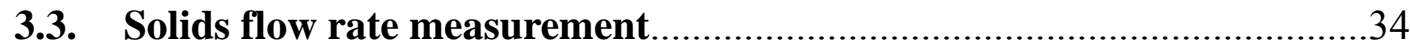

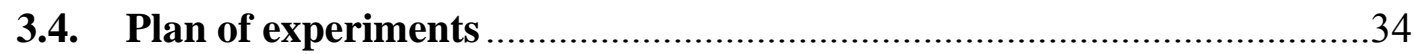

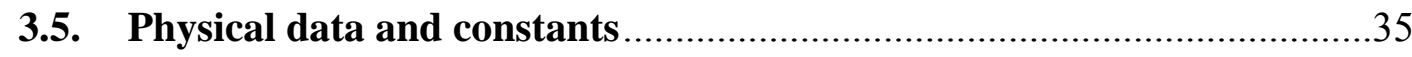

Chapter 4 Dynamic Model in the Riser...................... 37

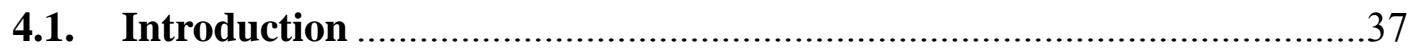

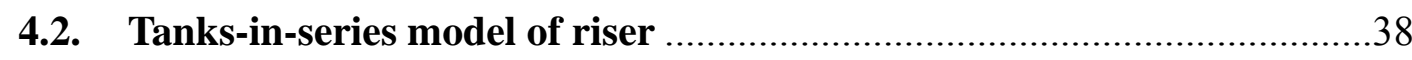

4.3. Steady state profile of voidage in the riser ..............................................45

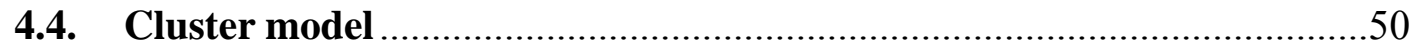

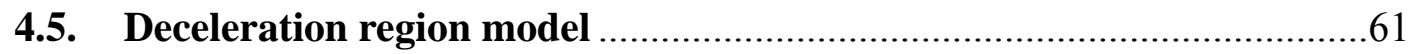

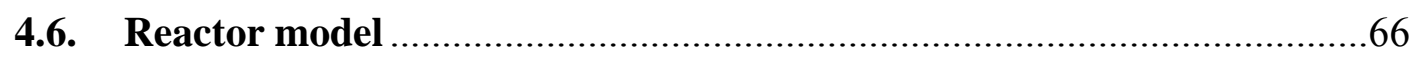

Chapter 5 Dynamic Model in the Standpipe .............70

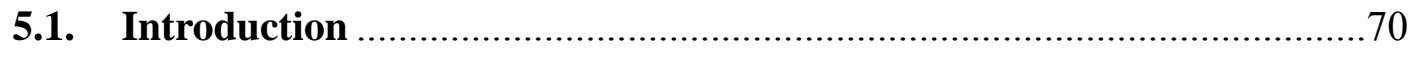

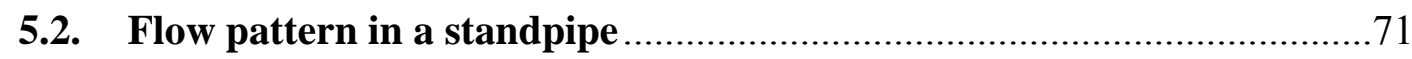

5.3. Prediction of solids flow rate by pressure drop measurement ................72

5.4. Profile of solids flow rate under unsteady state .......................................77

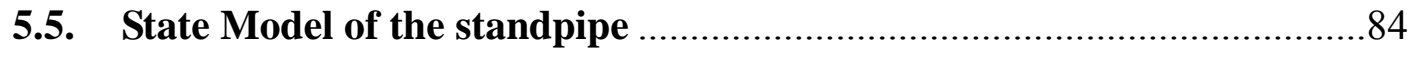

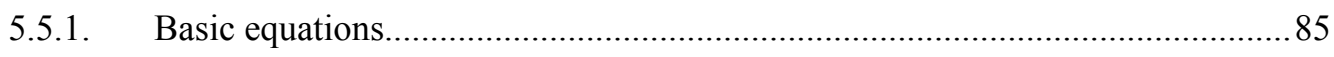

5.5.2. Prediction of standpipe bed height ............................................................. 86

5.5.3. Prediction of phase voidages....................................................................... 89

\section{Chapter 6 Integration of the CFB model ...................91}

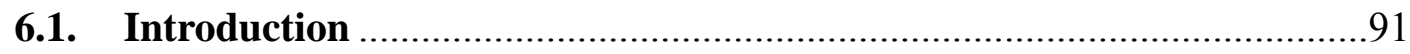

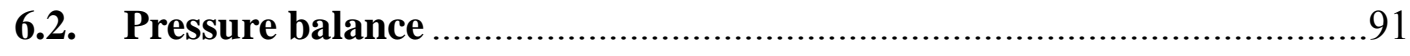


6.3. Integrated CFB model.

Chapter 7 Conclusions and Future Work .................98 98

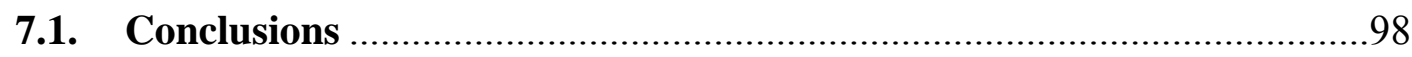

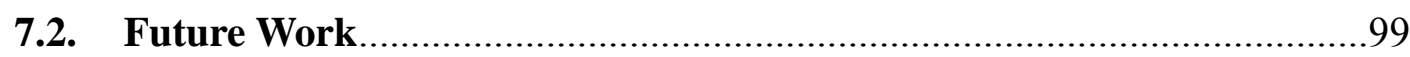

Nomenclature ................................................................. 100

References ................................................................. 103

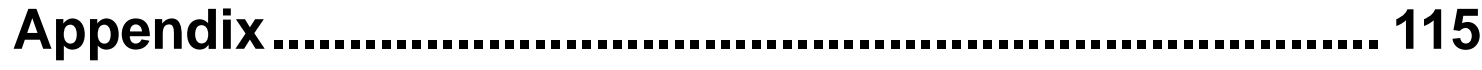

1. Matlab code for Cluster Model ..................................................... 115

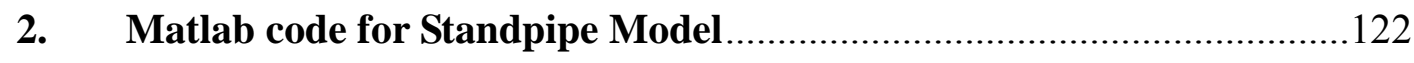

3. Matlab code for Integrated CFB Model ......................................... 124 


\section{List of Figures}

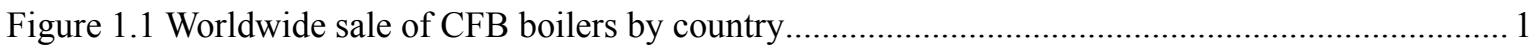

Figure 2.1 System configuration of circulating fluidized bed............................................................. 4

Figure 2.2 Different flow regimes (from Grace et al. [8]) .................................................................... 7

Figure 2.3 Fast fluidization boundaries......................................................................................... 9

Figure 2.4 Correlation of drag coefficients as a function of Reynolds number (from Turton et al. [15]) 11

Figure 2.5 Voidage distribution along bed height [20] ................................................................... 14

Figure 2.6 Computational time required to run a 1 second of simulation [37] .................................... 19

Figure 3.1 Cold flow CFB pilot plant at NETL ….......................................................................... 30

Figure 3.2 Schematic of cold flow CFB test facility ........................................................................ 31

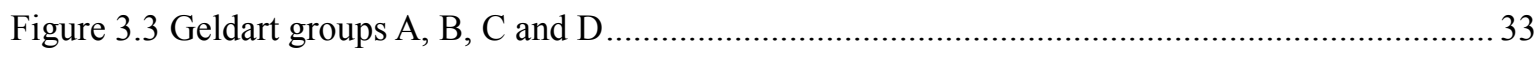

Figure 3.4 A helical-shaped spiral vane for solids flow rate measurement ............................................ 34

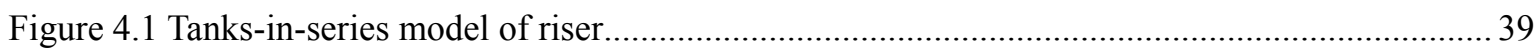

Figure 4.2 Concentrations of outflows for one-step input.................................................................. 40

Figure 4.3 Concentrations of outflows for sine function input ............................................................ 41

Figure 4.4 Mass flow rate of solids in a transient process ................................................................. 43

Figure 4.5 Prssure profiles at different locations in the riser for sine function input ............................. 44

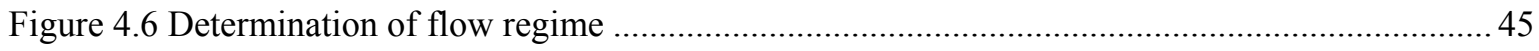

Figure $4.7 \mathrm{C}$-shape profiles of voidage in the experiments................................................................ 46

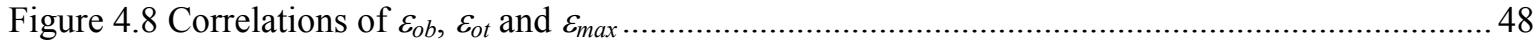

Figure 4.9 Comparison of steady state voidage profile model (dashed line) with the experimental data 49

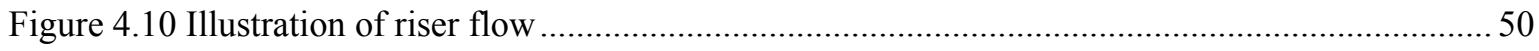

Figure 4.11 Cluster size prediction compared with LDV measurement in the lean phase of the riser.....53

Figure 4.12 An illustration of how cluster properties change along the height of the riser.....................54

Figure 4.13 Model predictions of axial pressure drop compared with experimental data at steady state 56

Figure 4.14 Model predictions of axial solids velocity profiles drop at steady state ..............................57

Figure 4.15 Model predictions of axial pressure drop compared with experimental data at different

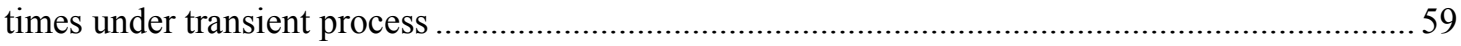

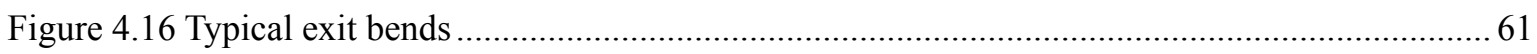

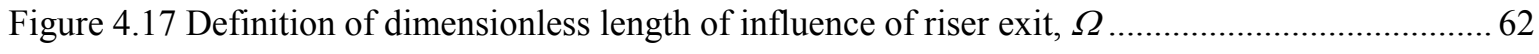

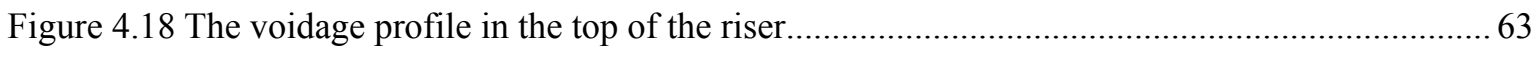

Figure 4.19 Model predictions of axial pressure drop along the entire riser compared with experimental data at different times under transient process ........................................................ 65

Figure 4.20 Model predictions of $\mathrm{O}_{2}$ concentration profile along the riser for steady state ...................68

Figure 4.21 Model predictions of $\mathrm{O}_{2}$ concentration profile along the riser for transient process ............ 69

Figure 5.1 Inconsistency between data for move-air and solids flows.................................................. 72

Figure 5.2 Linear relationship between pressure gradient and superficial velocity of solids for the

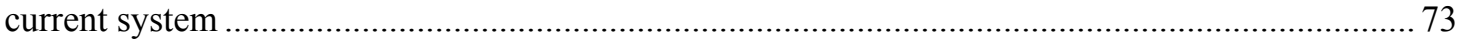

Figure 5.3 Linear relationship between gas and solids interstitial .................................................. 75 
Figure 5.4 Predictions of solids flow rate in the dense phase of standpipe by pressure drop ................. 76

Figure 5.5 Linearization of $U_{s}$ vs. $\varepsilon$ in non-fluidized flow regime..................................................... 78

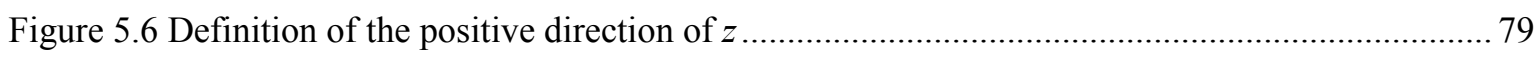

Figure 5.7 Pressure drop measurements used as boundary condition .................................................. 80

Figure 5.8 Experimental data and model predictions of pressure drop at $z=5 \mathrm{~m}$............................... 80

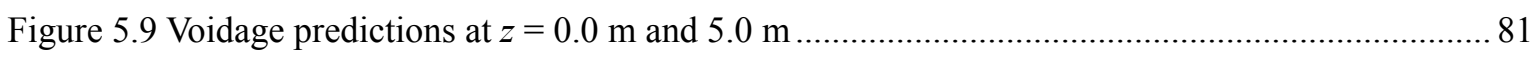

Figure 5.10 Control volume encompassing the continuity wave ...................................................... 83

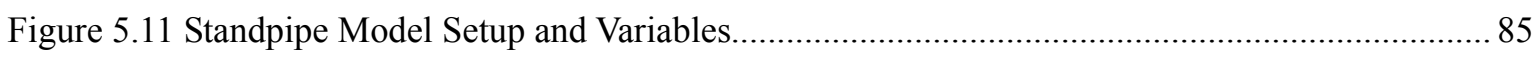

Figure 5.12 The known and unknown variables in standpipe model ................................................. 86

Figure 5.13 Diagram showing relationship between lean region, dense region, and overall bed

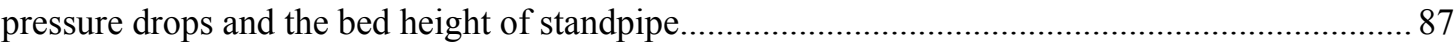

Figure 5.14 Prediction of the standpipe bed height using pressure measurements and Eqns 5.30, 5.33,

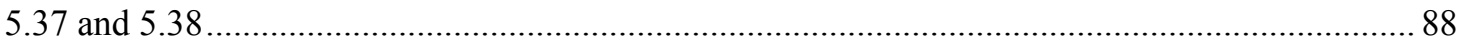

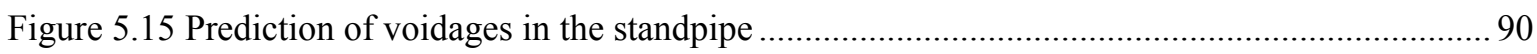

Figure 6.1 Schematic diagram for pressure balance of a CFB system ............................................. 92

Figure 6.2 Pressure drops along the CFB loop under a transient process ........................................... 93

Figure 6.3 Pressure balance from experimental measurements .......................................................... 93

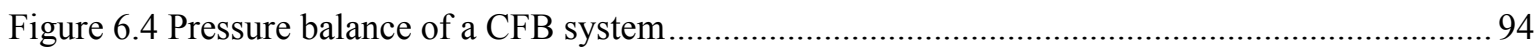

Figure 6.5 The known and unknown variables in the integrated CFB model ........................................ 95

Figure 6.6 Results of the integrated CFB model under Matlab 7.0 environment.................................. 97 


\section{List of Tables}

Table 2.1 Typical advantages and disadvantages of CFB reactors relative to conventional low-velocity

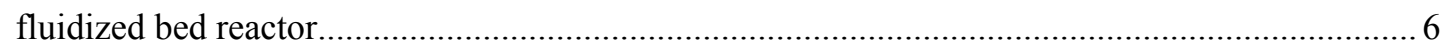

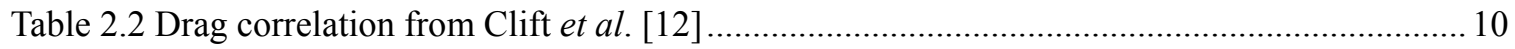

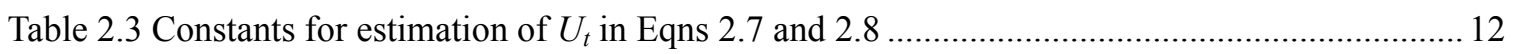

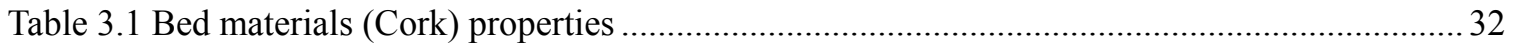

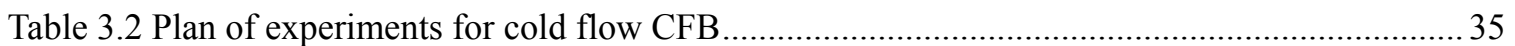




\section{Chapter 1 Introduction}

\subsection{Background of the research}

Since the late 1970s there has been an explosion of industrial and academic interest in circulating fluidized bed (CFB) technology due to its environmental advantages [1]. A number of CFB processes have been commercialized in the past two decades and have been widely used in the petrochemical industry [2], for power generation [3], and for waste treatment [4]. Currently, the CFB units are operating in more than 20 countries, with additional countries focusing on this technology to solve environmental, waste and fuel problems [1]. The worldwide sale of the CFB boilers is depicted in Figure 1.1. Percentages are calculated based on the number of installed units in each country.

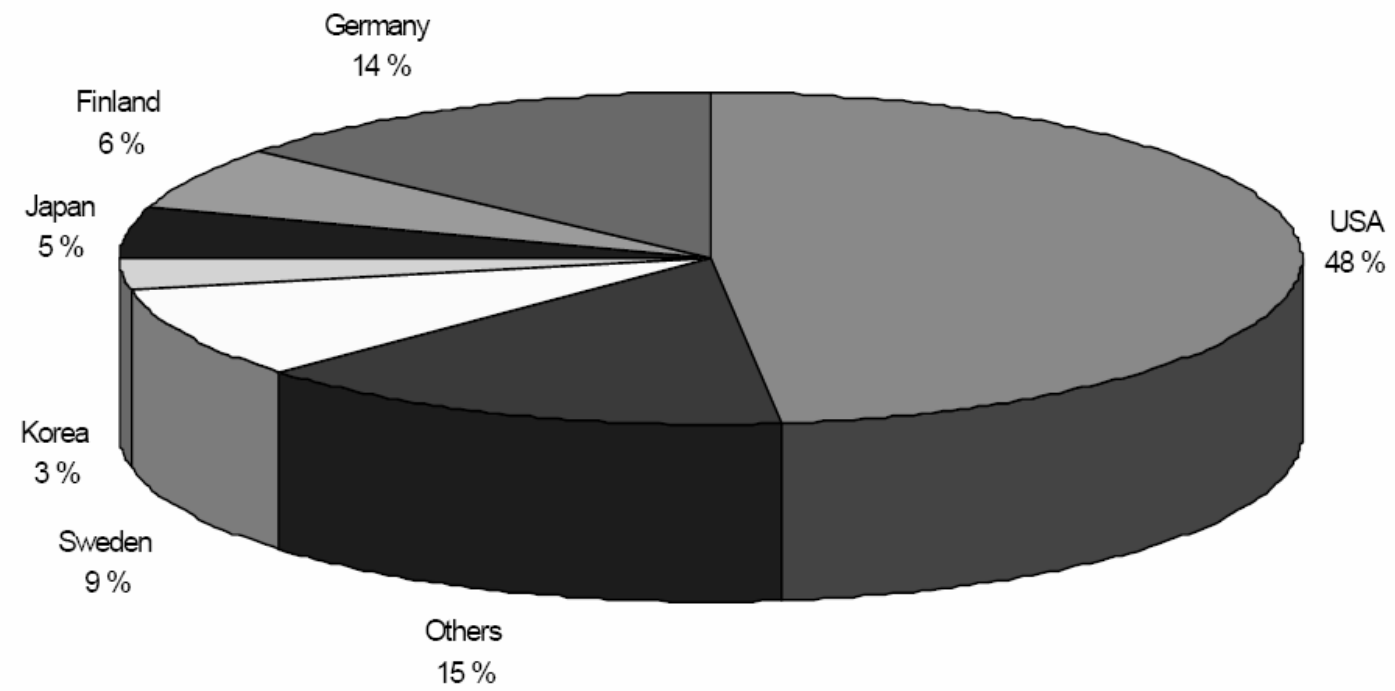

Figure 1.1 Worldwide sale of CFB boilers by country

Fluid catalytic cracking (FCC) and circulating fluidized bed combustion (CFBC) are 
by far the most common technologies that utilize CFBs.

FCC was the first application of fine-powder fluidization, and it has been commercialized for more than 60 years since the installation of the first FCC unit (Esso's Model I in 1942) [5]. FCC units convert heavy fuel oil and petroleum residue to lighter products. Major FCC products are gasoline, diesel fuel, heating oil, heavy cycle oils and light gases. Currently, FCC is still the major application of fluidization with over 350 FCC units operating worldwide, and with new ones coming on stream every year. FCC has an enormous economic impact on petroleum refining and hence on the worldwide economy.

Demand for electric power continues to rise steeply due to economic development and population growth. Pulverized coal-fired boilers continue to play a major role worldwide, but they have inherent issues such as fuel inflexibility, environmental concerns and higher maintenance costs. A new technology must be selected to utilize a wide range of low-cost solid fuels, reduce emissions, reduce life cycle costs and provide reliable steam generation for electrical power generation. Therefore, CFB is often the preferred technology. Currently, there are more than 400 CFB combustors in operation worldwide, ranging from $5 \mathrm{MW}$ to $250 \mathrm{MW}[6]$.

\subsection{Current problems and future objectives}

Automation system vendors, universities, research centers, and the process industry continually strive to invent new and better methods to keep processes under control. 
The reason is evident and simple: all companies must be competitive to survive. Better quality and performance, high availability and increased production at a lower cost are the targets to be achieved [7]. Much research, on several kinds of applications, has been performed to fulfill the existing demands.

CFB technology was developed approximately 30 years ago. It is relatively mature, and most likely will play an important role in future processes. Due to the large scale of processes using this technology, small increases in overall system efficiency, through both improved raw material usage and utility consumption, can yield substantial savings. Therefore, optimization and control for CFB applications is very important and requires an accurate, real time model to describe and quantify the process. Although large amounts of experimental data are available, a sufficiently general and reliable model for the purpose of on-line control and monitoring of pilot or industrial scale units has not yet been developed.

The research work introduced in this dissertation was carried out in co-operation with the National Energy Technology Laboratory (NETL), US Department of Energy (USDOE), in Morgantown, West Virginia since 2001. This work discusses the development of dynamic models for controlling and managing performance of a pilot-scale circulating fluidized bed. Its objective is to obtain a real-time, phenomenological model for the CFB system so that the solids inventory, flow rates of gas and solids, pressure profiles other essential information and can be predicted under transient processes. 


\section{Chapter 2 Literature Review}

\subsection{CFB overview}

The riser, cyclone separator, standpipe and solids flow control device are the four integral parts of a CFB loop (Figure 2.1).

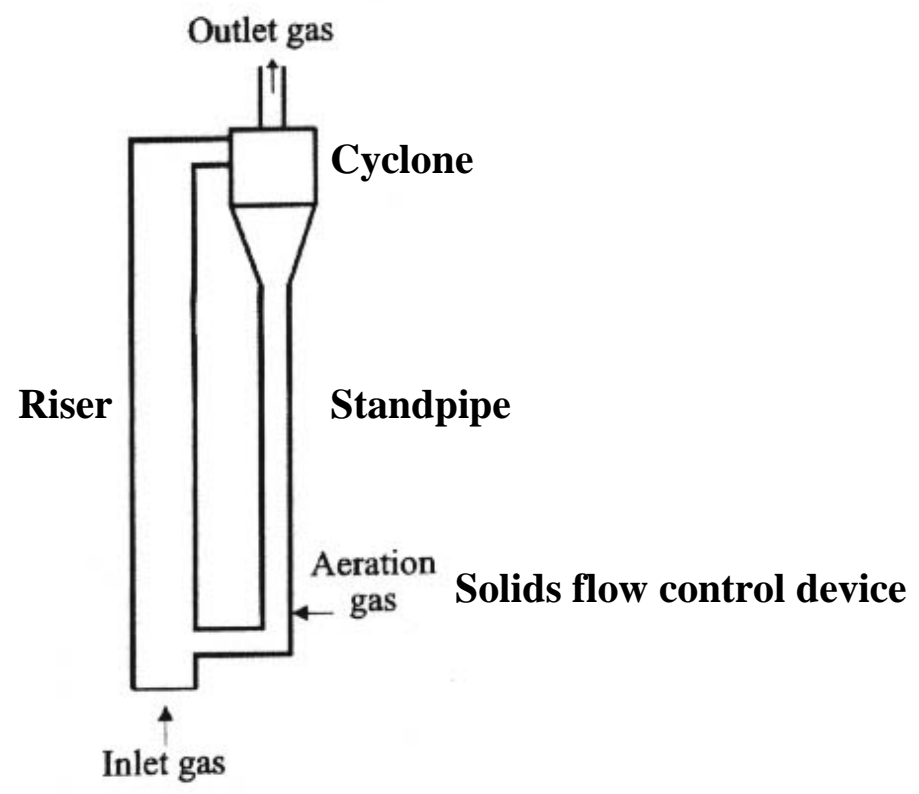

Figure 2.1 System configuration of circulating fluidized bed

The riser is the main component, in which gas and solids flow cocurrently upward. The gas is introduced at the bottom of the riser and the solid particles are fed from the standpipe via a flow control device and carried upward in the riser. Particles exit at the top of the riser into the cyclone separator and separated particles then flow to the standpipe and return to the riser. The entrance and exit geometries have a significant effect on the gas and solid flow behavior in the riser. 
The efficiency of the cyclone separator can affect the particle size distribution and solids circulation rate in the system.

The standpipe is a straight pipe which provides direct passage, and a static pressure head, for particles recycling to the riser. In applications involving chemical reactions, the standpipe may also be used as a heat exchanger or as a spent solids regenerator.

The key to smooth operation of a CFB system is the effective control of the solids circulation rate to the riser. The solids flow device serves two major functions, namely, sealing the riser gas flow from the standpipe and controlling the solids circulation rate. Both mechanical valves or feeders and nonmechanical valves are used to perform these functions, which will be discussed in Section 5.3.

A comparison of CFBs with conventional low velocity fluidized beds is given in Table $2.1[1]$. 
Table 2.1 Typical advantages and disadvantages of CFB reactors relative to conventional low-velocity fluidized bed reactor

\section{Advantages:}

1. Improved gas-solid contacting because of the lack of bubbles;

2. Reduced axial dispersion of gas;

3. Reduced cross-sectional area given the higher superficial velocities;

4. Potentially more control over suspension-to-wall heat transfer because of the ability to use the solids circulation flux as an additional variable;

5. No region like the freeboard region of low-velocity beds where there can be substantial temperature gradients;

6. Less tendency for particle segregation and agglomeration;

7. Recirculation loop provides a location where a separate operation (e.g. regeneration or heat transfer) can be carried out;

8. Higher solids flux through the reactor;

9. Increased turndown rate - allowing greater operating flexibility.

Disadvantages:

1. Increases overall reactor height;

2. Higher capital cost;

3. Decreased suspension-to-wall heat transfer coefficients for given particles;

4. Somewhat more restricted range of particle properties;

5. Added complexity in designing and operating recirculating loop;

6. Increased particle attrition. 


\subsection{Model of riser}

\subsubsection{Flow regimes}

Processes involving both a gas and solid phase are very common in the chemical industry. Heat or mass transfer and chemical reaction in such processes depend on the interaction of the two phases within the bed. Figure 2.2 [8] depicts the different flow regimes as defined by the solid-gas characteristics, bed geometry, gas velocity and solids circulation rate.
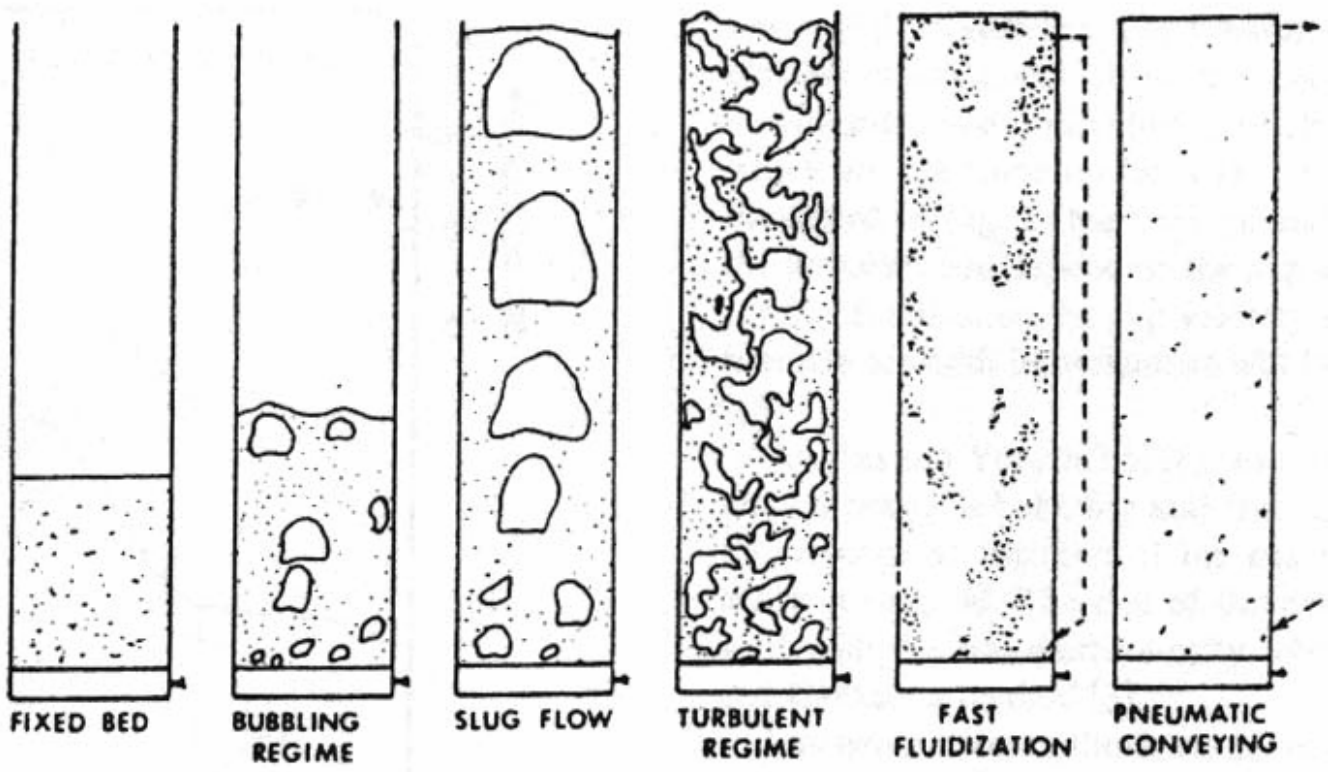

Figure 2.2 Different flow regimes (from Grace et al. [8])

A review of the fixed bed and bubbling fluidized bed regimes is beyond the scope of the present research. The fast-fluidized regime is the principal regime under which the circulating fluidized bed is operated, because it can provide sufficient contact between gas and solids to improve the heat and mass transfer and chemical reactions. The 
interrelationship of the fast fluidization regime with other fluidization regimes in dense-phase fluidization and with the dilute transport regime is reflected in the variations of the pressure gradient (i.e. $\Delta P / \Delta z$ ), gas velocity, and solids circulation rate [9], as given in Figure 2.3 [10]. With this in mind, three parameters are defined:

1) $U_{t f}$ is the minimum gas velocity for a given solids circulation rate. An empirical correlation was proposed as [11]

$$
\frac{U_{t f}}{\sqrt{g d_{p}}}=39.8\left(\frac{J_{s}}{\rho_{g} U_{t f}}\right)^{0.311} \operatorname{Re}_{t}^{-0.078}
$$

2) $U_{f d}$ is the maximum gas velocity for a given solids circulation rate. An empirical correlation has been proposed as [11]

$$
\frac{U_{f d}}{\sqrt{g d_{p}}}=21.6\left(\frac{J_{s}}{\rho_{g} U_{f d}}\right)^{0.542} A r^{0.105}
$$

3) The transport velocity, $U_{t r}$, marks the lower limit of the gas velocity for fast fluidization operation. It corresponds to the intersection point of the curves of the two parameters given above. 


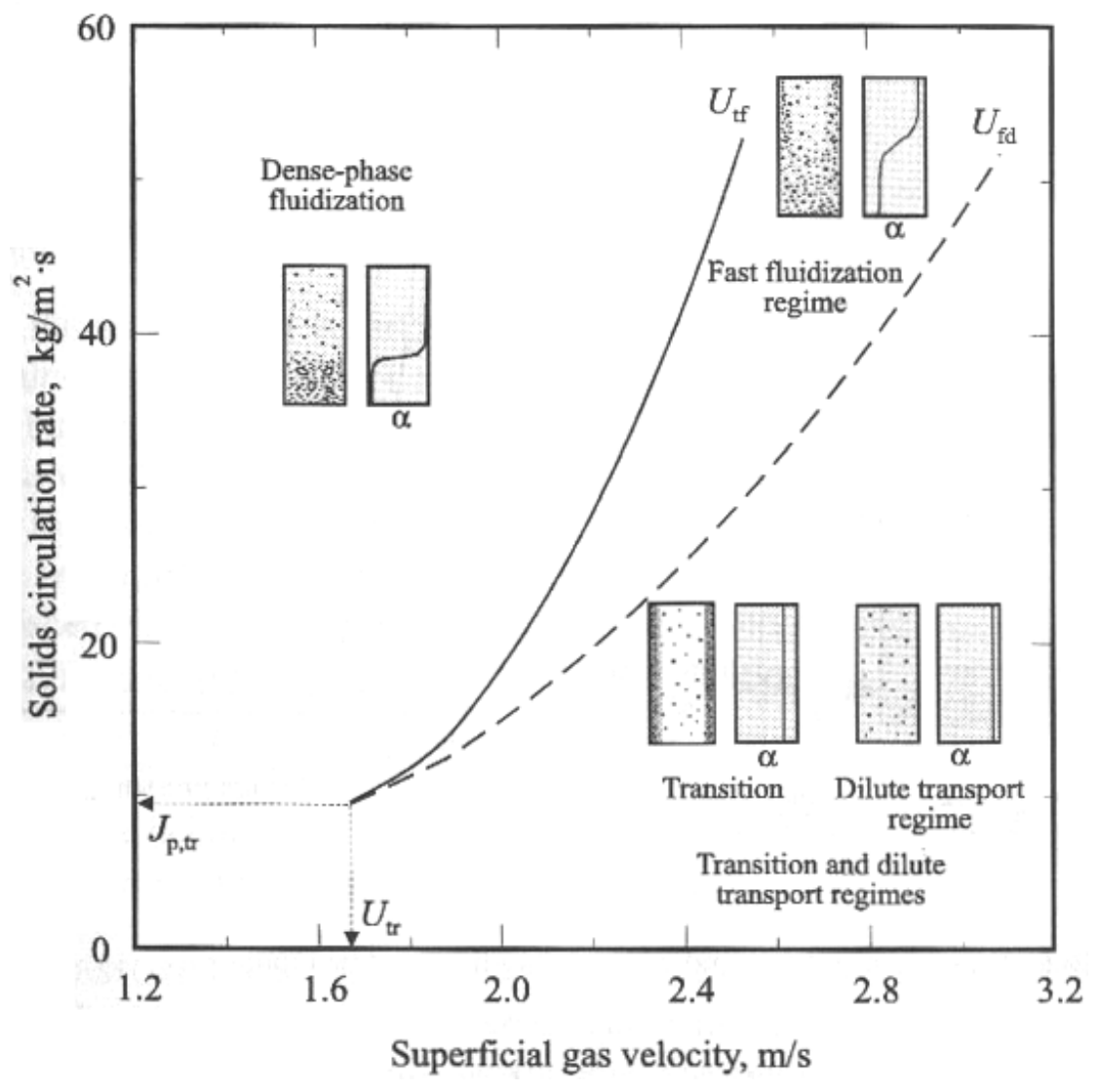

Figure 2.3 Fast fluidization boundaries

\subsubsection{Drag coefficient and terminal velocity}

In gas-solids flows, the flow patterns of both phases depend not only on the initial conditions and physical boundaries of the system but also on the mechanisms of momentum transfer or the interacting forces between the phases.

Among the interacting forces between the phases, the drag force is the most important, especially, in situations with a large slip velocity. The drag coefficient, $C_{D}$, is a number that is used to model all of the complex dependencies of shape and flow conditions on an object's drag. This equation, shown as Eq. 2.3, is simply a rearrangement of the drag equation where the drag coefficient is expressed in terms of the other variables. 


$$
C_{D}=\frac{F_{d}}{\rho_{f} A u^{2} / 2}
$$

where $F_{d}$ is the drag force; $\rho_{f}$ is the density of fluid, $u$ is the slip velocity and $A$ is the reference area.

There are well over 30 equations in the literature relating the drag coefficient $C_{D}$ to the Reynolds number, $R e$, of spheres falling at their terminal velocities.

A comprehensive review of the available correlations is given by Clift et al. [12], who present a new correlation based on a critical review of published data. This correlation consists of six polynomial equations with a total of 18 fitted constants, which is given in Table 2.2.

Table 2.2 Drag correlation from Clift et al. [12]

\begin{tabular}{ll}
\hline Re range & Correlation \\
\hline $0.01<\operatorname{Re} \leq 20$ & $\lg \left(\frac{C_{D} \operatorname{Re}}{24}-1\right)=-0.881+0.82 w-0.05 w^{2}$ \\
$20<\operatorname{Re} \leq 260$ & $\lg \left(\frac{C_{D} \operatorname{Re}}{24}-1\right)=-0.7133+0.6305 w$ \\
$260<\operatorname{Re} \leq 1500$ & $\lg C_{D}=1.6435-1.1242 w+0.1558 w^{2}$ \\
$1500<\operatorname{Re} \leq 1.2 \times 10^{4}$ & $\lg C_{D}=-2.4571+2.5558 w-0.9295 w^{2}+0.1049 w^{3}$ \\
$1.2 \times 10^{4}<\operatorname{Re} \leq 4.4 \times 10^{4}$ & $\lg C_{D}=-1.9181+0.6370 w-0.0636 w^{2}$ \\
$4.4 \times 10^{4}<\operatorname{Re} \leq 3.38 \times 10^{5}$ & $\lg C_{D}=-4.3390+1.5809 w-0.1546 w^{2}$ \\
& where $w=\lg \operatorname{Re}$
\end{tabular}

Khan and Richardson [13] compiled experimental results of various researchers, and using nonlinear regression on 300 data point, proposed the following drag equation for 
$\operatorname{Re}<3 \times 10^{5}$ :

$$
C_{D}=\left(2.25 \mathrm{Re}^{-0.31}+0.36 \mathrm{Re}^{0.06}\right)^{3.45}
$$

Flemmer and Banks [14] proposed, for $\operatorname{Re}<8.6 \times 10^{4}$,

$$
C_{D}=\frac{24}{\operatorname{Re}} 10^{0.261 \mathrm{Re}^{0.369}-0.105 \mathrm{Re}^{0.431}-\frac{0.124}{1+(\lg \mathrm{Re})^{2}}}
$$

Turton and Levenspiel [15], using the equation form proposed by Clift and Gauvin [16] plus 408 previously reported experimental data points, presented the following correlation for $\operatorname{Re}<2.6 \times 10^{5}$ :

$$
C_{D}=\frac{24}{\operatorname{Re}}\left(1+0.173 \operatorname{Re}^{0.657}\right)+\frac{0.413}{1+16300 \mathrm{Re}^{-1.09}}
$$

which is displayed in Figure 2.4.

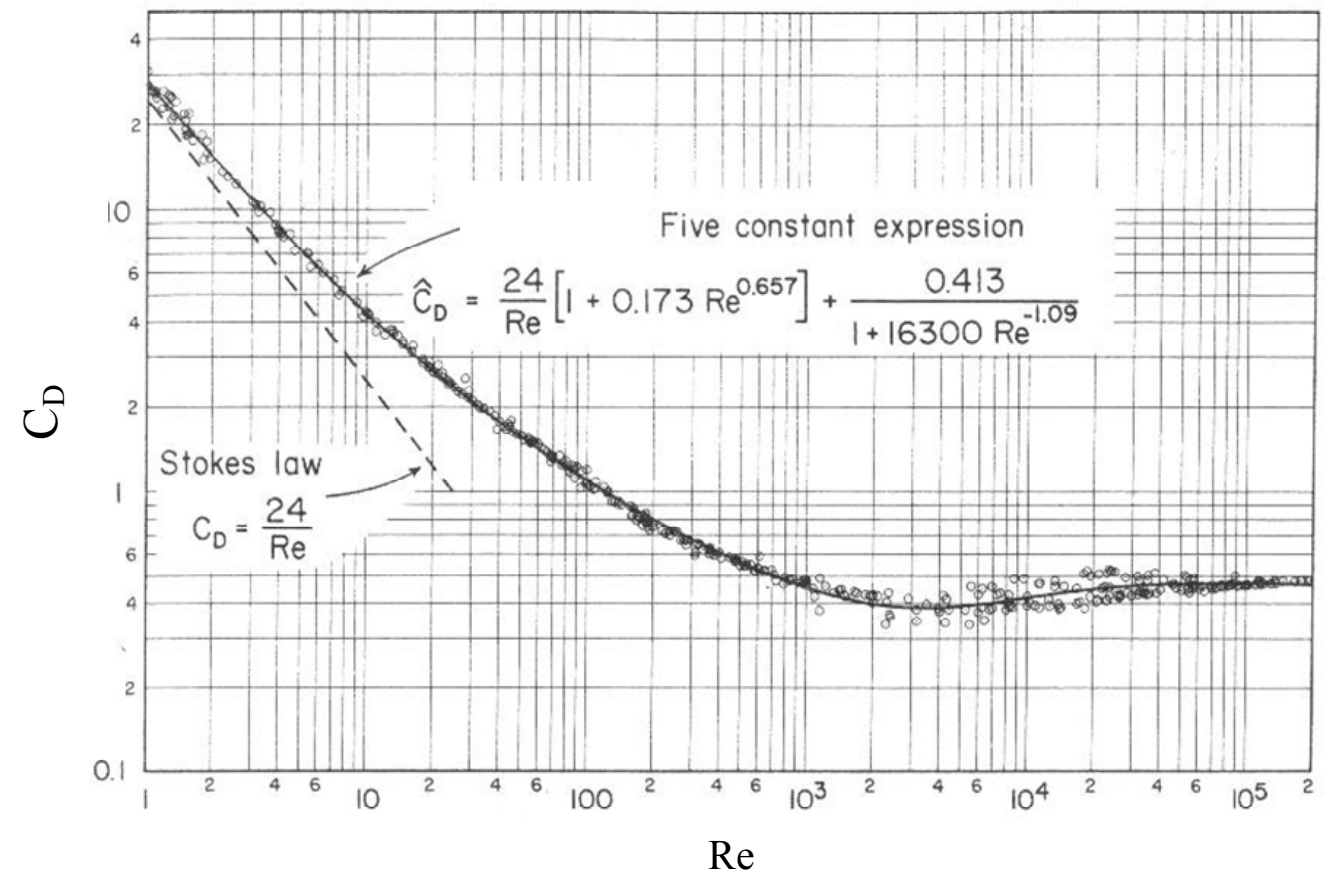

Figure 2.4 Correlation of drag coefficients as a function of Reynolds number (from Turton et al. [15]) 
Usually, it is the particle terminal velocity, $U_{t}$, rather than the drag coefficient, which is of ultimate interest. Geldart [17] presented an explicit equation for particle terminal velocity in solid-gas suspensions:

$$
\begin{aligned}
& U_{t}=\left[\frac{4 g\left(\psi d_{s v}\right)^{1+n}\left(\rho_{s}-\rho_{g}\right)}{3 b \mu^{n} \rho_{g}^{1-n}}\right]^{\frac{1}{2-n}} \\
& K=\left(\begin{array}{ll}
\psi & d_{s v}
\end{array}\right)\left[\frac{g \rho_{g}\left(\rho_{s}-\rho_{g}\right)}{\mu^{2}}\right]^{1 / 3}
\end{aligned}
$$

where the constants in Eqs 2.7 and 2.8 are given in Table 2.3.

Table 2.3 Constants for estimation of $U_{t}$ in Eqns 2.7 and 2.8

\begin{tabular}{|c|c|c|c|c|}
\hline Flow Region & $\mathbf{K}$ & $\mathbf{R e}_{\mathbf{p}}$ & $\mathbf{b}$ & $\mathbf{n}$ \\
\hline Laminar & $<3.3$ & $<2.0$ & 24 & 1 \\
\hline Intermediate & {$[3.3,43.6]$} & {$[2.0,500]$} & 18.5 & 0.6 \\
\hline Turbulent & $>43.6$ & $>500$ & 0.44 & 0 \\
\hline
\end{tabular}

$\operatorname{Re}_{p}$ in Table 2.3 is the particle Reynolds number.

Haider et al. [19] defined two dimensionless variables: a dimensionless terminal velocity $\mathrm{u}^{*}$ and a dimensionless particle diameter $\mathrm{d}^{*}$ as follows

and

$$
\begin{aligned}
& u^{*}=\left(\frac{4}{3} \frac{\mathrm{Re}}{C_{D}}\right)^{1 / 3}=u_{t}\left[\frac{\rho_{f}{ }^{2}}{g \mu\left(\rho_{s}-\rho_{f}\right)}\right]^{1 / 3} \\
& d^{*}=\left(\frac{3}{4} C_{D} \operatorname{Re}^{2}\right)^{1 / 3}=d_{p}\left[\frac{g \rho_{f}\left(\rho_{s}-\rho_{f}\right)}{\mu^{2}}\right]^{1 / 3}
\end{aligned}
$$


Zigrang and Sylvester presented an explicit equation for particle terminal velocities in solid-liquid suspensions:

$$
u^{*}=\frac{\left[\left(14.51+1.83 d^{* 1.5}\right)^{0.5}-3.81\right]^{2}}{d^{*}}
$$

Turton et al. [18] presented an asymptotic expression for particle terminal velocities as follows

$$
u^{*}=\left[\left(\frac{18}{d^{* 2}}\right)^{0.824}+\left(\frac{0.321}{d^{*}}\right)^{0.412}\right]^{-1.214}
$$

Considering the sphericity, a general correlation for isometric particles was obtained by Haider et al. [19]

$$
u^{*}=\left[\frac{18}{d^{* 2}}+\frac{(2.3348-1.7439 \psi)}{d^{* 0.5}}\right]^{-1}
$$

where $0.5 \leq \psi \leq 1$

2.2.3. Voidage distribution in the riser (Empirical models)

The distribution of solid particles in circulating fluidized bed risers has been widely studied because of its importance in reactor design. CFB risers normally contain a relatively dense region near the bottom and a dilute zone toward the top [20],[21]. Radially, the upper region consists of a dilute core surrounded by a relatively dense annulus, with solids downflow along the wall [22]. The hydrodynamics of the CFB riser have been analyzed and two typical models (i.e. axial and radial profiles of voidage) were obtained based on observations of the macro-scale. 


\section{1) Axial profiles of voidage}

The axial profile of the cross-sectional averaged voidage in the riser is typically S-shaped, as shown in Figure 2.5 for Group A particles in Geldart's classification [23]. An increase in the gas flow rate at a given solids circulation rate reduces the dense region (from curve (a) to (c) in Fig 2.5), whereas an increase in the solids circulation rate at a given gas flow rate results in an expansion of the dense region (from curve (c) to (a) in Fig 2.5). When solids circulation rate is very low or the gas velocity is very high, the dilute region covers the entire riser, which is shown as curve (d) in Fig 2.5.

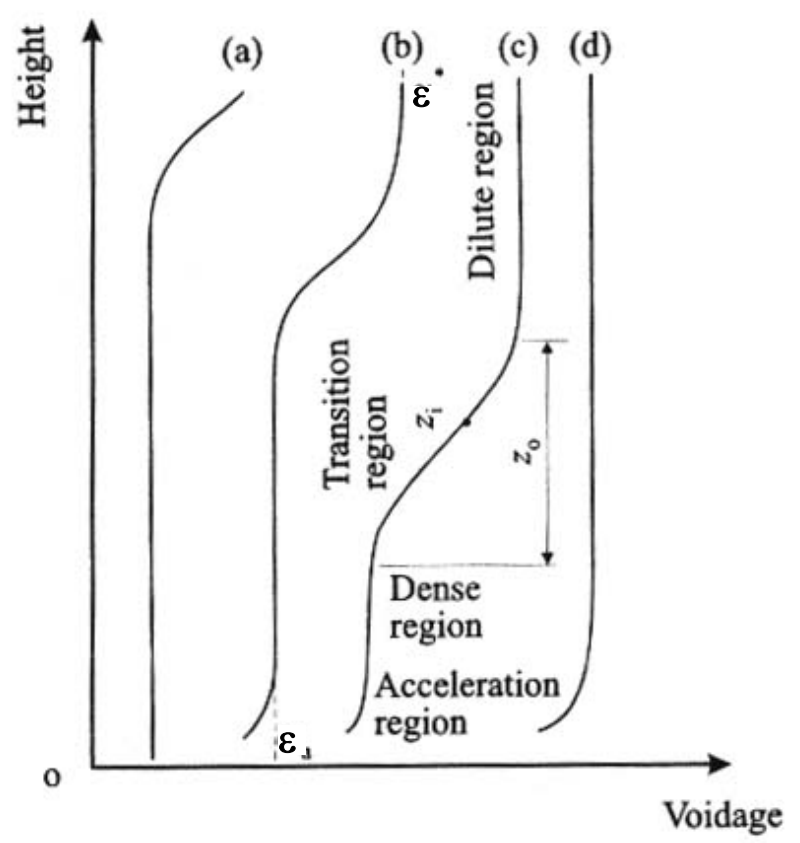

Figure 2.5 Voidage distribution along bed height [20]

The voidage profile can be represented by an equation of the following form [20]:

$$
\frac{\bar{\varepsilon}-\varepsilon_{a}}{\varepsilon^{*}-\bar{\varepsilon}}=\exp \left(\frac{z-z_{i}}{z_{o}}\right)
$$

where $\varepsilon_{a}$ is the asymptotic voidage in the bottom dense region; $\varepsilon^{*}$ is the asymptotic 
voidage in the top dilute region; $z_{o}$ is the length of the transition region between the dilute and dense regions; and $z_{i}$ is the location of the inflection point. This model reflects an axial solids concentration distribution with a dense region at the bottom and a dilute region at the top of the riser, which is influenced not only by solids circulation rate and gas velocity, but also by the particle properties. The values of $z_{o}, \varepsilon_{a}$ and $\varepsilon^{*}$ can be empirically correlated by [24]:

$$
\begin{aligned}
& z_{o}=500 \exp \left[-69\left(\varepsilon^{*}-\varepsilon_{a}\right)\right] \\
& 1-\varepsilon_{a}=0.2513\left(\frac{18 \mathrm{Re}_{a}+2.7 \mathrm{Re}_{a}^{1.687}}{A r}\right)^{-.4037} \\
& 1-\varepsilon^{*}=0.05547\left(\frac{18 \mathrm{Re}^{*}+2.7 \mathrm{Re}^{* 1.687}}{A r}\right)^{-.6222}
\end{aligned}
$$

where

$$
\begin{aligned}
\operatorname{Re}_{a} & =\frac{d_{p} \rho}{\mu}\left(U-\frac{J_{s}}{\rho_{p}} \frac{\varepsilon_{a}}{1-\varepsilon_{a}}\right) \\
\operatorname{Re}^{*} & =\frac{d_{p} \rho}{\mu}\left(U-\frac{J_{s}}{\rho_{p}} \frac{\varepsilon^{*}}{1-\varepsilon^{*}}\right)
\end{aligned}
$$

The value of $z_{i}$ can be determined by considering the overall pressure drop across the riser.

However, the S-shape voidage distribution was not observed in some other experiments when the average voidage was measured [25]. For this situation, the inflection point moved downward and almost disappeared, and a C-shape profile was found. A simple exponential function can often be used to represent the axial average voidage with high voidage in the top section and low voidage in the bottom section of the 
bed [26]:

$$
\frac{\varepsilon^{*}-\bar{\varepsilon}}{\varepsilon^{*}-\varepsilon_{a}}=\exp \left[-a\left(z-z_{d}\right)\right]
$$

\section{2) Radial profiles of voidage}

A core-annulus flow structure in the radial direction gives rise to a radial voidage profile model [22]. The core-annulus flow is characterized by the absence of axial solids segregation, with solids carried upward in the core and traveling downward near the outer wall due to the formation of particle streamers. Its validity was also confirmed by experiments in a large-scale CFB [27]. When the radial profile is normalized with respect to the cross-sectional averaged voidage, at the corresponding axial location, the results can be empirically correlated by [22]

$$
\varepsilon=\bar{\varepsilon}^{\left[0.191+\left(\frac{r}{R}\right)^{2.5}+3\left(\frac{r}{R}\right)^{11}\right]}
$$

Rhodes et al. [28] observed from sets of voidage data that the solids concentration at the wall of dilute risers was on average about twice the cross-sectional mean. Aided by this simplification, they correlated the local voidage by means of

$$
\frac{1-\varepsilon}{1-\bar{\varepsilon}}=2\left(\frac{r}{R}\right)^{2}
$$

Goedicke et al. [29] correlated the local voidage at the wall, $\varepsilon_{w}$, with $\bar{\varepsilon}$ from differential pressure measurements for $62 \mu \mathrm{m}$ particles and obtained:

$$
\varepsilon_{w}=0.322+0.196 \bar{\varepsilon}+15.09(\bar{\varepsilon}-0.4)^{6.74}
$$




\section{3) Dynamic modeling}

The empirical profiles given above are used in steady state situations, and alone are not suitable for modeling the transient process.

Yang [30] developed a mathematical model that describes the dynamics of flow around a circulating fluidized bed loop. But the model, represented by a system of non-linear algebraic equations, can not be used in transient situations. Monazam et al. [31] determined the saturation carrying capacity (SCC) based on transient pressure drop measurement across the riser during a solids flow cut-off experiment in which the solids circulation rate is abruptly stopped and the response of the system to the step change in solids flow is observed. Pallares and Johnsson [32] developed a comprehensive dynamic model for larger CFB units, which can be used to predict the solids flux from operating variables. However, the validation of the model was not tested for a transient process.

Secchi et al. [33] developed an integrated dynamic model for a reactive process, which is capable of capturing the major dynamic effects that occur in the system and can be used for dynamic analysis, control and optimization. In this model, the riser was modeled as an adiabatic plug flow reactor, and predictions were in good agreement with the plant data (conversion and temperature profiles).

\subsubsection{CFD and DEM simulation}

The use of computational fluid dynamics (CFD) for multiphase flows has become an 
accepted and useful tool in modeling of gas/solids flow systems. The CFD method is usually combined with experimental studies of the complex flow behavior of CFB systems to provide information to refine conservation equations and constitutive laws for gas/solids flow systems, [34]. The main drawback of CFD approaches is the long simulation time required to obtain a solution. This is particularly problematic when the dynamics of the systems are being investigated and a model capable of close to real time simulation is desired.

Realistic numerical simulations prove very helpful for analysis of CFB. Such models are based on an advanced computational technique which integrates the discrete element (or particle) method (DEM [35] or DPM [36]) for the solid phase with a computational fluid dynamics (CFD) algorithm for the fluid phase. Such an approach makes available a series of powerful tools, not available with classical techniques, capable of predicting the core-annulus flow structure, etc. The positions and velocities are calculated for each particle in the system from the forces acting on that particle through integration of Newton's second law of dynamics, and a CFD algorithm (i.e. finite volume approach to solve the continuity and momentum balance equations) is implemented for solving the pressure, velocity, density and voidage fields throughout the system.

Although the combined DEM-CFD method is based on the fundamental physics of the system, so that a very wide range of applications can be modeled and very detailed results can be obtained, the simulated system is limited in its size and properties due to the computational time required. The time required to run a 1 second simulation is 
usually at least 10 hours, even for laboratory scale equipment, which makes it practical for process design but not for real-time control. Information on the total CPU time required to run 1 second of simulation on a reference $1 \mathrm{GHz}$ Intel-Windows $\mathrm{PC}$ is illustrated in Figure 2.5 [37], where $D_{p}$ is the particle diameter. Simulation for smaller particles requires longer computational time because of shorter impact time (i.e., more time steps per simulated second). For a perfectly elastic collision with linear elements, the impact time can be expressed analytically by

$$
\tau_{c}=\pi \sqrt{\frac{m}{K}}=\pi \sqrt{\frac{\pi}{6} \frac{\rho_{s}}{K} D_{p}^{3}}
$$

where $K$ is the spring constant, which is one of the mechanical properties of the material required in the DEM model.

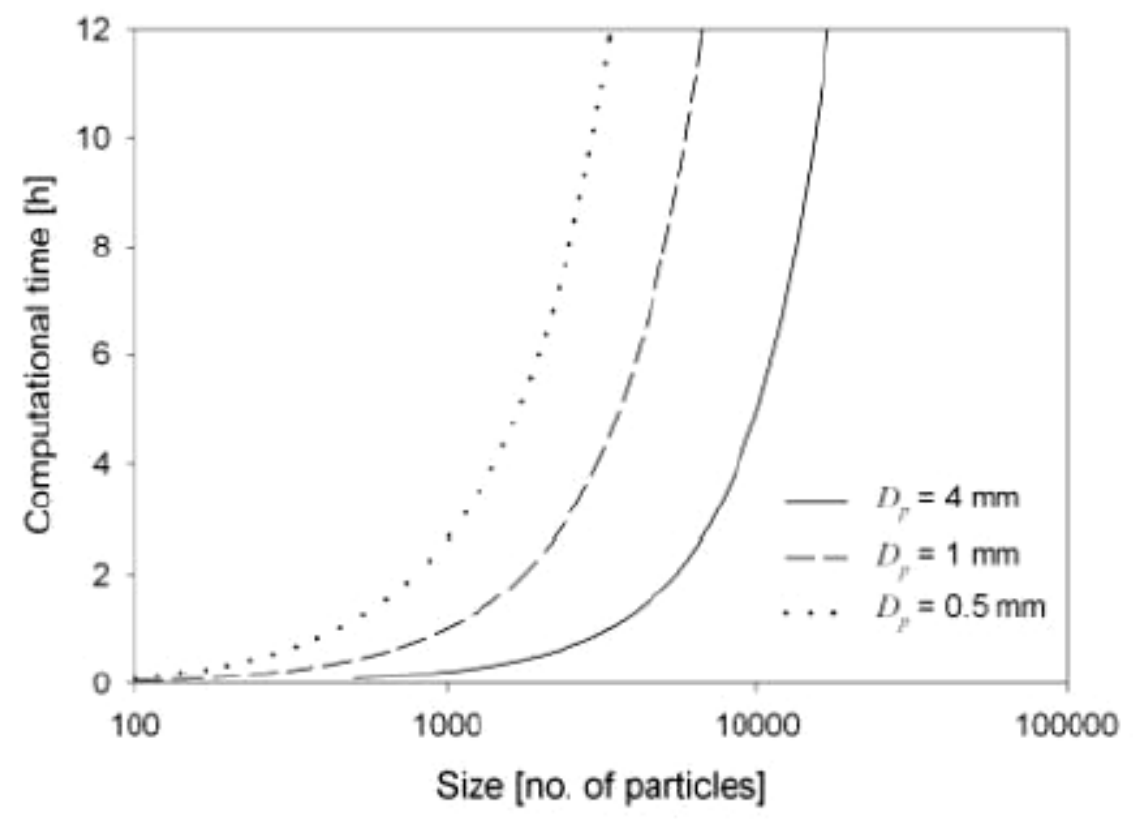

Figure 2.6 Computational time required to run a 1 second of simulation [37] 


\subsubsection{Governing equations}

In the two-phase flow model, gas and solid phases are treated as interpenetrating continua using an Eulerian model. Each solid phase is characterized by a particle diameter, density and other properties, and each phase has its own set of governing hydrodynamic equations. The averaging approach is applied to derive the equations for both gas and solid phases. The phasic volume fractions are introduced to track the fraction of the averaging volume occupied by various phases. For the cold flow model, the continuity and momentum balance will be considered. Solids continuity equation is given by [38]

$$
\nabla\left[\rho_{S}(1-\varepsilon) u_{s}\right]=0
$$

And solids momentum balance is given by [38]

$$
(1-\varepsilon) \rho_{s} g+\beta\left(u_{g}-u_{S}\right)-\nabla P_{S}+2 \nabla\left(\mu_{S} S_{S}\right)=0
$$

where $\beta$ is the effective drag coefficient; $P_{s}$ is solids phase pressure; $\mu_{s}$ is solids phase viscosity and $S$ is the rate of deformation tensor.

Gas continuity equation is given by [39]

$$
\nabla\left(\rho_{g} \varepsilon u_{g}\right)=0
$$

And gas momentum balance is given by [38]

$$
-\nabla P+\beta\left(u_{g}-u_{S}\right)+2 \mu_{e g} \nabla S=0
$$

where $P$ is gas phase pressure; $\mu_{e g}$ is effective gas viscosity. 


\subsection{Model of standpipe}

A standpipe is essentially a length of pipe through which solids flow. Solids can flow through a standpipe in either dilute or dense phase flow. The standpipe can be vertical, angled, or a mixture of angled and vertical pipes.

\subsubsection{Estimation of solids circulation rate}

The key to smooth operation of a CFB system is the effective control of the solids circulation rate to the riser. Solids circulation rate is one of the most important parameters in the operation of CFB, since it affects mass and heat transfer characteristics, which in turn impact the efficiency of the processes. There are two different types of recirculation systems in which the solids flow back to the riser:
i) uncontrolled;
ii) controlled (in some fashion).

The loop seal in uncontrolled systems is not a valve (it does not control the solids flow rate). The focus here is on large controlled CFB units, so uncontrolled systems are beyond the scope of the present modeling work. In the present system, the solids from the cyclone pass through an underflow standpipe and non-mechanical valve before being returned to the riser.

The primary operational parameters of the system are the pressure drop and the gas flow rate, whereas the solids circulation rate is normally unknown and must be estimated. 
Many methods for the measurement of the solids circulating rate have been discussed in the recent literature. Burkell et al. [40] assessed and tested five methods to determine circulation rate in CFB systems. The first method employed a permeable butterfly valve upon which solids were collected while the valve was closed. The solids flow rate was determined by recording the time needed for solids to accumulate, or by monitoring the pressure drop of gas through the accumulated solids section. This method is commonly used for non-reacting, laboratory-scale CFBs. Liu and Huan [41] developed a turbine meter that was on-line and non-intrusive. Davies and Harris [42] designed a slot flow meter consisting of a chamber with one or more slots on its sides. Solids flow rate was correlated with the weight of solids in the chamber; however, it was inconvenient to weigh the solids in the chamber in a practical application. Ludlow et al. [43], developed a twisted vane flow meter. The meter consists of a vertical twisted vane inserted into the packed bed portion of the standpipe. The solids downward flow causes the vane to rotate, and from the rate of rotation the solids velocity is calculated. This velocity combined with the cross sectional area of the standpipe and the bulk density of the circulating material allow the overall circulation rate to be determined. Circulation rates as high as 45,000 kg/h have been measured for coke breeze bed material. An advantage of the spiral device is that the solids flow rate is measured continuously. A disadvantage is that the measurement becomes unreliable in the rare occasions when the standpipe starts to bubble.

The above techniques have been used to determine the solids circulation rate, however, 
the measurement of this parameter in industrial-scale CFB units, operating at extreme process conditions is very difficult. An indirect method based on the pressure measurement around the loop of CFB was developed. Patience et al. [44] correlated the pressure drop along the horizontal section between a CFB riser and the cyclone with the solids circulation and gas flow rates. Lim et al. Error! Reference source not found. demonstrated that the solids circulation rate in a CFB system could be estimated by performing detailed pressure analysis around the circulation system. These methods were on-line, non-intrusive, not limited by high temperature and represent a useful and practical approach for this application.

For this system, the high-pressure point in the recirculation loop is at the aeration point of the non-mechanical valve, and the pressure balance is [46]

$$
\Delta P_{\text {valve }}+\Delta P_{\text {riser }}+\Delta P_{\text {cyclone }}=\Delta P_{\text {standpipe }}
$$

where $\Delta P_{\text {valve }}$ is the pressure drop around loop-seal to riser base; $\Delta P_{\text {riser }}$ is the pressure drop across riser; $\Delta P_{\text {cyclone }}$ is the pressure drop across the solids separator; and $\Delta P_{\text {standpipe }}$ is the pressure drop across the standpipe.

Based on the pressure balance around the CFB loop, the pressure drop across the standpipe above the aeration point in a loop-seal is balanced so that $\Delta P_{\text {standpipe }}$ must equal the sum of the pressures. As the solids in the standpipe are in moving bed flow, an increase in the move air causes an increase in the pressure drop across the standpipe. The system responds with an increase in solids flow rate resulting in an increase in riser solids loading and an increase in riser pressure drop, satisfying the balance of Eq. 2.29. 
2.3.2. Estimation of voidage in moving bed

The measurement of pressure drop across the dense bed in the standpipe can be used to estimate the voidage.

The pressure drop through a bed of spheres can be described by the well-known Ergun equation Error! Reference source not found.

$$
\frac{\Delta P}{L}=150 \frac{\mu(1-\varepsilon)^{2}}{\varepsilon^{3} d^{2}} U+1.75 \frac{\rho_{g}(1-\varepsilon)}{\varepsilon^{3} d} U^{2}
$$

which is an correlation over a wide porosity range from 0.36 to 0.92 . Macdonald et al. [48] suggested that replacing the $\varepsilon^{3}$ term arising from above equation with the empirically derived term $\varepsilon^{3.6}$ would give an even better fit of data. Paterson et al. [49] measured the pressure drops of moving beds and/or frozen beds and revised the Ergun equation as

$$
\frac{\Delta P}{L}=189 \frac{\mu(1-\varepsilon)^{2}}{\varepsilon^{3} d^{2}} U+1.59 \frac{\rho_{g}(1-\varepsilon)}{\varepsilon^{3} d} U^{2}
$$

\subsection{Control of CFB}

Currently there is no way to construct a reliable model of such a complex system of CFB using traditional methods, especially at the pilot or industrial scale. Three major obstacles in characterizing the system are[50]:

- Chaotic nature of the system

- Non-linearity of the system

- Number of immeasurable unknowns internal to the system 
Advanced control theories and methods have the ability to characterize the system, and can overcome all three of these obstacles.

\subsubsection{Neural network}

Neural networks generally consist of a number of interconnected processing elements or neurons. How the inter-neuron connections are arranged and the nature of the connections determines the structure of the network. Its learning algorithm governs how the strength of the connections are adjusted or "trained" to achieve the desired overall behavior for the network. The modeling and control of the standpipe using neural networks have been applied successfully to a CFB system [50]. The solids flow rate was modeled as a function of the differential pressures in the standpipe section and the flow rate of the aeration, and a neural network controller was developed to manipulate the mass flow rate by varying the aeration.

\subsubsection{Fuzzy logic}

The theory of fuzzy sets was first introduced in 1965 by Lofti Zadeh of the University of California, Berkeley, [51]. One of the first implementations of fuzzy type of control was made for a cement kiln in 1972, [52]. The idea of implementing a control strategy as a decision table, which basically was a rough description of the manual control scheme, was copied from the text book made for the kiln operators. Currently, it is common to find fuzzy applications throughout the process industry. Process control system suppliers, universities, research centers, and the process industries have 
implemented thousands of applications. This success has been possible not only because of higher knowledge of fuzzy set theory but also due to the development of easier and more advanced tools for Fuzzy Logic Control (FLC) implementation.

According to industrial experiments, four applications using FLC (pressure control, compensation of fuel quality fluctuation, fuel-feed optimization and increased bed inventory monitoring) in the CFB boiler system discussed by Karppanen [7], showed satisfactory performance and various improvements to the CFB control were achieved.

\subsubsection{Extended Kalman filter}

In 1960, R.E. Kalman [53] published his famous paper describing a recursive solution to the discrete-data linear filtering problem. Since that time, due in large part to advances in digital computing, the Kalman filter has been the subject of extensive research and application, particularly in the area of autonomous or assisted navigation. The Kalman filter is a set of mathematical equations that provides an efficient computational (recursive) means to estimate the state of a process, in a way that minimizes the mean of the squared error. The filter is very powerful in several aspects: it supports estimations of past, present, and even future states, and it can do so even when the precise nature of the modeled system is unknown.

Kalman filter addresses the general problem of trying to estimate the state of a discrete-time controlled process that is governed by a linear stochastic difference equation. But if the process to be estimated and (or) the measurement relationship to 
the process is non-linear, then a Kalman filter that linearizes about the current mean and covariance is used and is referred to as an extended Kalman filter (EKF). Some of the most interesting and successful applications of Kalman filter have been in such situations.

Shim et al. [54] developed an EKF model that can be used to estimate the state (void fraction and the pressure profiles) of the standpipe for a CFB. The dynamic model was based on the continuity equation and a modified Richardson-Zaki correlation. The truncated Ergun equation was used to relate the pressure drop measurements to the amount and velocity of solids in the standpipe. The EKF estimator consists of a Kalman filter obtained by a step-by-step linearization around the current estimate of the state vector.

\subsection{Summary}

Control engineers do not worry about the precise nature of the system because sometimes it can be modeled even without an understanding of the process. But developing a dynamic model based on a good understanding of the CFB process is still very important. On the one hand, for chemical engineers, there is essential information for chemical reaction and mass or heat transport processes. On the other hand, the control system should be made as simple as possible since the tuning required with complicated structures of multiphase flows is rather difficult due to the large number of tunable parameters. In general, the better the understanding of the process, the better 
will be the design of the controller. 


\section{Chapter 3 System Configuration}

\subsection{CFB pilot plant}

A cold flow circulating fluidized bed (Figure 3.1) has been built at the National Energy Technology Laboratory (NETL), in Morgantown, West Virginia [55]. The experimental set up used in this work is shown in Figure 3.2. It consists of a riser, $0.305 \mathrm{~m}$ in diameter and $21.3 \mathrm{~m}$ high, and a standpipe of $0.25 \mathrm{~m}$ diameter, a solids transfer leg and a cyclone. The solids transfer device is a nonmechanical valve (L- or J-valve). The solids are separated from the gas by two cyclones. The main fluidizing air is fed through a perforated plate into the riser. An aeration port was located near the base of the standpipe approximately $0.4 \mathrm{~m}$ above the valve. This stream is commonly referred to as the move air because it has been found to directly affect the solids flow rate. A helical-shaped spiral vane was installed $4 \mathrm{~m}$ above the inlet to the nonmechanical solids valve in the standpipe and the frequency of its revolution was recorded to measure the solids flow rate. The frequency of the rotation of the spiral was calibrated for each bed material by draining solids from the bottom of the standpipe over a period of time and weighing the solids. This calibration confirmed that the measurement device yielded volumetric solids velocity data with no slip along the spiral.

To minimize static charge buildup, the riser consists of carbon steel segments except for one acrylic section at the base. The riser is instrumented with more than 20 differential pressure transmitters that are connected in series to measure the incremental 
differential pressure drops along the bed. The pressure balance around the CFB loop was checked by comparing the sum of the standpipe incremental pressure gains with that from the riser pressure drops. In addition, the sum of the incremental pressure drops across the riser was routinely verified against an overall riser pressure drop measurement.

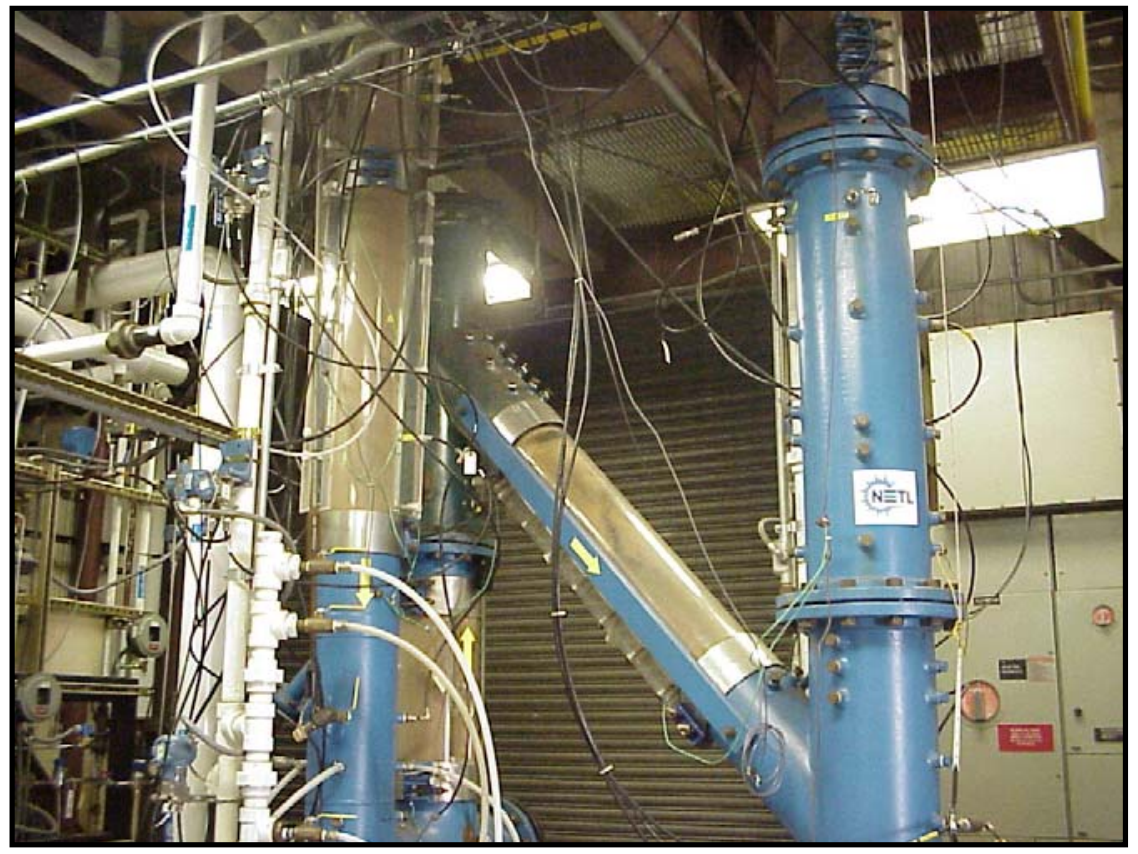

Figure 3.1 Cold flow CFB pilot plant at NETL

The aim of current research is to analyze the data of CFB under transient processes taken from the DOE-NETL cold flow facility and to establish a predictive model for the CFB. 


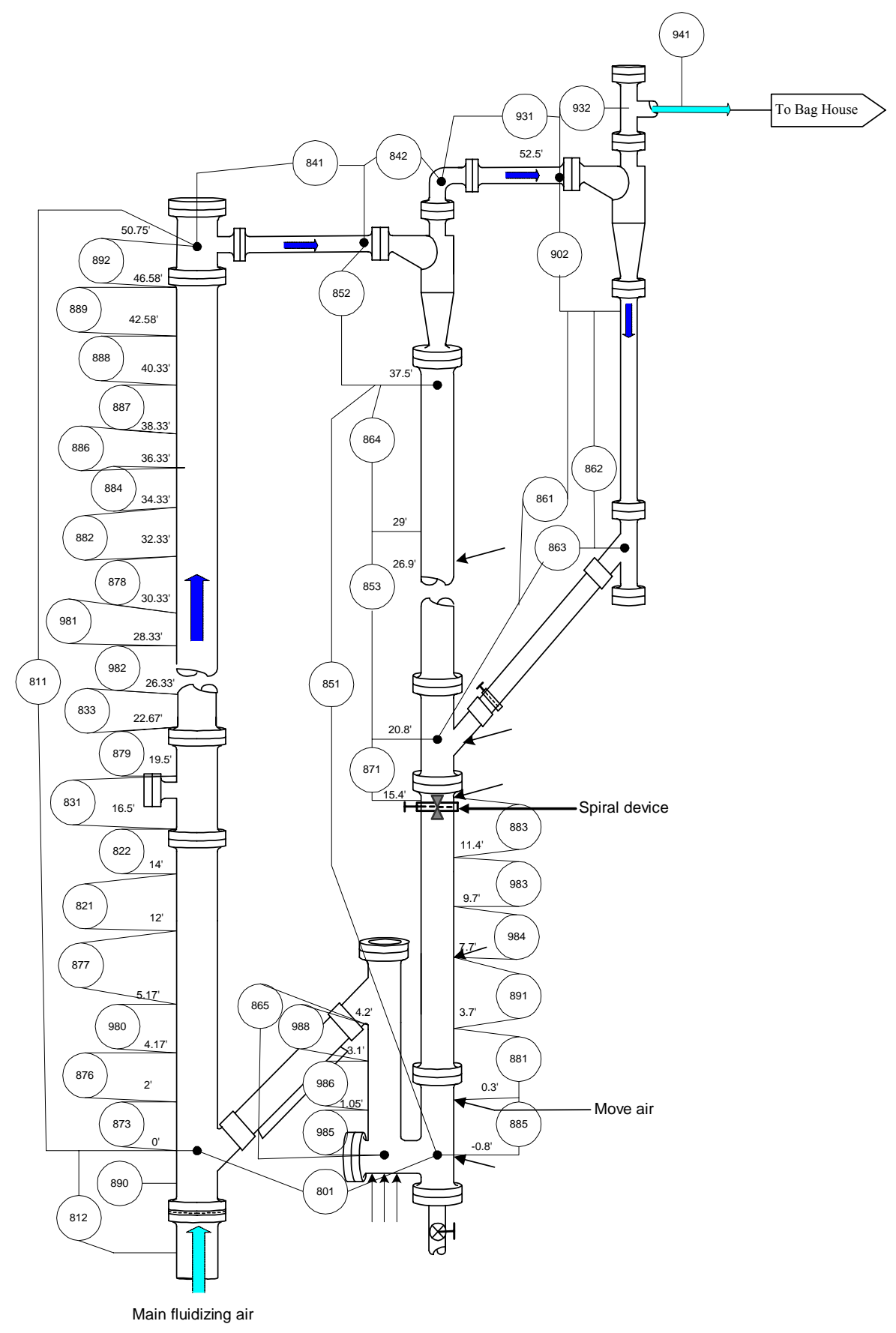

Figure 3.2 Schematic of cold flow CFB test facility

\subsection{Materials and operating conditions}

The bed material is cork, its characteristics are listed in Table 3.1, and the gas phase is air at approximately ambient conditions. Simulations with these materials at atmospheric 
temperature and pressure are used to represent coal particles at elevated temperatures and pressures typical of a coal-fired combustor. For the experiments performed in this work, the flow rate of air injected into the bottom of the riser is kept constant. The air injected at the base of the standpipe, the move air, is changed and causes the mass flow of solids entering the bottom of the riser to change. The cork at the bottom of the riser is transported vertically upwards by the riser air. After reaching the top of the riser, it is transferred to a two-staged cyclone that separates the solid particles from the air and returns them to the standpipe.

\section{Table 3.1 Bed materials (Cork) properties}

\section{Cork characteristics}

\begin{tabular}{ccc}
\hline$\rho_{s}$ & 189 & $\mathrm{~kg} / \mathrm{m}^{3}$ \\
$\rho_{b}$ & 95 & $\mathrm{~kg} / \mathrm{m}^{3}$ \\
$d_{p}$ & 812 & $\mu \mathrm{m}$ \\
$U_{t}$ & 0.86 & $\mathrm{~m} / \mathrm{s}$ \\
$U_{m f}$ & 0.07 & $\mathrm{~m} / \mathrm{s}$ \\
$\varepsilon_{m f}$ & 0.49 & - \\
\hline
\end{tabular}

Before going into a detailed discussion enclosed in this dissertation, it is best to consider and present here some limitations and important points for those in industry and academia who will use the information here.

Very small particles (below 20 microns) are almost impossible to fluidize: the gas tends to circulate through discreet canals (channelling). A bubbling behavior is possible 
in a range between 0.1 and $1 \mathrm{~mm}$. Larger particles may be fluidized in a bed of finer particles, but when the difference in density or size is too high and the gas flow rate too small, segregation (i.e. settling of dense or floating of light material) will occur.

Geldart's classification of powders subdivides these materials into the following groups (Figure 3.3) [23]:
a. aeratable powders, e.g. FCC catalyst
b. powders fluidizable with a bubbling regime, e.g. sand;
c. cohesive powders, difficult to fluidize, e.g. cement and fly-ash;
d. spoutable powder, e.g. plastic pellets, corn.

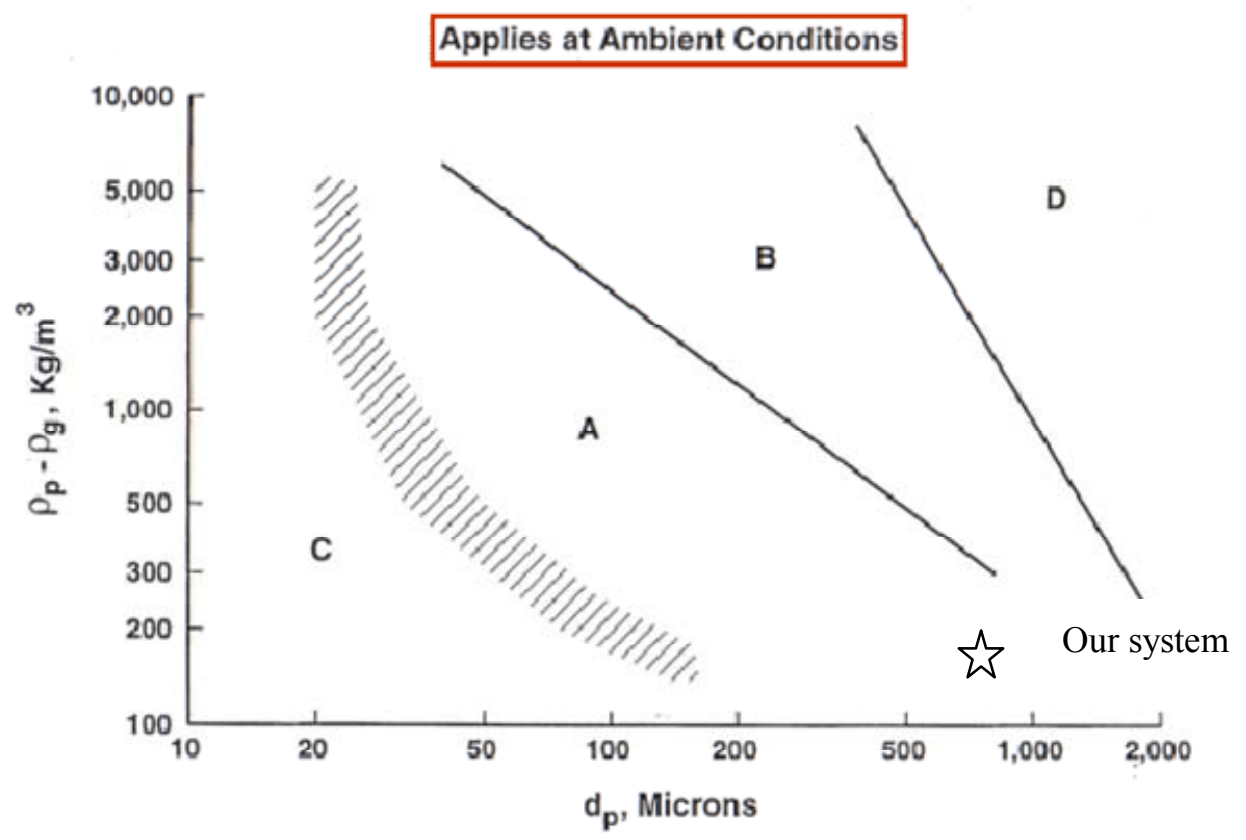

Figure 3.3 Geldart groups A, B, C and D

The different flow regimes are shown in Figure 2.2, [8]. 


\subsection{Solids flow rate measurement}

A helical-shaped spiral vane was installed $4 \mathrm{~m}$ above the inlet to the nonmechanical solids valve in the standpipe and the frequency of its revolution was recorded to measure the solids flow rate. As the solids pass by this spiral, the solids force it to rotate. The speed of this rotation is measured and is converted to a volumetric flow rate. This volumetric flow rate is converted to mass circulation using the bulk density. A picture of the spiral is shown in Figure 3.4 [43].

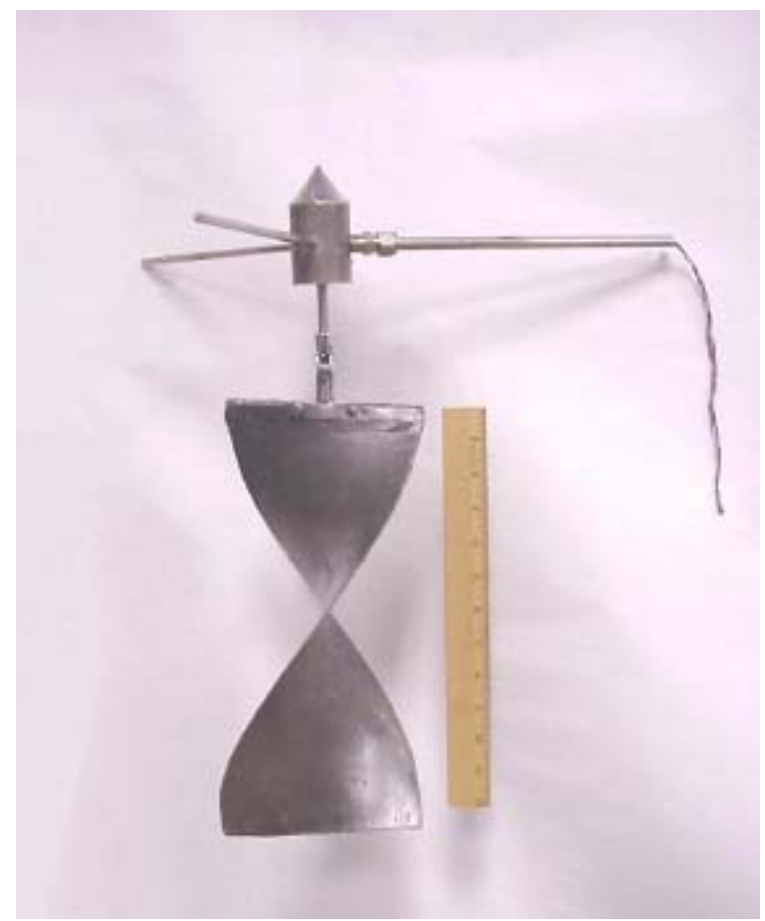

Figure 3.4 A helical-shaped spiral vane for solids flow rate measurement

\subsection{Plan of experiments}

The experimental data used to develop the model in this work were obtained under different operation conditions (i.e. flow rate of gas in riser, average flow rate and period 
of move air as a sine function), according to the plan of experiments given in Table 3.1.

Table 3.2 Plan of experiments for cold flow CFB

\begin{tabular}{|c|c|c|c|c|c|c|c|c|c|}
\hline & \multicolumn{2}{|c|}{$\boldsymbol{U}_{\boldsymbol{g}}$} & \multicolumn{2}{c|}{$\boldsymbol{F}_{\boldsymbol{m}}$} & \multicolumn{3}{c|}{ Period } & \multicolumn{2}{c|}{ Data } \\
\cline { 2 - 9 } & $\mathbf{L}$ & $\mathbf{H}$ & $\mathbf{L}$ & $\mathbf{H}$ & $\mathbf{L}$ & $\mathbf{M}$ & $\mathbf{H}$ & $\begin{array}{c}\text { Replicate } \\
\mathbf{1}\end{array}$ & $\begin{array}{c}\text { Replicate } \\
\mathbf{2}\end{array}$ \\
\hline 1 & $\sqrt{ }$ & & $\sqrt{ }$ & & $\sqrt{ }$ & & & $\mathrm{K} 44$ & $\mathrm{~K} 52$ \\
\hline 2 & $\sqrt{ }$ & & $\sqrt{ }$ & & & $\sqrt{ }$ & & $\mathrm{K} 42$ & $\mathrm{~K} 48$ \\
\hline 3 & $\sqrt{ }$ & & $\sqrt{ }$ & & & & $\sqrt{ }$ & $\mathrm{K} 45$ & $\mathrm{~K} 51$ \\
\hline 4 & $\sqrt{ }$ & & & $\sqrt{ }$ & $\sqrt{ }$ & & & $\mathrm{K} 46$ & $\mathrm{~K} 53$ \\
\hline 5 & $\sqrt{ }$ & & & $\sqrt{ }$ & & $\sqrt{ }$ & & $\mathrm{K} 43$ & $\mathrm{~K} 50$ \\
\hline 6 & $\sqrt{ }$ & & & $\sqrt{ }$ & & & $\sqrt{ }$ & $\mathrm{K} 47$ & $\mathrm{~K} 49$ \\
\hline 7 & & $\sqrt{ }$ & $\sqrt{ }$ & & $\sqrt{ }$ & & & $\mathrm{K} 31$ & $\mathrm{~K} 41$ \\
\hline 8 & & $\sqrt{ }$ & $\sqrt{ }$ & & & $\sqrt{ }$ & & $\mathrm{K} 32$ & $\mathrm{~K} 36$ \\
\hline 9 & & $\sqrt{ }$ & $\sqrt{ }$ & & & & $\sqrt{ }$ & $\mathrm{K} 34$ & $\mathrm{~K} 38$ \\
\hline 10 & & $\sqrt{ }$ & & $\sqrt{ }$ & $\sqrt{ }$ & & & $\mathrm{K} 35$ & $\mathrm{~K} 40$ \\
\hline 11 & & $\sqrt{ }$ & & $\sqrt{ }$ & & $\sqrt{ }$ & & $\mathrm{K} 30$ & $\mathrm{~K} 39$ \\
\hline 12 & & $\sqrt{ }$ & & $\sqrt{ }$ & & & $\sqrt{ }$ & $\mathrm{K} 33$ & $\mathrm{~K} 37$ \\
\hline
\end{tabular}

For this experimental plan, there are three factors:

- $\quad U_{g}$ : Superficial velocity of gas in riser, which has two levels (4.06 or 5.25

$\mathrm{m} / \mathrm{s})$

- $F_{m}$ : Flow rate of move air, which has two levels $\left(0.0029\right.$ or $\left.0.0086 \mathrm{~m}^{3} / \mathrm{s}\right)$;

- Period: period of sine function of move air's flow rate, which has three levels (60, 90 or 120 seconds).

\subsection{Physical data and constants}

The physical data and constants are listed as follows: 
- Inside cross-sectional area of standpipe: $A_{s}=0.05067 \mathrm{~m}^{2}$

- Inside cross-sectional area of riser: $A_{r s}=0.07296 \mathrm{~m}^{2}$

- Density of particles: $\rho_{s}=189 \mathrm{~kg} / \mathrm{m}^{3}$

- Density of gas: $\rho_{g}=1.22 \mathrm{~kg} / \mathrm{m}^{3}$ (air, at $15^{\circ} \mathrm{C}$ and $1 \mathrm{~atm}$ )

- Viscosity of gas: $\mu=1.8 \times 10^{-5} \mathrm{~Pa} \cdot \mathrm{s}$

- Particle sphericity: $\psi=0.84$

- Surface-volume diameter of particles: $d_{s v}=8.12 \times 10^{-4} \mathrm{~m}$

- Particle terminal velocity: $U_{t}=0.81 \mathrm{~m} / \mathrm{s}$, which is determined by [17] 


\section{Chapter 4 Dynamic Model in the Riser}

\subsection{Introduction}

The riser is the most important component in a CFB system because it plays a key role as a reactor in industrial practice. The gas and solids flow in the riser is inherently very complex. Many modeling efforts making various assumptions regarding the gas and solids flow structure and employing very different mathematical formulations, have appeared in the recent literature. The variety of models have been classified into three groups [57]:

(1) those that predict the axial variation of the solids suspension density, but not the radial variation, [20], [21], [26];

(2) those that predict the radial variation by assuming two or more regions, such as core-annulus or clustering annular flow models, [22], [58];

(3) those that employ the fundamental equations of fluid dynamics to predict the two-phase gas-solid flow, [59], [60].

This chapter presents two models which were developed in this research. The models describe the dynamic behavior of the riser in CFBs. The purpose of the models is to predict the time variations of pressure gradient, voidage, so that it can be extended to reacting systems. 


\subsection{Tanks-in-series model of riser}

Hydraulic characteristics of flow in reactor units may be thought of as variations of two ideal types:

- Plug flow;

- Completely mixed.

The plug flow reactor (PFR) assumes that all flow is unidirectional with no mixing in the axial direction. An element of fluid entering a PFR will travel from the inlet to the outlet in a period of time equal to the reactor volume divided by the flow rate. A completely mixed reactor, also referred to as a continuously stirred tank reactor (CSTR), assumes that mixing is complete and instantaneous. An element of fluid entering a CSTR, therefore, will become uniformly dispersed with all other elements of fluid in the tank. If a pulse of tracer material is injected at the inlet of a CSTR, the tracer concentration at the reactor outlet would initially equal the total mass of tracer divided by the reactor volume, and would then decay at an exponential rate.

A tanks-in-series model visualizes the riser as consisting of a series of completely mixed tanks, where the output of an upstream tank becomes the input to the downstream tank (Figure 4.1). 


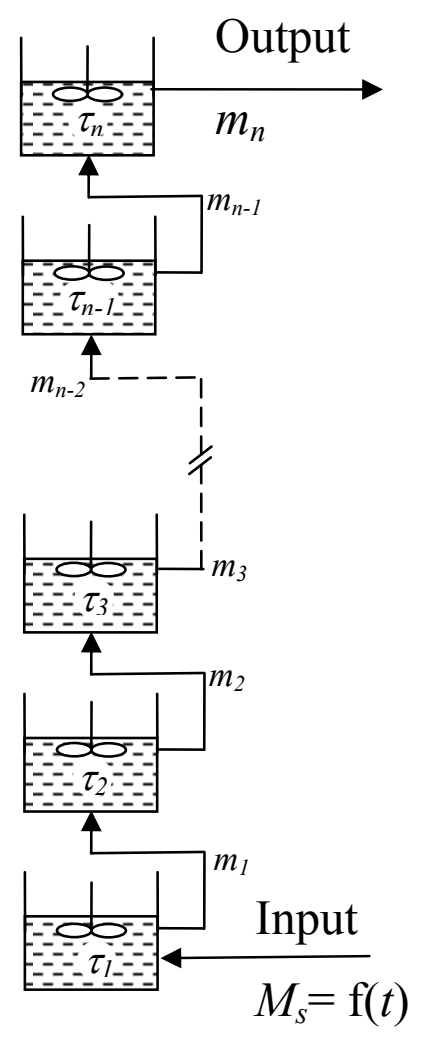

\section{Figure 4.1 Tanks-in-series model of riser}

$\tau_{i}$ is the characteristic time in the $\mathrm{i}^{\text {th }}$ tank, which equals the volume of fluid in the $\mathrm{i}^{\text {th }}$ tank divided by the flow rate. Despite the importance of backflow phenomenon (movement of solids from a tank to a previous tank), which strongly influences the solids residence time and hence combustion efficiency and/or selectivity of reactions, the current study focuses only on the solids inventory in the riser and therefore the effect of backflow was neglected in the model to simplify the formulation. The model can be presented by the following set of ODEs:

$$
\tau_{1} \frac{d C_{1}}{d t}=C_{o}-C_{1}
$$




$$
\begin{gathered}
\tau_{2} \frac{d C_{2}}{d t}=C_{1}-C_{2} \\
\vdots \\
\tau_{n} \frac{d C_{n}}{d t}=C_{n-1}-C_{n}
\end{gathered}
$$

where the input to the system, initial concentration $\left(C_{o}\right)$, is a function of time, $\mathrm{f}(t)$.

For a one-step input (i.c. $C_{o}=0$ when $t<0 ; C_{o}=1$ when $t \geq 0$ ), if the original concentration in each tank is zero and the characteristic time, $\tau_{i}$, is identical, the concentrations of outflows are shown in Figure 4.2.

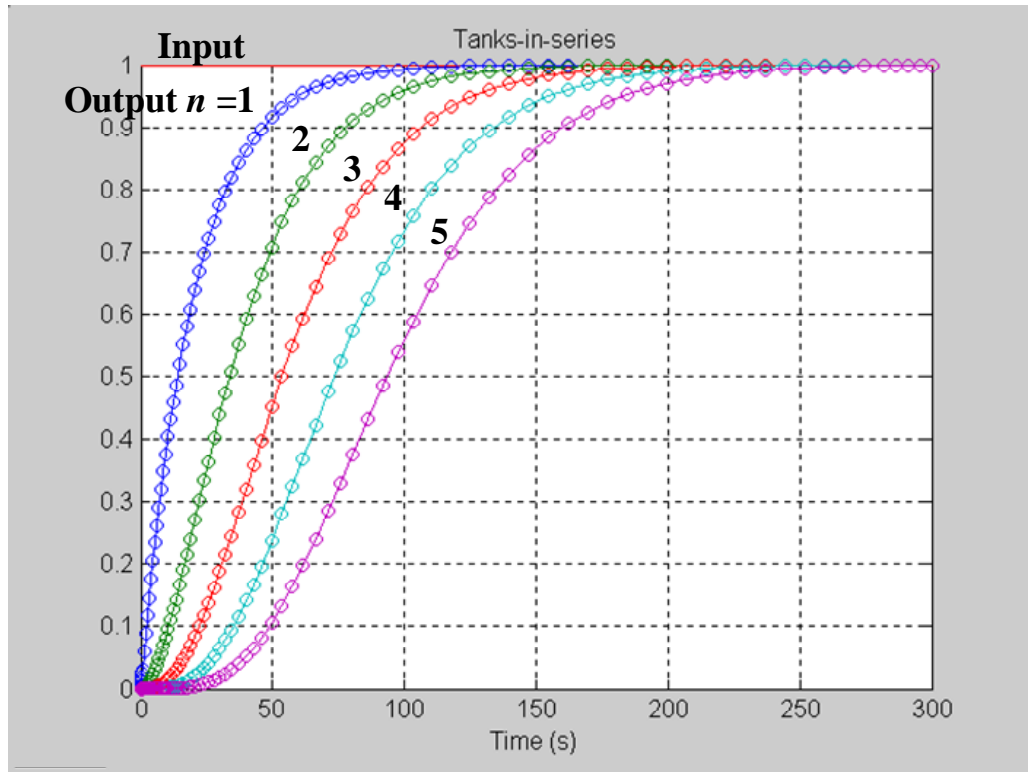

\section{Figure 4.2 Concentrations of outflows for one-step input}

For a sine wave input (e.g. $\left.C_{o}=2+\sin (2 \pi t / 60)\right)$, if the original concentration of each tank is 2 , the concentrations of outflows are shown in Figure 4.3. 


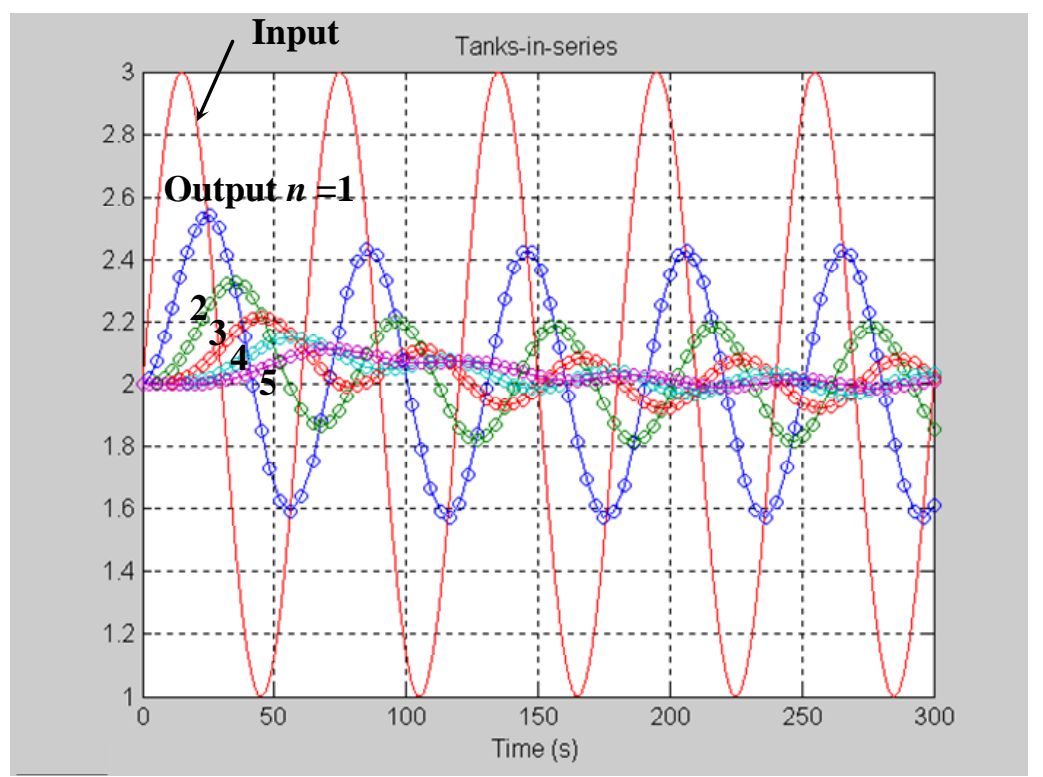

Figure 4.3 Concentrations of outflows for sine function input

Similarly, we can handle the riser as tanks connected in series:

$$
\tau_{i} \frac{d m_{i}}{d t}=m_{i-1}-m_{i}
$$

where

$$
m_{i}=\frac{\left(\Delta P_{i}\right) A_{i n}}{\tau_{i} g}
$$

and $m_{i}$ is the solids mass flow rate from the $i^{\text {th }}$ tank to the downstream one. $A_{\text {in }}$ is the internal cross-sectional area of the riser; $g$ is the acceleration due to gravity. Eq.(4.5) assumes that suspended solids constitute the sole contribution to the pressure drop, and friction and acceleration effects are negligible. With these definitions, the above equations become

$$
\tau_{i} \frac{d\left(\Delta P_{i}\right)}{d t}=\frac{\tau_{i}}{\tau_{i-1}} \Delta P_{i-1}-\Delta P_{i}, \quad i=2,3, \ldots, n
$$




$$
\tau_{1} \frac{d\left(\Delta P_{1}\right)}{d t}=\frac{m_{\text {circ }} g \tau_{1}}{A}-\Delta P_{i}
$$

where

$$
\tau_{i}=\frac{\bar{M}_{i n v, i}}{M_{s, a v e}}=\frac{\overline{\Delta P}_{i} A_{i n} / g}{M_{s, a v e}}
$$

and $n$ is the number of completely mixed tanks, and corresponds to the number of pairs of differential pressure taps located along the riser. There are 18 tanks in the current model, and their characteristic times are determined by pressure drop measurements.

A series of experiments was performed in which the mass flow rates of solids fed to the riser were changed sinusoidally while the superficial velocity was held constant. The move air is located near the base of the standpipe approximately $0.4 \mathrm{~m}$ above the $\mathrm{J}$-valve. Its flow rate was varied sinusoidally. The move air has been found to directly affect the solids flow rate and, therefore, the solids feed flow rate to the riser is given by

$$
M_{s}(t)=M_{s, a v e}+A_{m} \sin \left(\frac{2 \pi t}{T}\right)
$$

The mass flow rates of solids are illustrated in Figure 4.4. 


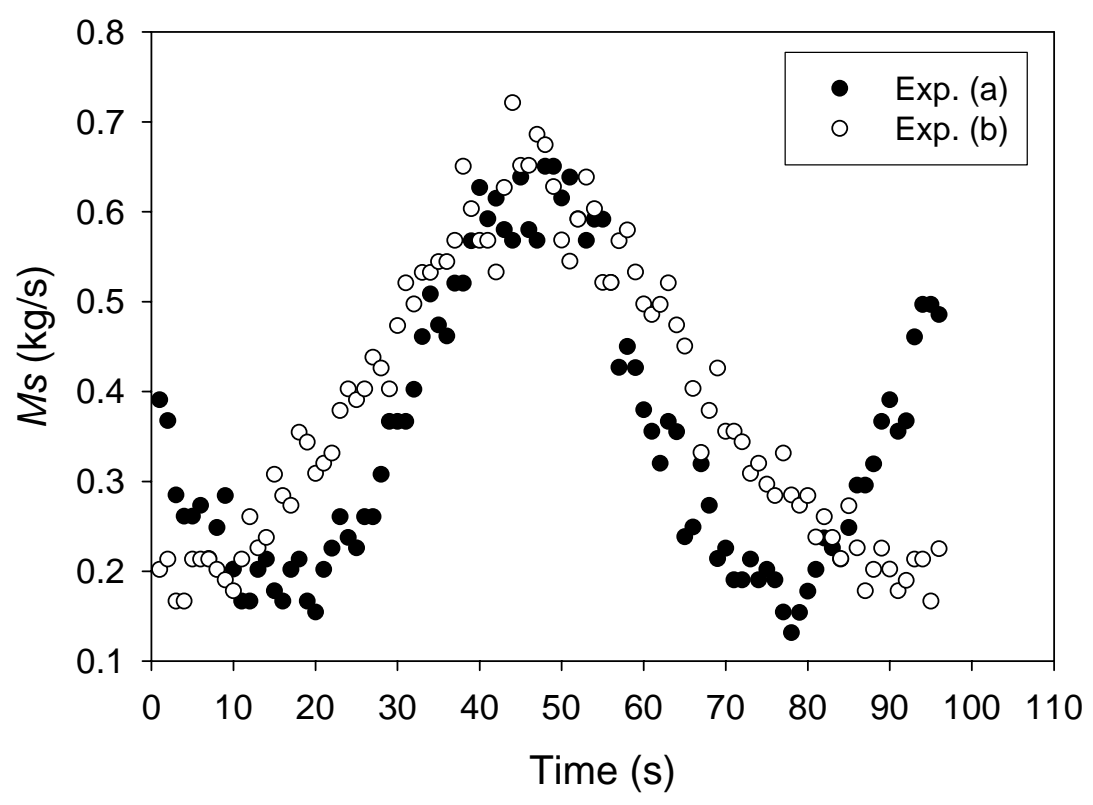

Figure 4.4 Mass flow rate of solids in a transient process
(a) $U_{g}=5.24 \mathrm{~m} / \mathrm{s} ; M_{s, \text { ave }}=0.386 \mathrm{~kg} / \mathrm{s} ; T=60 \mathrm{~s}$
(b) $U_{g}=5.24 \mathrm{~m} / \mathrm{s} ; M_{s, \text { ave }}=0.394 \mathrm{~kg} / \mathrm{s} ; T=90 \mathrm{~s}$

Pressure drops at different locations (bottom, middle and top) are shown in Figure 4.5, where the points are experimental data and lines are model predictions. It can be seen that there are significant phase shifts between pressure drops at different locations.

This model successfully predicts the phase shift at different locations. However, the calculation of characteristic times is based on the average inventory of each section of the riser. In industrial applications, the inventory at any point in the system is usually unknown and changes in a transient (or fluctuating) process. Therefore, it is difficult to estimate the amplitude of the pressure drops a priori. However, this model may be used to estimate the dynamic response time in the riser once a pressure profile has been measured. On the other hand, the characteristic times, $\tau_{i}$, are constants in this study, but 
they should be changed with time, $t$. Therefore, the characteristic times at time $t$ could be calculated from the solids inventories at time $t$ - $\Delta t$ during the numerical calculation.

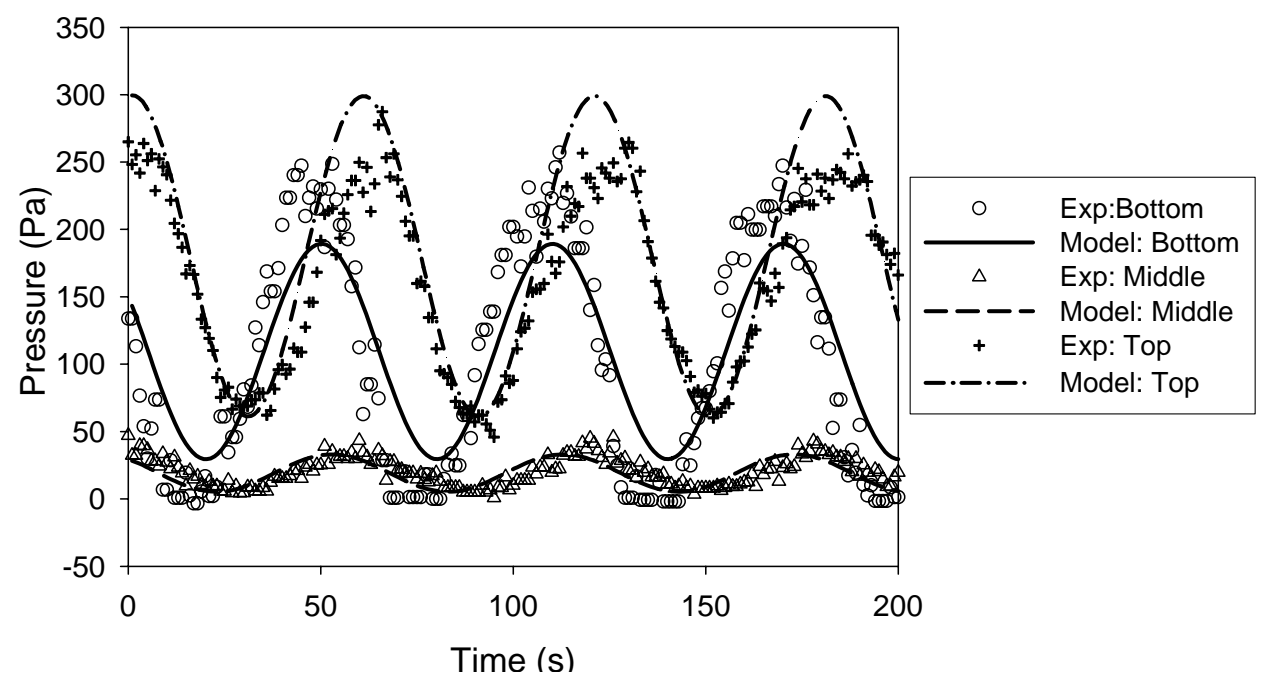

(a)

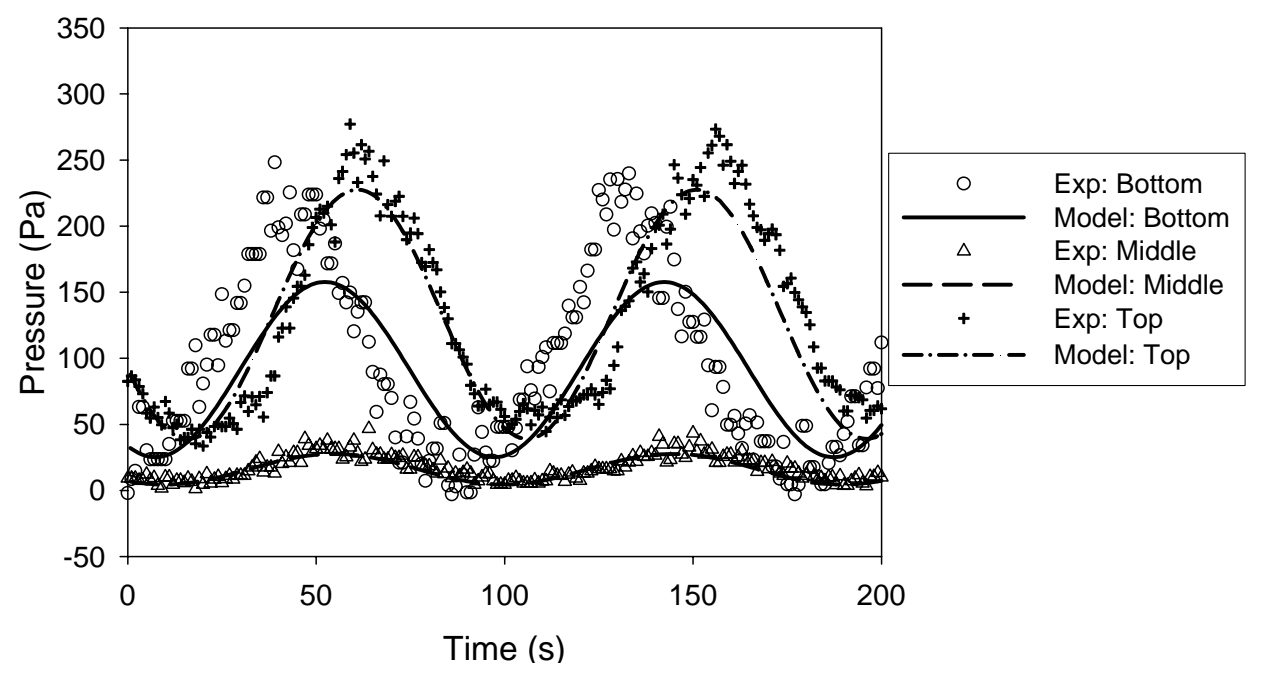

(b)

Figure 4.5 Prssure profiles at different locations in the riser for sine function input

(a) $U_{g}=5.24 \mathrm{~m} / \mathrm{s} ; M_{s, a v e}=0.386 \mathrm{~kg} / \mathrm{s} ; T=60 \mathrm{~s}$

(b) $U_{g}=5.24 \mathrm{~m} / \mathrm{s} ; M_{s, a v e}=0.394 \mathrm{~kg} / \mathrm{s} ; T=90 \mathrm{~s}$ 


\subsection{Steady state profile of voidage in the riser}

A) Determination of flow regime

Using Eq. 2.1 and 2.2, $U_{t f}$ and $U_{f d}$ can be calculated and are compared with current experimental data in Figure 4.6. From this figure, it can be seen that all the experiments are in the dilute transport regime.

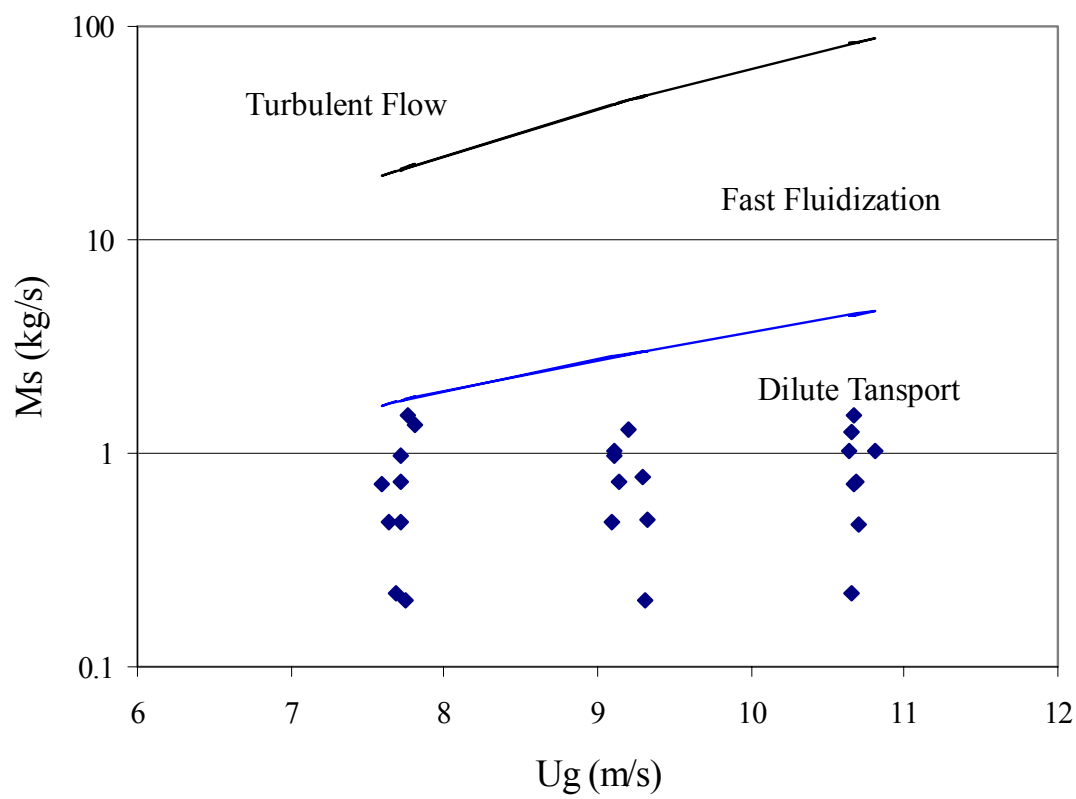

Figure 4.6 Determination of flow regime

The voidages measured in the experiments typically have C-shaped profiles as shown in Figure 4.7. 


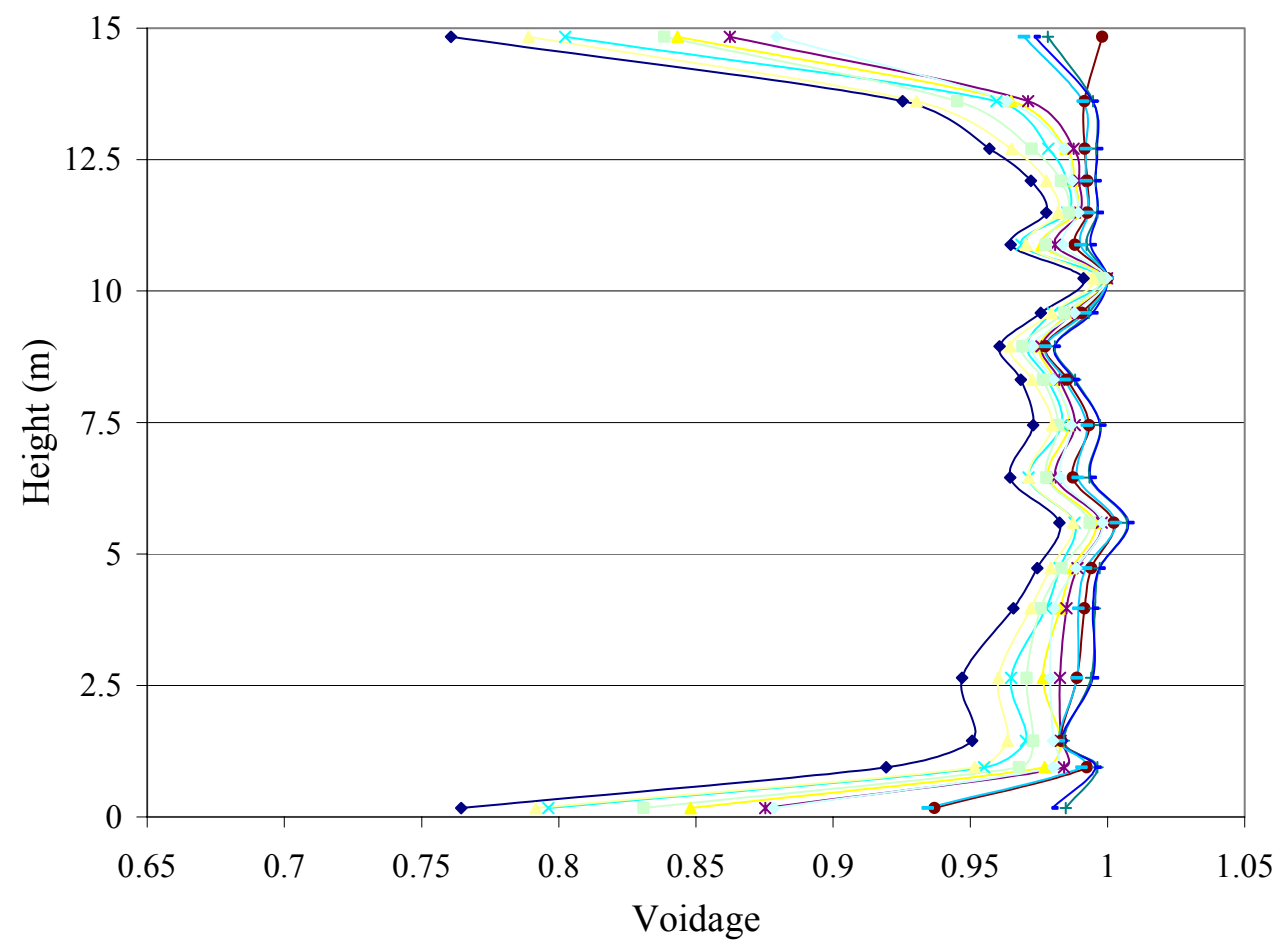

Figure 4.7 C-shape profiles of voidage in the experiments

B) Correlation of steady state voidage profiles

From the above analysis, all the experiments are in the dilute transport regime, and the voidage profiles are C-shaped, not S-shaped [24], as given by Eq. 2.3. Therefore, a new correlation for this C-shaped regime is necessary and the form of Eq. 2.3 can be used for reference:

$$
\frac{\varepsilon_{\max }-\varepsilon}{\varepsilon_{\max }-\varepsilon_{o}}=e^{-k R\left(z-z_{o}\right)^{n}}
$$

\section{At the bottom:}

$$
\text { If } n \neq 1 \quad \frac{\varepsilon_{\max }-\varepsilon}{\varepsilon_{\max }-\varepsilon_{o b}}=e^{-0.1811 R(z-0.168)^{1.12}}
$$




$$
\text { If } n=1 \quad \frac{\varepsilon_{\max }-\varepsilon}{\varepsilon_{\max }-\varepsilon_{o b}}=e^{-0.1836 R(z-0.168)}
$$

\section{At the top:}

$$
\begin{aligned}
& \text { If } n \neq 1 \quad \frac{\varepsilon_{\max }-\varepsilon}{\varepsilon_{\max }-\varepsilon_{o t}}=e^{-0.0686 R(14.84-z)^{1.28}} \\
& \text { If } n=1 \quad \frac{\varepsilon_{\max }-\varepsilon}{\varepsilon_{\max }-\varepsilon_{o t}}=e^{-0.0816 R(14.84-z)}
\end{aligned}
$$

where $\varepsilon$ is local voidage at $z(\mathrm{~m}) ; \varepsilon_{o b}$ is voidage at the bottom of the riser; $\varepsilon_{o t}$ is voidage at the top of the riser; $\varepsilon_{\max }$ is the maximum voidage in the lean phase of the riser; $R$ is the ratio of gas to solids, which can be represented as:

$$
R=\frac{U_{g}}{G_{s}}
$$

where $U_{g}$ is the superficial velocity of gas in the riser and $G_{s}$ is solids flow rate.

The voidages, $\varepsilon_{o b}, \varepsilon_{o t}$ and $\varepsilon_{\max }$ can be correlated from experimental data (Figure 4.8) and can be represented by the following Equations 4.16 4.18.

$$
\begin{aligned}
& \varepsilon_{o b}=1-0.3912 e^{-0.0913 R} \\
& \varepsilon_{o t}=1-0.4041 e^{-0.1143 R} \\
& \varepsilon_{\text {max }}=1-0.0413 e^{-0.0901 R}
\end{aligned}
$$




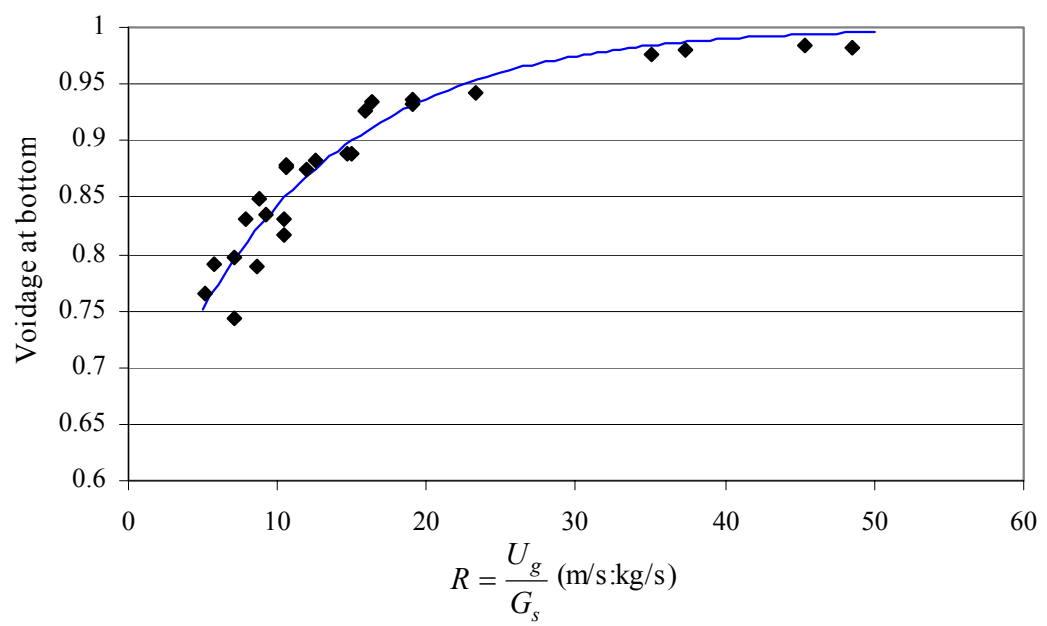

(a) $\varepsilon_{o b}$

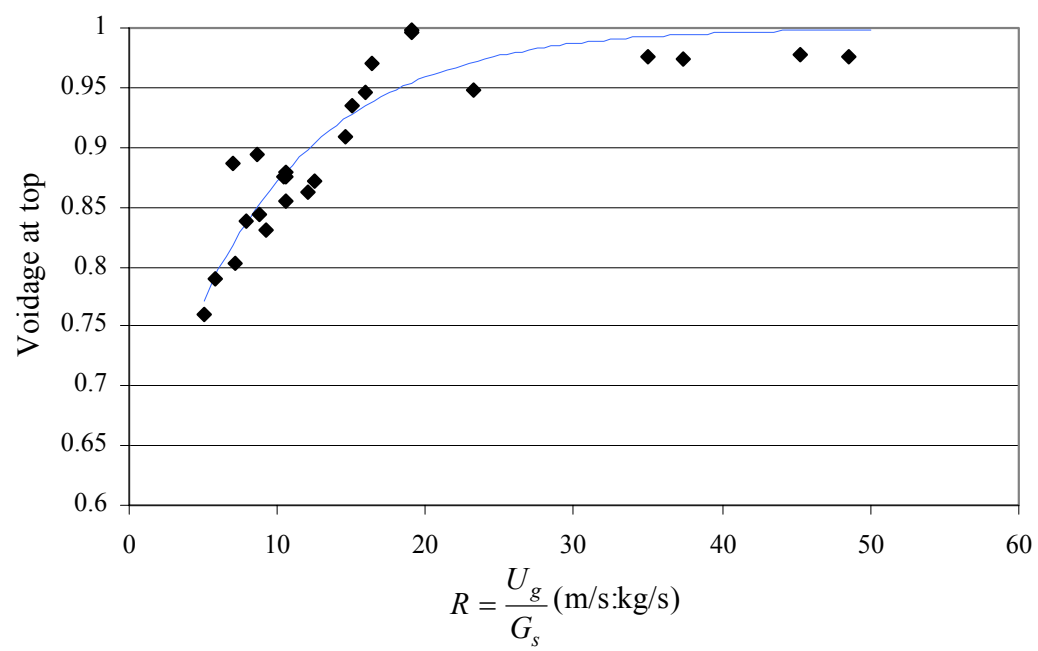

(b) $\varepsilon_{o t}$

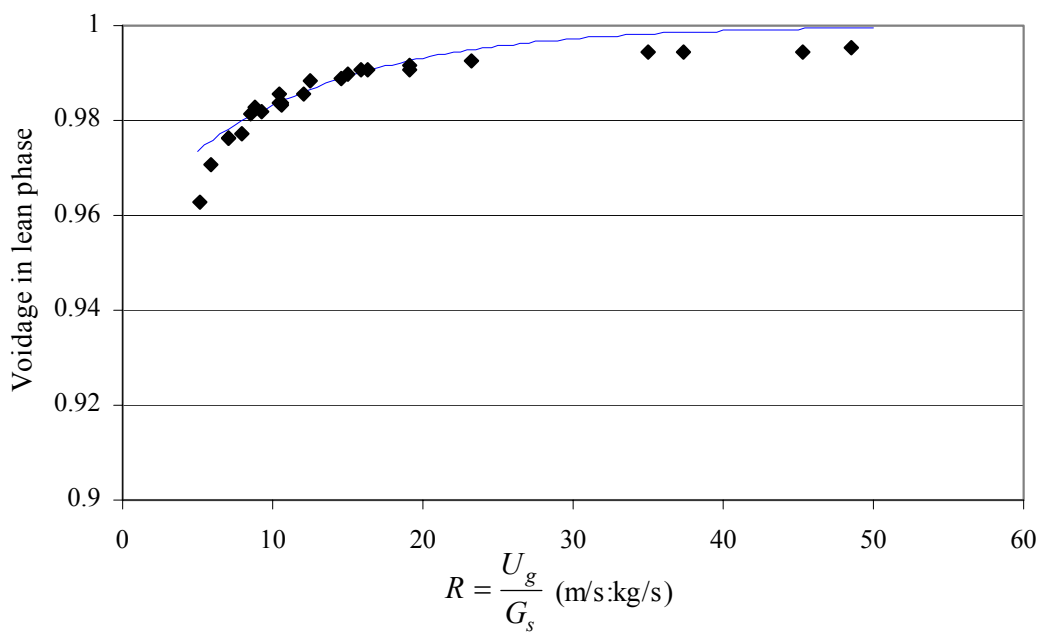

(c) $\varepsilon_{\max }$

Figure 4.8 Correlations of $\varepsilon_{o b}, \varepsilon_{o t}$ and $\varepsilon_{\max }$ 
From the above model, voidage profiles in the riser at steady state can be predicted, and two examples are shown in Figure 4.9.
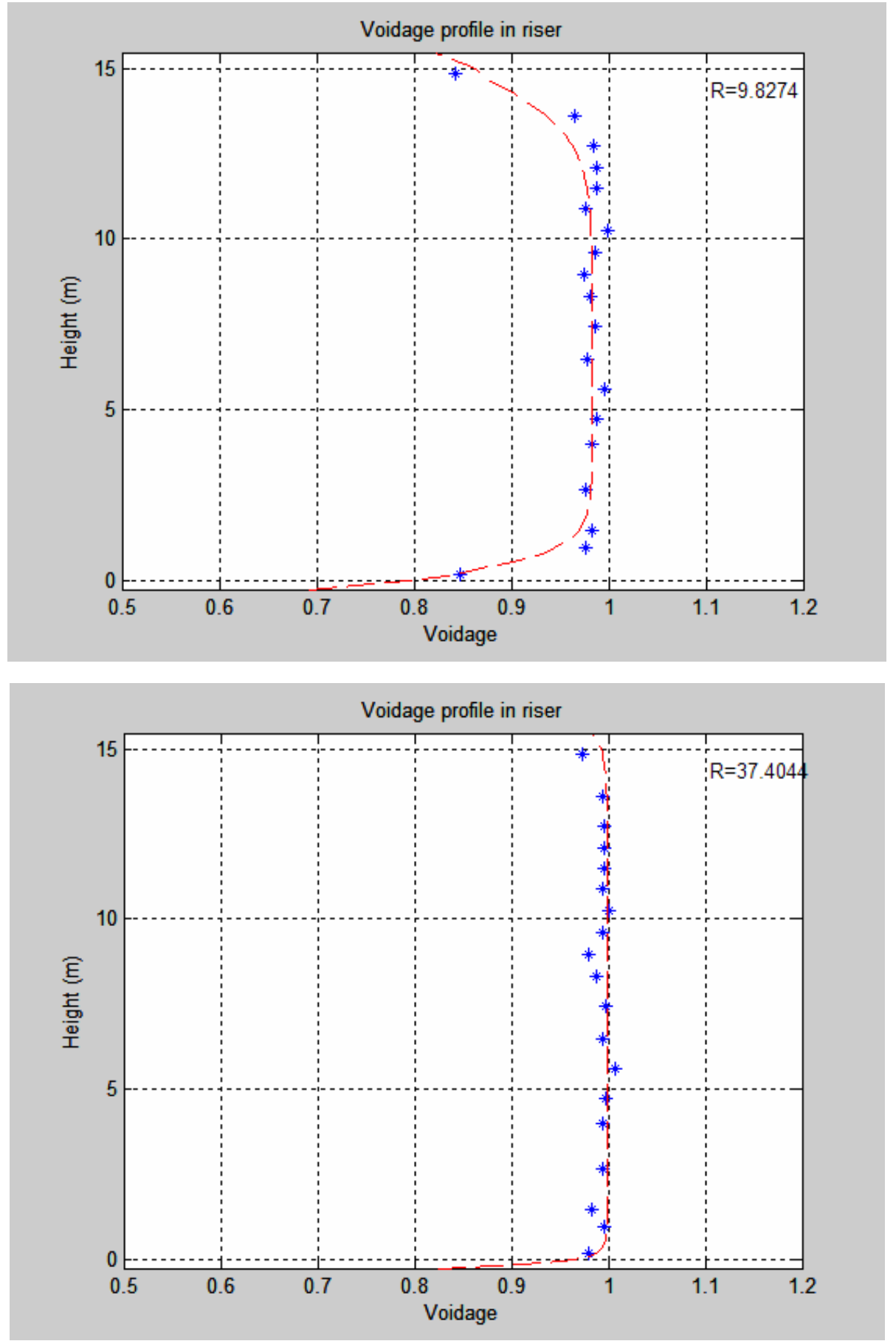

Figure 4.9 Comparison of steady state voidage profile model (dashed line) with the experimental data 


\subsection{Cluster model}

In the last two decades, two main categories of structural models have been proposed to predict the hydrodynamics of circulating fluidized bed riser, as shown in Figure 4.10. One category of models assumes a core/annulus two-region structure, [22]. The other category of models assumes the existence of particle clusters dispersed in a homogeneously upflowing dilute gas-solids mixture, [17]. Key parameters for this type of model are the cluster size and fraction of the cluster phase. The 1-D axisymetric cluster model developed here, assumes that all flow is unidirectional with no mixing in the axial direction. The mass of solids in the dilute phase is negligible because the vast majority of solids is in the cluster phase, [61].

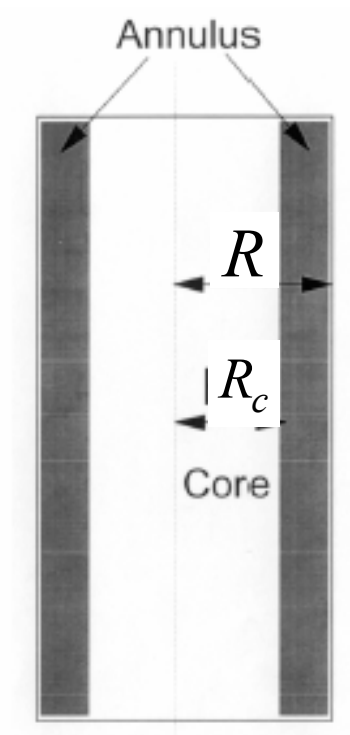

(a)

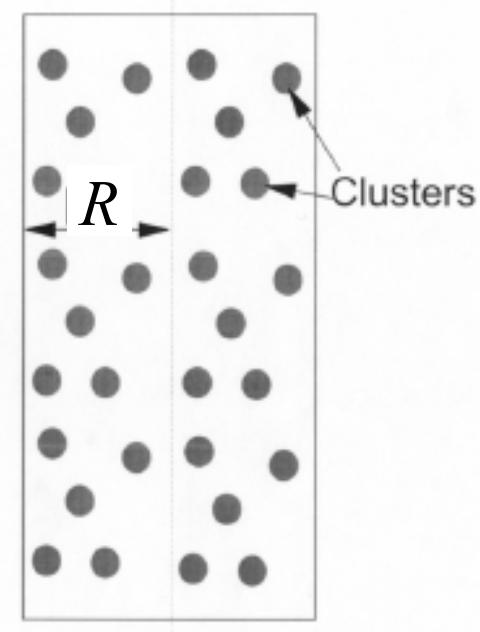

(b)

Figure 4.10 Illustration of riser flow
(a) the core-annulus model
(b) the cluster model 
Previous research undertaken to characterize particle clusters has produced results for a range of different cluster properties. Size and voidage of clusters are important in this research because these properties determine the interphase forces and their prediction is one of the basic needs for analyzing gas-solid flow. A significant body of experimental work has been published on the solids concentration of particle clusters, [22], [62]-[65]. Cluster voidage, $\varepsilon_{c l}$, (i.e. the void fraction within a cluster) can be correlated to the cross-sectionally averaged voidage, $\varepsilon$. Lints [66] suggested the following correlation:

$$
\varepsilon_{c l}=1-1.23(1-\varepsilon)^{0.54}
$$

Harris et al. [67] summarized the experimental data from 13 different studies and obtained the following correlation:

$$
\varepsilon_{c l}=1-\frac{0.58(1-\varepsilon)^{1.48}}{0.013+(1-\varepsilon)^{1.48}}
$$

$\mathrm{Xu}$ and Kato [68] developed a simplified correlation for the hydrodynamic equivalent cluster diameter $d_{c l}$ :

$$
d_{c l}=A\left(\frac{\rho_{s}}{\rho_{c l}}\right) d_{p}
$$

where

$$
\begin{aligned}
& A=\frac{\left(3333 \cdot U_{s} \cdot g-M_{2}\right)\left(1-\varepsilon_{m f}\right)\left(\rho_{s}-\rho_{g}\right)}{\left(Q_{1}-2 M_{2}\right) \rho_{s}} \\
& Q_{1}=\frac{\left(\rho_{s}-\rho_{g}\right) g}{\rho_{s}}\left[U_{g}+\frac{U_{s} \varepsilon_{m f}}{1-\varepsilon_{m f}}+\frac{U_{t} \varepsilon_{m f}^{4.7}}{4}\right] \\
& M_{2}=\left(U_{m f}+\frac{U_{s} \varepsilon_{m f}}{1-\varepsilon_{m f}}\right) g
\end{aligned}
$$




$$
\frac{\rho_{s}}{\rho_{c l}}=\frac{1}{1-\varepsilon_{c l}}
$$

Pandey et al. [69] used a backscatter laser Doppler velocimeter (LDV) system to record the length of clusters in the near-wall region of the riser at essentially the same conditions (gas velocities, solids properties and flows) as the current work. The experimental results are compared with the two correlations in Figure 4.11. A dimensionless solids-to-gas loading ratio, $m$, was defined to characterize the operating conditions, and is given as follows:

$$
m=\frac{M_{s}}{\rho_{g} A_{i n} U_{g}}
$$

where $M_{s}$ is the mass flow rate of solids ; $\rho_{g}$ is the gas density ; $A_{\text {in }}$ is the internal cross-sectional area of the riser and $U_{g}$ is the superficial velocity of gas. In Figure 4.11, the cluster size in the lean phase of the riser is seen to increase with increasing loading ratio, $m$. There is also no significant difference between these two correlations, but the experimental results of Pandey et al [69] are always greater than the predictions of these two correlations. Two reasons contribute to this difference between the experimental data and the correlations. First, the cluster length was measured by the LDV system while correlations predict the equivalent diameter of clusters. The clusters in the riser are usually in the stream-like shape; hence, the length of a cluster is much greater than its width. The LDV measures the length of cluster which is greater than the equivalent diameter. Second, the LDV system also measures near-wall clusters while correlations give a cross-sectionally averaged value; measurement results are usually greater than 
cross-sectionally averaged value because of the core-annual structure of flow [70]. Both of these phenomena cause experimental data to lie above correlations in Figure 4.11. The trend of cluster size and loading ratio is similar for experimental data and correlations, therefore, the correlations are used to predict the cluster size in the model.

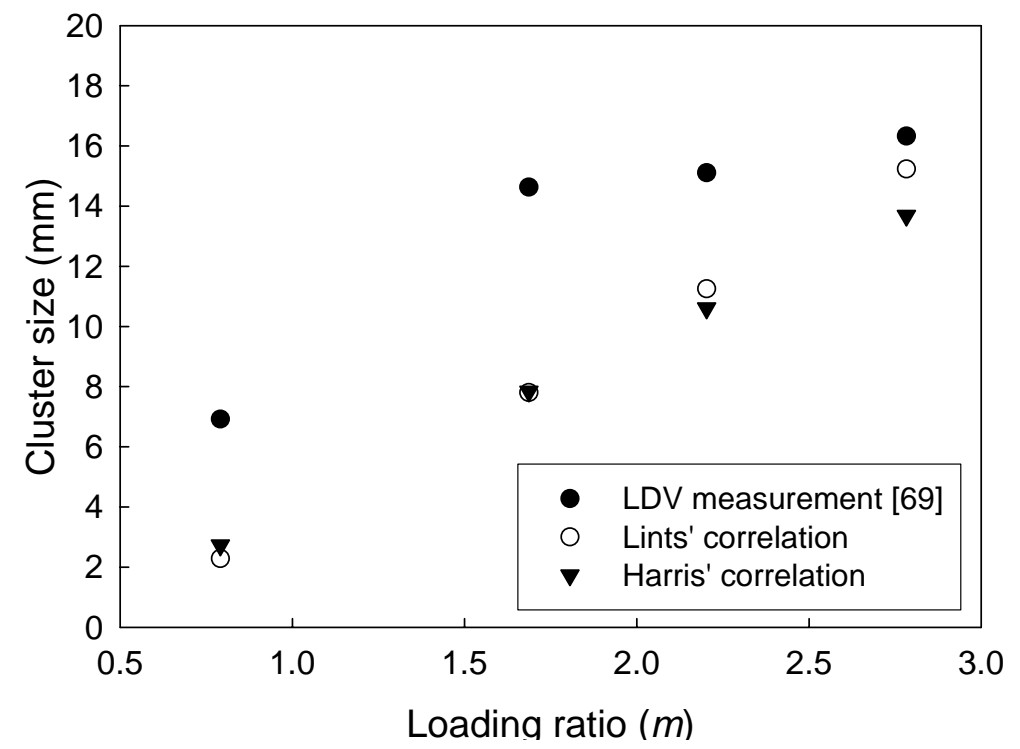

Figure 4.11 Cluster size prediction compared with LDV measurement in the lean phase of the riser

According to the above correlations, cluster properties (i.e. $\varepsilon_{c l}$ and $d_{c l}$ ) will change in the solids acceleration zone at the lower region of the riser, and become constant in the fully developed lean phase region (shown in Figure 4.12). Therefore, the solids velocity can be estimated from a force balance on the upward moving cluster:

$$
\frac{\pi}{6} d_{c l}{ }^{3} \rho_{c l} \frac{d u_{s}}{d t}=\frac{\pi}{8} d_{c l}{ }^{2} \beta u_{c l, s l}{ }^{2}+\frac{\pi}{6} d_{c l}{ }^{3} g\left(\rho_{g}-\rho_{c l}\right)
$$

where $u_{c l, s l}$ is the cluster slip velocity (i.e., relative velocity between the cluster and gas phase), and is given as follows: 


$$
u_{c l, s l}=\frac{U_{g}}{\varepsilon}-u_{s}
$$

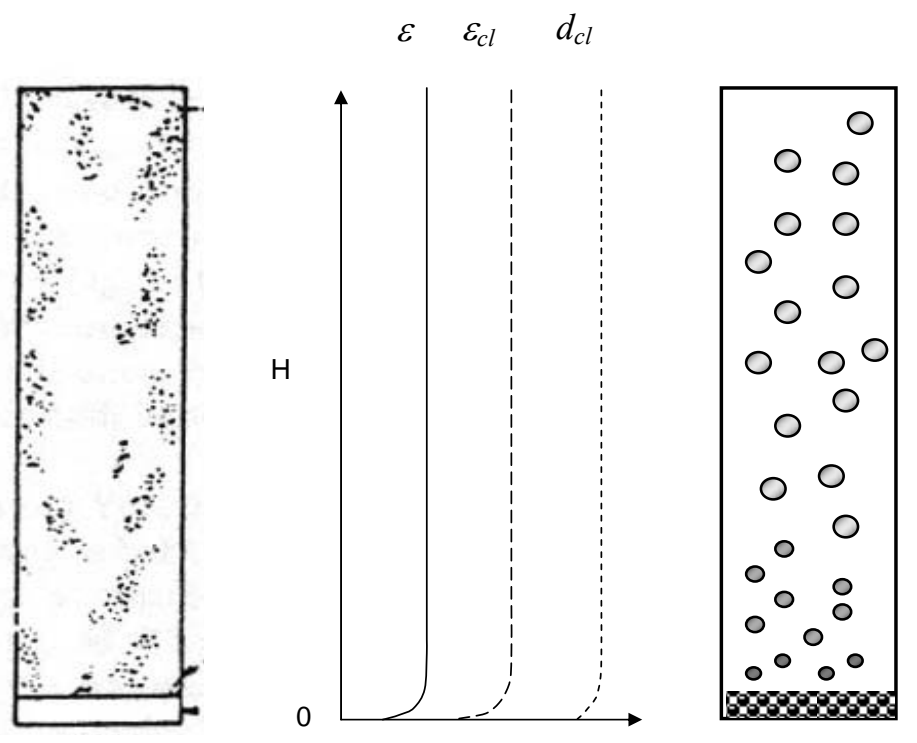

Figure 4.12 An illustration of how cluster properties change along the height of the riser

The effective drag coefficient, $\beta$, was calculated from [71]:

$$
\beta=C_{D} \varepsilon^{-4.7}
$$

where the standard drag coefficient, $C_{D}$, was calculated from the following correlation given by [15]:

$$
C_{D}=\frac{24}{R e_{p}}\left(1+0.173 R e_{p}^{0.657}\right)+\frac{0.413}{1+16300 R e_{p}^{-1.09}}
$$

A dense phase voidage, $\varepsilon_{o}$, which is a little greater than the voidage at choking, is chosen as the boundary condition in order to obtain stable numerical solutions. $\varepsilon_{o}$ is given as follows:

$$
\varepsilon_{o}=\varepsilon_{c h}+0.005
$$


And the voidage at choking, $\varepsilon_{c h}$, was calculated from [72]:

$$
\varepsilon_{c h}=\frac{U_{g} \sqrt{\rho_{g}}}{U_{g} \sqrt{\rho_{g}}+U_{s} \sqrt{\rho_{s}}}
$$

The experimental data available in this research are given in terms of pressure drop rather than solids velocity profiles. Therefore, the results of the model, which are the cluster velocities as a function of height in the riser, can be converted to pressure drop profiles according to the following equation [73]:

$$
\frac{d}{d z}\left[\rho_{g} \varepsilon u_{g}{ }^{2}+\rho_{s}(1-\varepsilon) u_{s}{ }^{2}\right]=-\frac{d P}{d z}-g\left[\rho_{g} \varepsilon+\rho_{s}(1-\varepsilon)\right]
$$

Experimental data and model predictions of pressure drop along the height of the riser at steady state are shown in Figure 4.13. It is seen that the 1-D axisymetric cluster model fits the experimental data satisfactorily. Because of the chaotic nature of the system, experimental data show a wavy structure that is not represented by the model.

The cluster concept evolved as a result of the recognition of a large slip velocity between gas and solid particles, [17]. The solids velocity profiles are shown in Figure 4.14. The slip velocity is around $4 \sim 5 \mathrm{~m} / \mathrm{s}$. Compared with wall-particle and particle-particle frictional forces, drag force becomes more important in gas-solid flows. Hence, frictional forces are not considered in Eq. (4.33). 


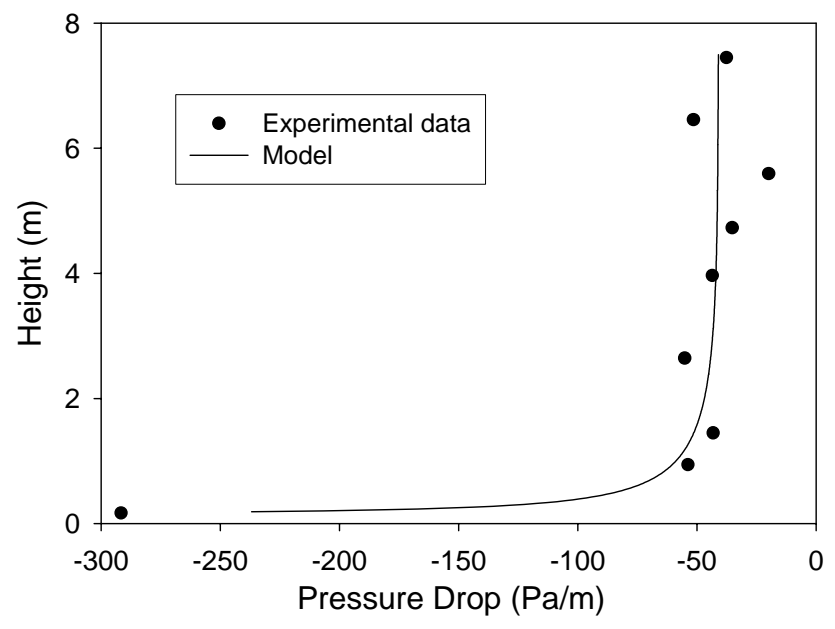

(a)

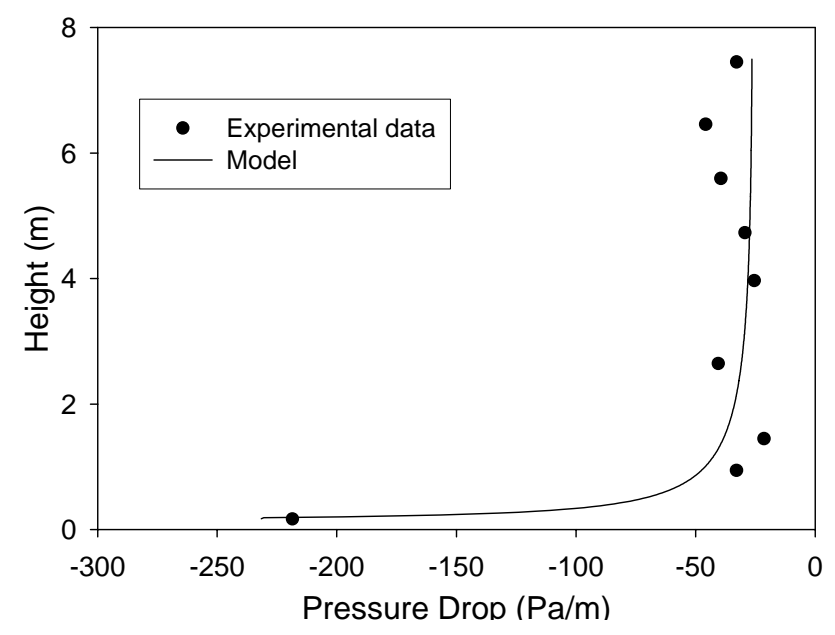

(b)

Figure 4.13 Model predictions of axial pressure drop compared with experimental data at steady state

(a) $U_{g}=9.10 \mathrm{~m} / \mathrm{s} ; M_{S}=0.926 \mathrm{~kg} / \mathrm{s} ; R=1.16$

(b) $U_{g}=10.68 \mathrm{~m} / \mathrm{s} ; M_{s}=0.733 \mathrm{~kg} / \mathrm{s} ; R=0.825$ 


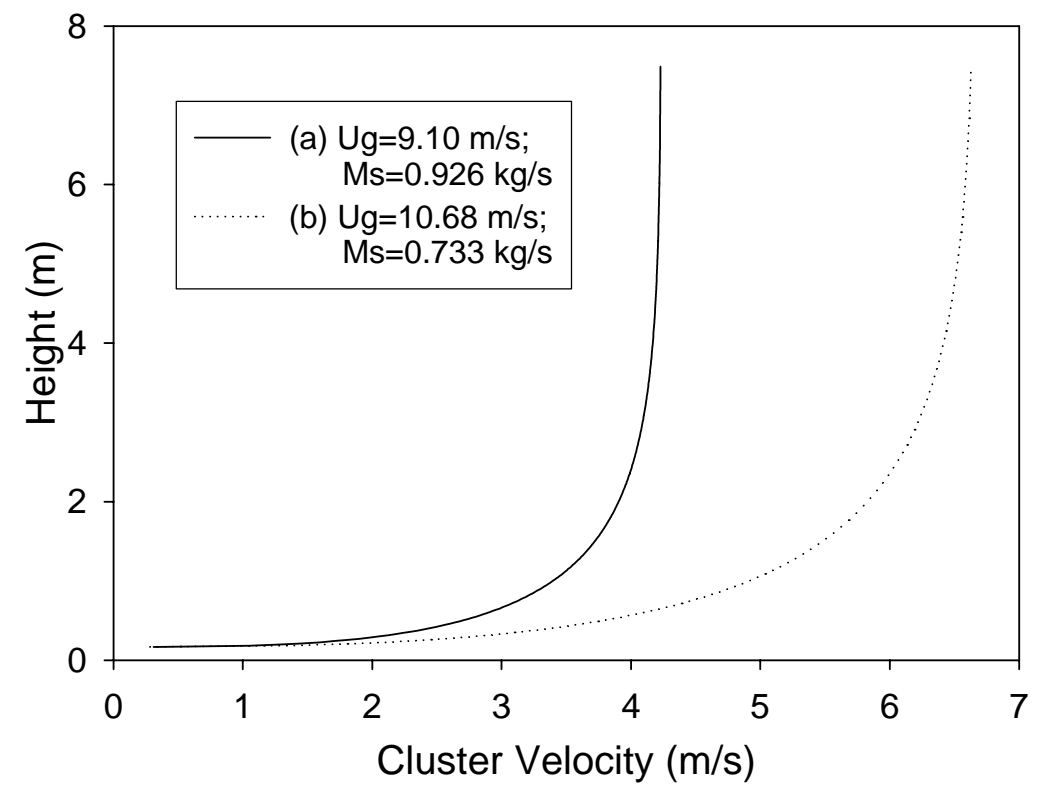

Figure 4.14 Model predictions of axial solids velocity profiles drop at steady state

For a transient process, the continuity equation for particle flow is as follows:

$$
\rho_{s} \frac{\partial \varepsilon}{\partial t}=\frac{\partial\left[u_{s}(1-\varepsilon)\right]}{\partial z}
$$

If a small element of solids $\mathrm{d} V$ is considered, it will move as it is carried up at the instantaneous velocity at the point that it occupies. If the flow is steady, it will move on a streamline, but this is not generally true. The time rate of change of any quantity relating to the element $\mathrm{d} V$ will be expressed by the substantial derivative, $\mathrm{D} / \mathrm{D} t$. The acceleration will be $\mathrm{D} u_{s} / \mathrm{D} t . \mathrm{D} / \mathrm{D} t$ is expressed as the sum of the change at the point $(x, y, z)$ as $\mathrm{t}$ varies, or $\partial / \partial t$, and the change due to moving from point $(\mathrm{x}, \mathrm{y}, \mathrm{z})$ to $(x+\mathrm{d} x, y+\mathrm{d} y, z+\mathrm{d} z)$ in unit time. Therefore,

$$
\frac{D u_{s}}{D t}=\frac{\partial u_{s}}{\partial t}+\vec{u} \bullet\left(\frac{\partial u_{s}}{\partial x}+\frac{\partial u_{s}}{\partial y}+\frac{\partial u_{s}}{\partial z}\right)
$$


For the current 1-dimensional analysis,

$$
\frac{D u_{s}}{D t}=\frac{\partial u_{s}}{\partial t}+u_{s} \frac{\partial u_{s}}{\partial z}
$$

Replacing the term $\mathrm{d} u_{s} / \mathrm{d} t$ by the above substantial derivative, gives

$$
\frac{\pi}{6} d_{c l}{ }^{3} \rho_{c l}\left(\frac{\partial u_{s}}{\partial t}+u_{s} \frac{\partial u_{s}}{\partial z}\right)=\frac{\pi}{8} d_{c l}{ }^{2} C_{D} u_{c l, s l}{ }^{2}+\frac{\pi}{6} d_{c l}{ }^{3} g\left(\rho_{g}-\rho_{c l}\right)
$$

An experiment, in which the mass flow rates of solids fed to the riser were changed sinusoidally, is illustrated in Figure 4.4 (a) for a period, $T$, of 60 seconds. Experimental data and model predictions of pressure drops along the height of the riser at different times are shown in Figure 4.15. As can be seen in Figure 4.15 (a) (e), the solid lines fit the experimental data satisfactorily, except for the pressure drops at the lowest region of the riser. In the bottom of the riser, the solids are accelerated to a constant upward velocity, and there is a very large voidage gradient. Therefore, the pressure drop changes greatly even within a very short distance. The pressure fluctuations of the significantly turbulent flow in this region are also another factor that gives rise to random changes in pressure drop and solids velocities. 


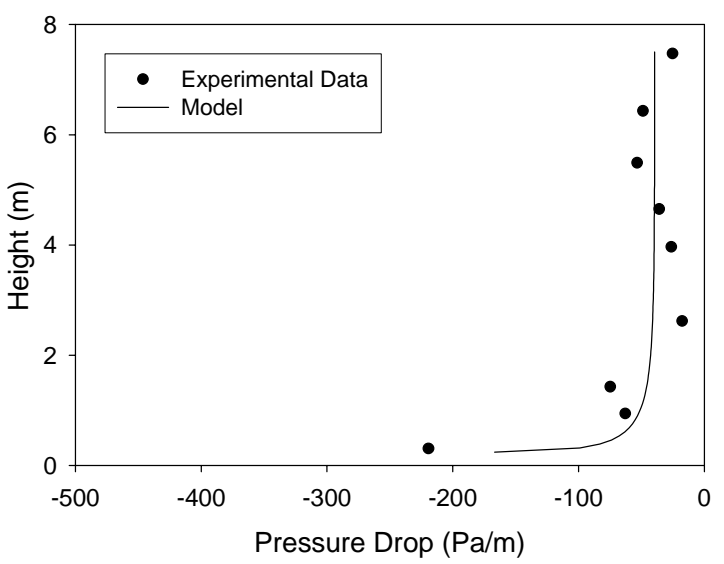

(a) $t=0 \mathrm{sec}$

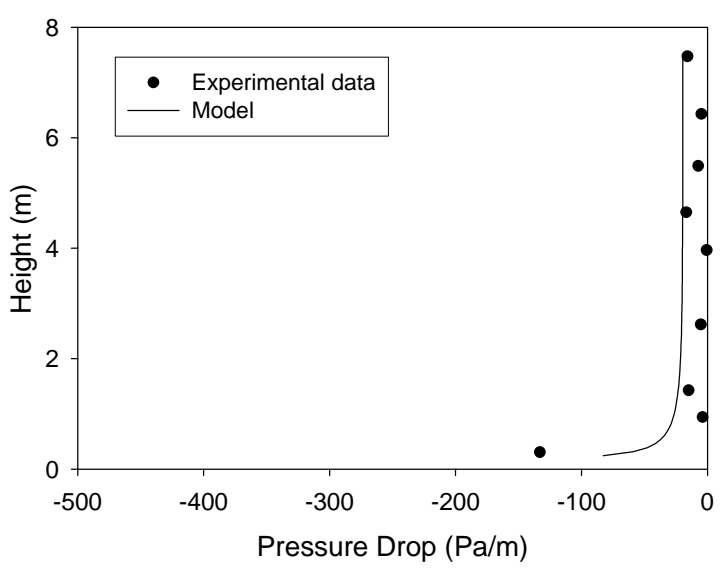

(c) $t=30 \mathrm{sec}$

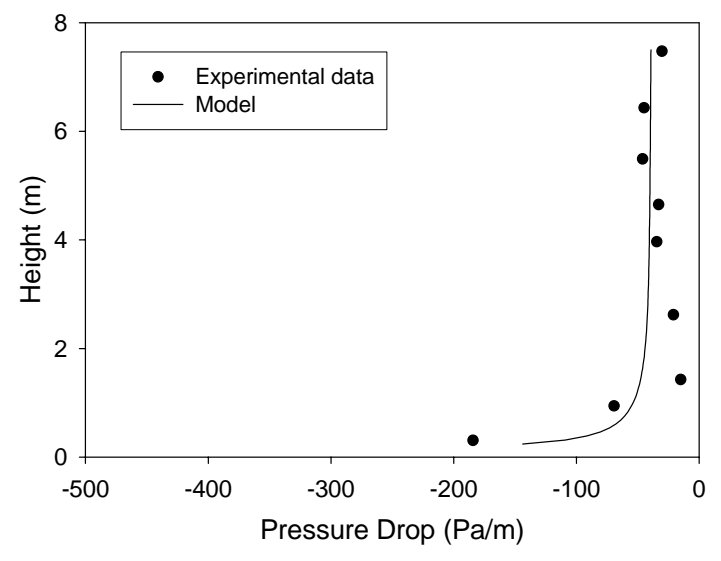

(e) $t=60 \mathrm{sec}$

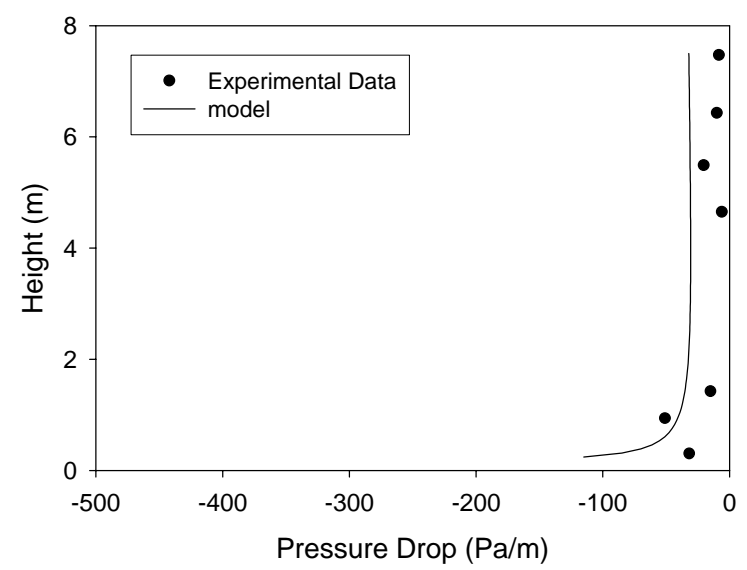

(b) $t=15 \mathrm{sec}$

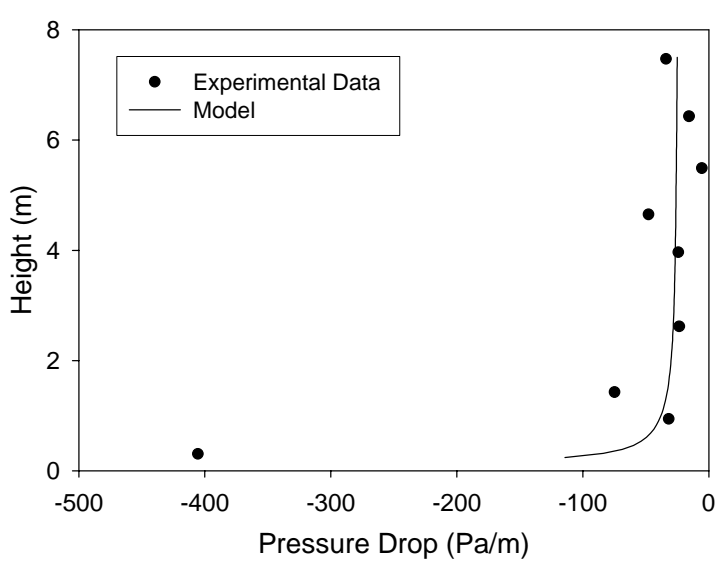

(d) $t=45 \mathrm{sec}$

Figure 4.15 Model predictions of axial pressure drop compared with experimental data at different times under transient process 
The total CPU time required to run 1 second of simulation on a $3.0 \mathrm{GHz}$ Intel-Windows PC is around 0.6 second, which is fast enough for the model to be used in process control.

The importance of CFB hydrodynamics in reactor modeling should be stressed because the poor contact efficiency can cause conversion to be as low as that in well mixed reactors [74]. The cause of such a poor contact efficiency may be attributed to the separation of solids from the gas phase, [75], by the formation of clusters. In the current work, the voidage and velocity profiles are predicted by the 1-D axisymetric cluster model, so that the gas-solids contact efficiency of CFB reactors can be estimated. The cluster model given here is not only a mathematical description of the transient solids holdup process in the riser, but may also to be used to explore the effect of operating conditions on conversion and used in advanced control of a pilot (or industrial) scale unit. 


\subsection{Deceleration region model}

Previously, the cluster-based model was used to model the acceleration of solids. Therefore, it can be applied to both the bottom and the fully-developed region of the riser. The model of the deceleration region needs to be considered.

The riser exit geometry of a circulating fluidized bed (CFB) has been reported to have a significant impact upon the hydrodynamics of the whole unit. In particular, the effect upon the particle residence time distribution (RTD) in the riser can influence the temperature profile for a CFB combustor or conversion for a CFB reactor [76].

Harris et al. [77] proposed a comparative dimensionless length of influence of riser exit, $\Omega$. It is defined as

$$
\Omega=\frac{\text { Length of influence }}{\text { Riser height }}
$$

where the length of influence is the distance along the riser from the top, where the pressure profiles from smooth and abrupt exits (Figure 4.16) coincide, which is shown in Figure 4.17.

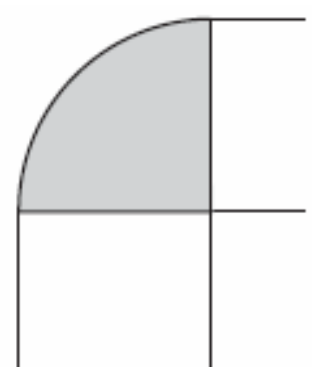

(a) Smooth exit

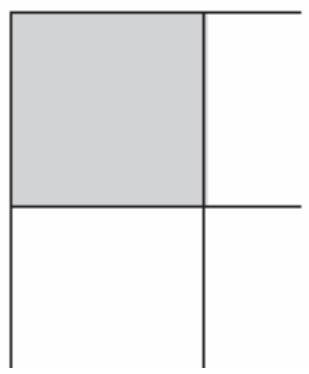

(b) Abrupt exit

Figure 4.16 Typical exit bends 

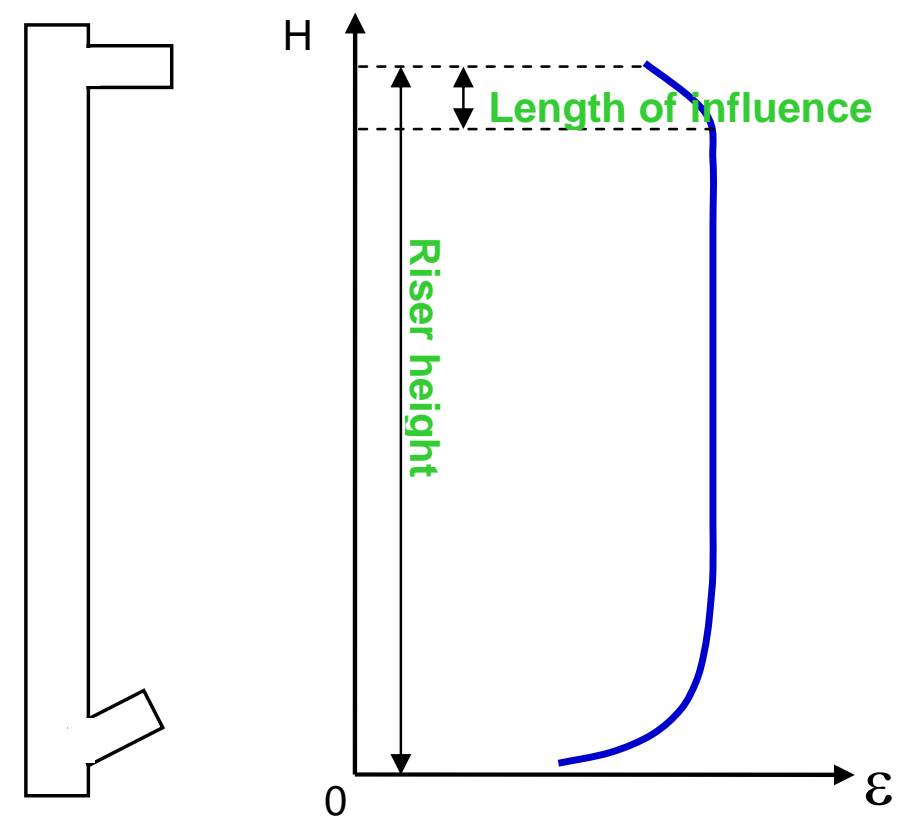

Figure 4.17 Definition of dimensionless length of influence of riser exit, $\Omega$

The influence of the riser exit has been investigated by numerous researchers. It has shown that the length of influence of the riser exit is influenced by the riser and riser exit geometry, experimental conditions and particle properties [77]. Thus

$$
\Omega=f\left(d_{p}, \rho_{s}, U_{g}, U_{t}, M_{s}, \rho_{g}, \mu_{g}, D\right)
$$

Reviews by Horio [78], Werther et al. [79], and Lim et al. [80] concluded that the exit design can affect the density profile over several meters in the upper region of a riser. Lim et al. [80] also noted that a strong exit restriction gives a C-shaped solids concentration profile, while a weak exit restriction does not. These conclusions are in agreement with those of Martin et al. [81],[82], who performed experiments in both laboratory and industrial scale FCC risers. 
In our current CFB system, the typical voidage profiles in the riser are shown in Figure 4.7. The length of influence is almost a constant, i.e., $\Omega \cong 0.2$.

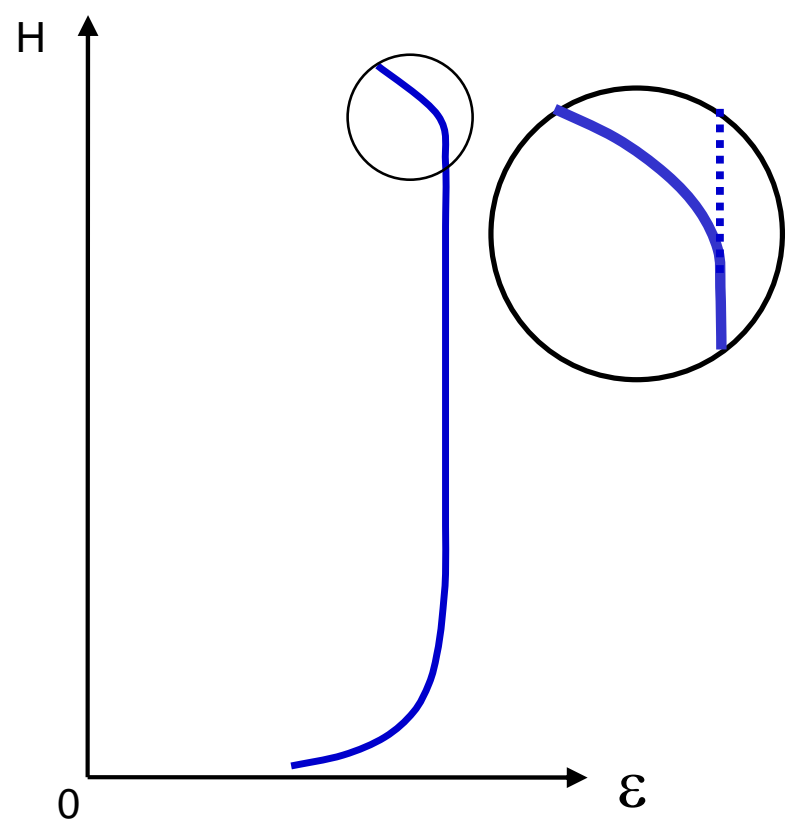

Figure 4.18 The voidage profile in the top of the riser

The voidage profile in the top of the riser is shown in Figure 4.18. Its pressure gradient profile is easily obtained from

$$
\frac{\Delta P}{L}=\rho_{s} g(1-\varepsilon)
$$

It is assumed that the pressure gradient has a parabolic-shaped profile which is a function of location, $h$, given as

$$
\frac{\Delta p}{L}=f(h)=a \cdot h^{2}+b \cdot h+c
$$

where the coefficients, $a, b$ and $c$ should be determined by 3 equations. These equations are: 


$$
\begin{aligned}
& \left.\frac{\Delta p}{L}\right|_{h=0.8 H}=\left.\left(\frac{\Delta p}{L}\right)^{-}\right|_{\text {cluster model }} \\
& \frac{\left.\partial \frac{\Delta p}{L}\right|_{h}}{\partial h}=0 \\
& \left.\frac{\Delta p}{L}\right|_{h=0.8 H}=-\rho_{s}\left(1-\left.\varepsilon\right|_{h=H}\right) g
\end{aligned}
$$

where $H$ is the riser height; and

$$
\left.\varepsilon\right|_{h=H}=f(R)
$$

which can be determined by Eq. 4.17 .

Eq. 4.42 ensures that the pressure gradient is continuous at the point between the developed region and exit region in the riser. Eq. 4.43 ensures that its derivative is also continuous at that point. Eq. 4.44 gives the pressure gradient at the exit region determined by the steady state profile, which is the function of loading ratio, $R$. Based on the above equations, the pressure gradient profile can be obtained.

Combined with the cluster model in Section 4.4, the model coverage can be extended to the entire riser which includes the acceleration region, developed region and exit region. An experiment, in which the mass flow rates of solids fed to the riser were changed sinusoidally, is illustrated in Figure 4.4 (a) for a period, $T$, of 60 seconds. Experimental data and model predictions of pressure drops along the entire riser at different times are shown in Figure 4.19. 


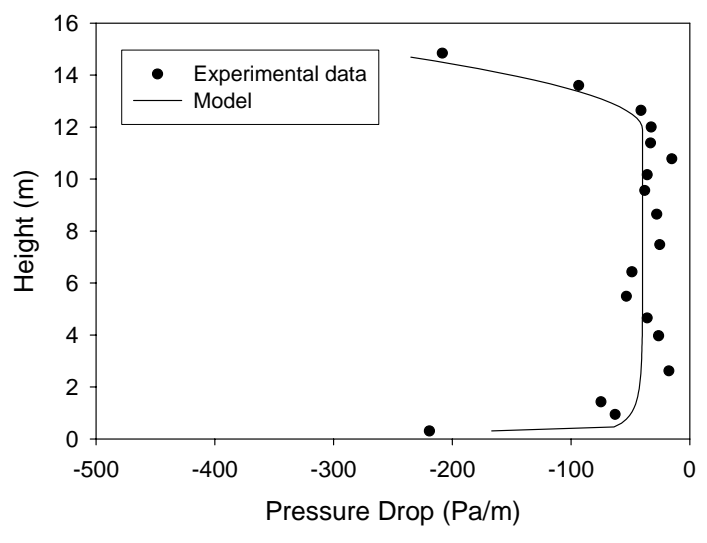

(a) $t=0 \mathrm{sec}$

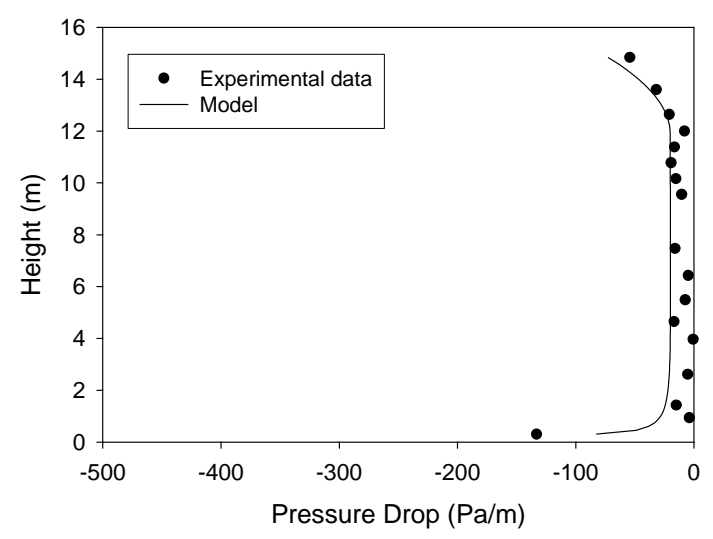

(c) $t=30 \mathrm{sec}$

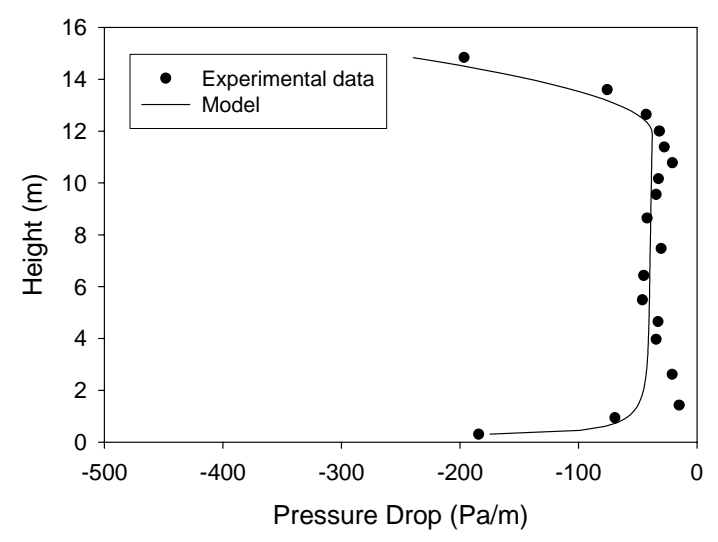

(e) $t=60 \mathrm{sec}$

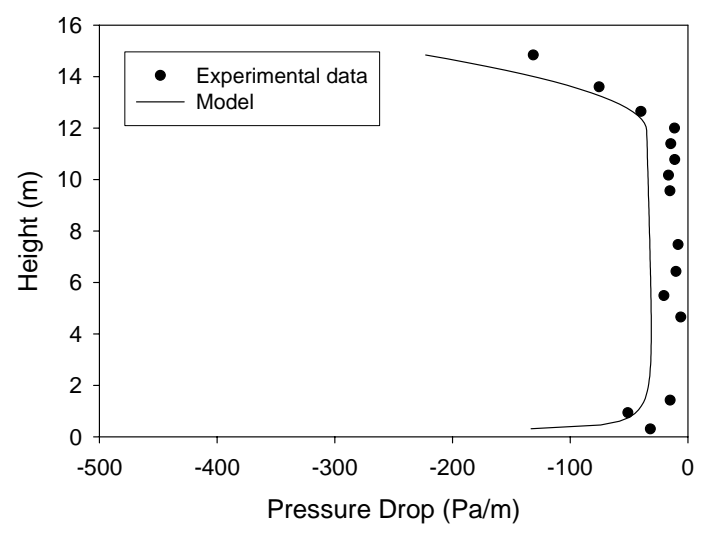

(b) $t=15 \mathrm{sec}$

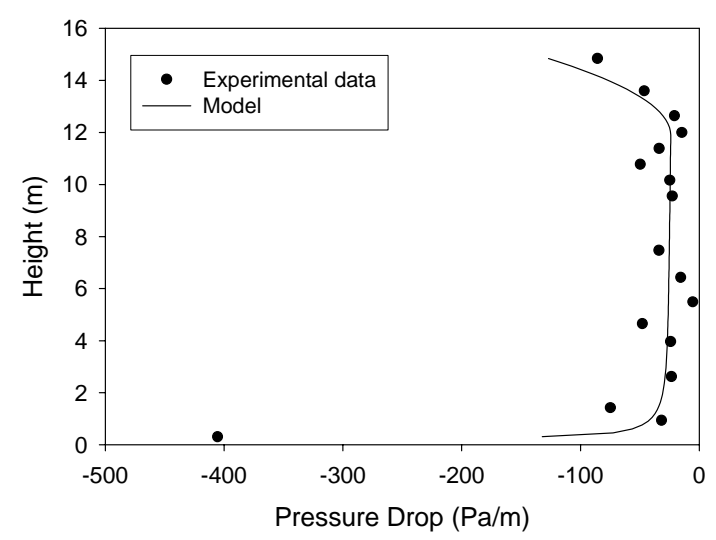

(d) $t=45 \mathrm{sec}$

Figure 4.19 Model predictions of axial pressure drop along the entire riser compared with experimental data at different times under transient process 


\subsection{Reactor model}

The current cluster model divides the particle flow into a continuous dilute phase and a dispersed cluster phase. The cluster phase contains all the particles and the dilute phase contains only gas. Clusters are generally treated as spherically shaped with an equivalent diameter. Rudnick and Werther [83] proposed two equations to describe the reaction system in these two phases:

$$
U_{g} \frac{\partial C_{d}}{\partial z}+\frac{6 K_{C}\left(1-f_{c}\right)}{D_{c}}\left(C_{d}-C_{c l}\right)+\left(-r_{A}\right)\left(1-f_{c}\right)\left(1-\varepsilon_{d}\right)=0
$$

for the dilute phase, and

$$
\frac{6 K_{C}\left(1-f_{c}\right)}{D_{c}}\left(C_{d}-C_{c l}\right)+\left(-r_{A}\right) f_{c}\left(1-\varepsilon_{c l}\right)=0
$$

for the cluster phase, where $K_{c}$ is the interphase mass transfer coefficient between cluster and dilute phase; $f_{c}$ is the volume fraction of particle clusters; $D_{c}$ is the equivalent cluster diameter; $C_{d}$ is the reactant concentration in the dilute phase; $C_{c l}$ is the reactant concentration in the cluster phase; $\varepsilon_{d}$ is the average voidage of the dilute phase and $\varepsilon_{c l}$ is the average voidage of the cluster phase.

Combining the above two equations, it gives

$$
U_{g} \frac{\partial C_{d}}{\partial z}+\left(-r_{A}\right)\left(1-f_{c}\right)\left(1-\varepsilon_{d}\right)=\left(-r_{A}\right) f_{c}\left(1-\varepsilon_{c l}\right)
$$

Because the cluster phase contains all the particles and the dilute phase contains only gas, it can be assumed that reaction occurs only in the cluster phase with mass transfer of the feed and product between the two phases. With these assumptions, Eq. 4.48 becomes 


$$
U_{g} \frac{\partial C}{\partial z}=\left(-r_{A} f_{c}\right)\left(1-\varepsilon_{c l}\right)
$$

For the first order reactions, such as coal combustion, it has been obtained that

$$
-r_{A}=k_{A} C_{A}
$$

where $A=\mathrm{O}_{2}$ for coal combustion. Based on Eq. 4.49, reactant concentration profiles along the riser under steady state can be predicted. For different values of rate constants, $k_{A}, \mathrm{O}_{2}$ concentration profiles are shown in Figure 4.20 (a) $\sim(\mathrm{d})$. 


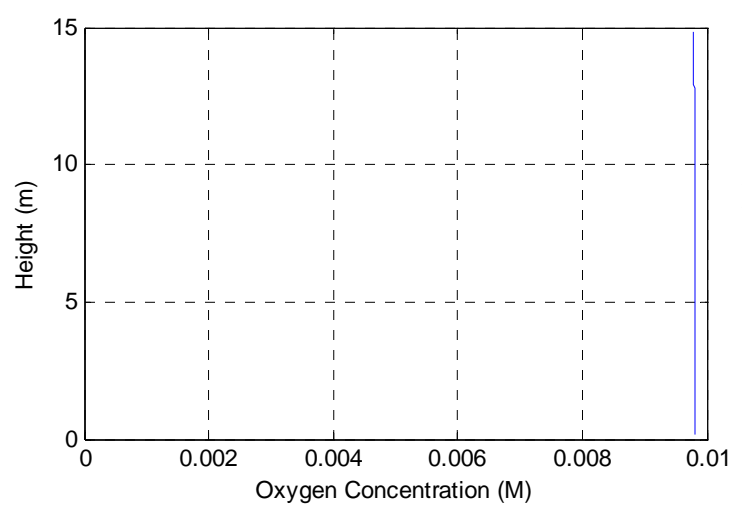

(a)

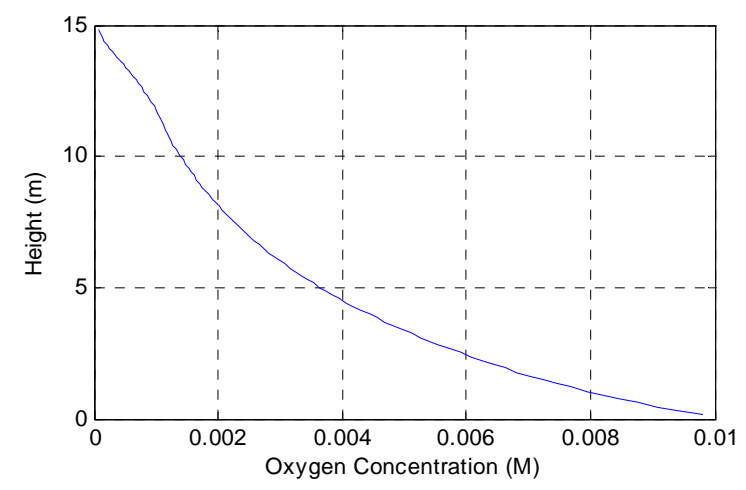

(c)

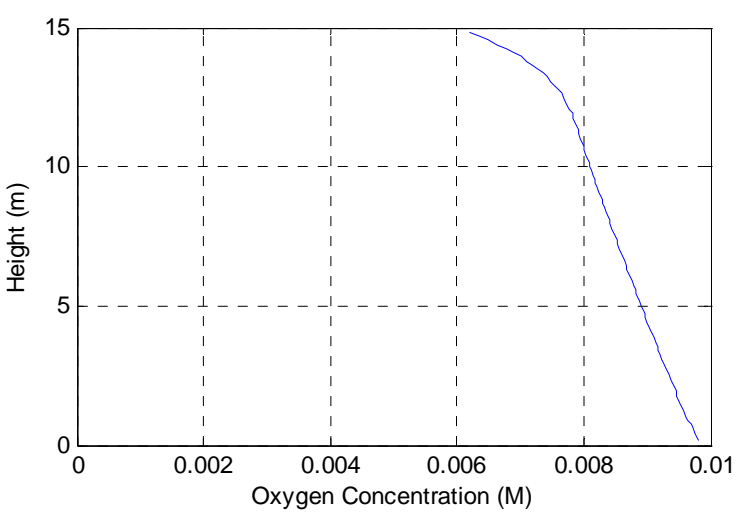

(b)

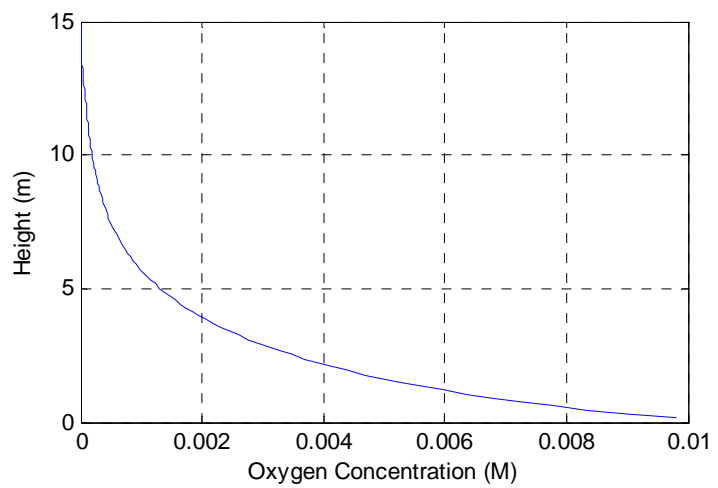

(d)

Figure 4.20 Model predictions of $\mathrm{O}_{2}$ concentration profile along the riser for steady

\section{state}
(a) $k=0.1 \mathrm{~s}^{-1}$;
(b) $k=10 \mathrm{~s}^{-1}$;
(c) $k=100 \mathrm{~s}^{-1}$;
(d) $k=200 \mathrm{~s}^{-1}$.

Combining with the cluster model for transient processes, the reactant concentration profile can also be predicted at different times. For $k_{A}=100 \mathrm{~s}^{-1}, \mathrm{O}_{2}$ concentration profiles at different times are shown in Figure 4.21.

The cluster model can be applied to reaction systems to predict the reactant and product concentration profiles in either steady or transient processes. Our current cold flow facility can not collect reaction experimental data, hence, further study is required to 
validate the current reactor model.

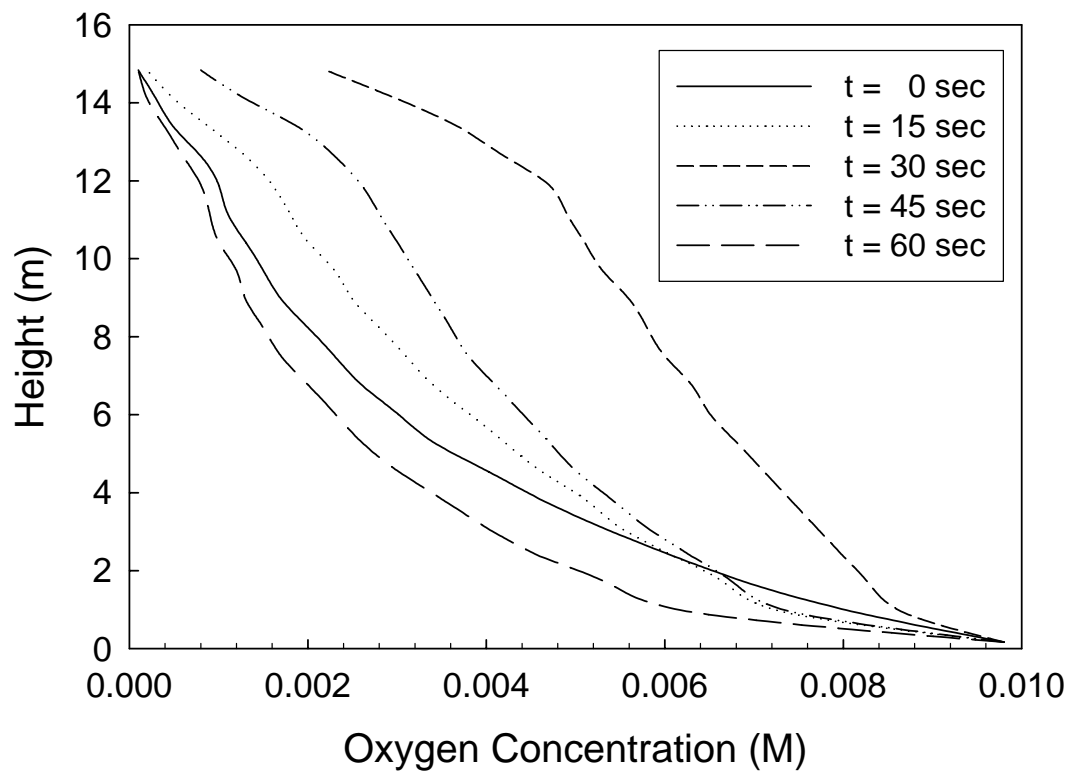

Figure 4.21 Model predictions of $\mathrm{O}_{2}$ concentration profile along the riser for transient process 


\section{Chapter 5 Dynamic Model in the Standpipe}

\subsection{Introduction}

The solids circulation rate is one of the prerequisites for ensuring fast fluidization. The solids circulation rate depends on the design and operation of the solids recycle loop, [84]. Generally, the solids recycle system of a CFB consists of a gas-solid separator, a standpipe and a seal device at the bottom of the standpipe. The solids circulation rate is very important for the operation of CFBs, since it affects mass and heat transfer characteristics, which in turn impact the efficiency of the processes. For example, the rate at which a catalyst can be circulated has significant effects on the operability of catalytic cracking units. A system that circulates badly is difficult to operate and may be run at lower catalyst-to-oil ratios than desired, having an adverse effect on yields and product selectivities, [85].

The objective of this chapter is to present a method for solids flow metering from pressure drop measurement in the dense phase of the standpipe. Crucial parameters in the standpipe are the pressure gradients under different solids circulation rates. A state model of the standpipe will be built to estimate the bed height, voidage and solids velocities. 


\subsection{Flow pattern in a standpipe}

Standpipe flow refers to the downward flow of solids, with the aid of gravitational force, against a gas pressure gradient. The gas flow with respect to the downward-flowing solids is in the upward direction. Although the actual direction of flow of gas relative to the wall can be either upward or downward, in standpipe flow, generally both gas and solid flow cocurrently in the downward direction due to drag force between two phases. Two types of flow pattern are possible [86]: fluidized bed flow (in which particles are in suspension) and moving bed flow (in which particles move en bloc at the voidage of a packed bed with little relative motion between particles). The flow type can be determined by the slip velocity as follows [87]:

$$
\begin{aligned}
& U_{s l}<\frac{U_{m f}}{\varepsilon_{m f}} \quad \text { for moving bed } \\
& U_{s l} \geq \frac{U_{m f}}{\varepsilon_{m f}} \quad \text { for fluidized bed } \\
& \text { where } \quad U_{s l}=u_{g}-u_{s}=\frac{U_{g}}{\varepsilon}-\frac{U_{s}}{1-\varepsilon}
\end{aligned}
$$




\subsection{Prediction of solids flow rate by pressure drop measurement}

Solids feeding devices can be categorized into mechanical and non-mechanical valves [88]. Typical mechanical valves having moving parts to control solids flow rate are rotary, screw, butterfly, and solid valves [89]. However these are rarely employed under high temperature and pressure conditions due to sealing and mechanical problems. For the experiments performed in this work, the air injected at the base of the standpipe, the move-air, is changed and causes the mass flow of solids to change. The solids flow rates were measured under different move-air flow rates (Figure 5.1). The results indicate that solids flow rate cannot be predicted directly from the flow rate of move-air. A model developed by Park et al. [90] indicates that the gas flow in the riser and the total solids inventory in the system also affect the solids flow rate.

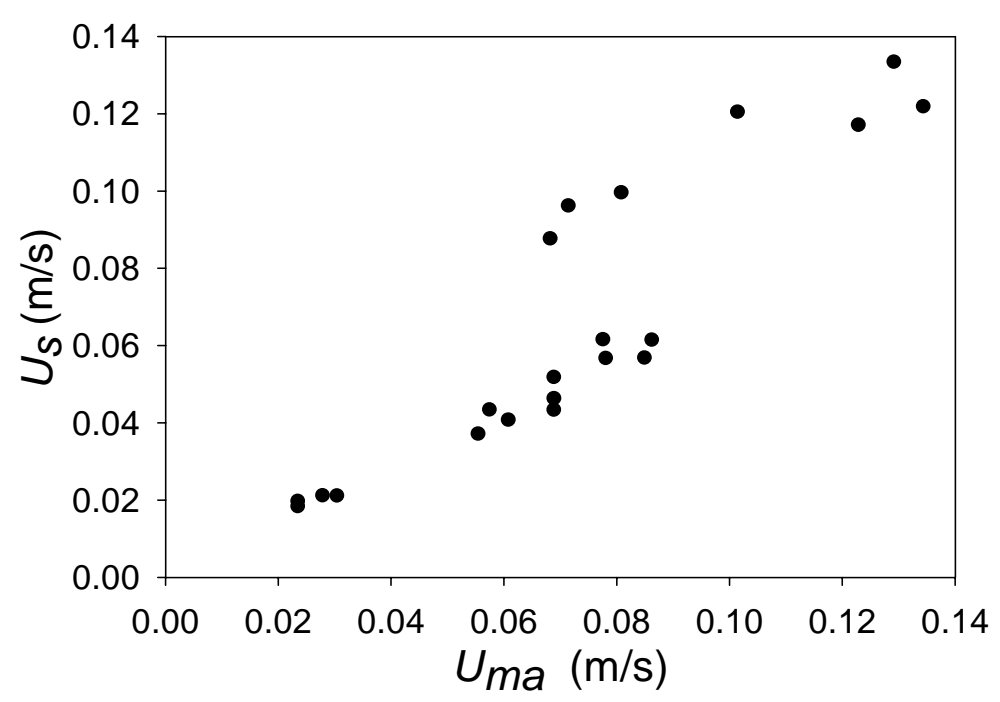

Figure 5.1 Inconsistency between data for move-air and solids flows

Patience et al. [44] found that the relationship between pressure drop and solids flow 
rate for the horizontal section between the riser and cyclone is linear. For the current system, this relationship also holds for the dense phase in the standpipe and is shown in Figure 5.2, where the superficial velocity of solids was obtained from the spiral device measurement and the pressure drop was measured across the spiral device. In the current study, if the flow rates of gas and solids are known, the measurement of pressure drop across the dense bed in the standpipe can be used to estimate the voidage. The pressure drop through a bed of spheres is described by the well-known Ergun equation Error!

\section{Reference source not found.:}

$$
\frac{\Delta P}{L}=150 \frac{\mu(1-\varepsilon)^{2}}{\varepsilon^{3} d^{2}} U+1.75 \frac{\rho_{g}(1-\varepsilon)}{\varepsilon^{3} d} U^{2}
$$

which is an excellent correlation over a wide voidage range from 0.36 to 0.92 .

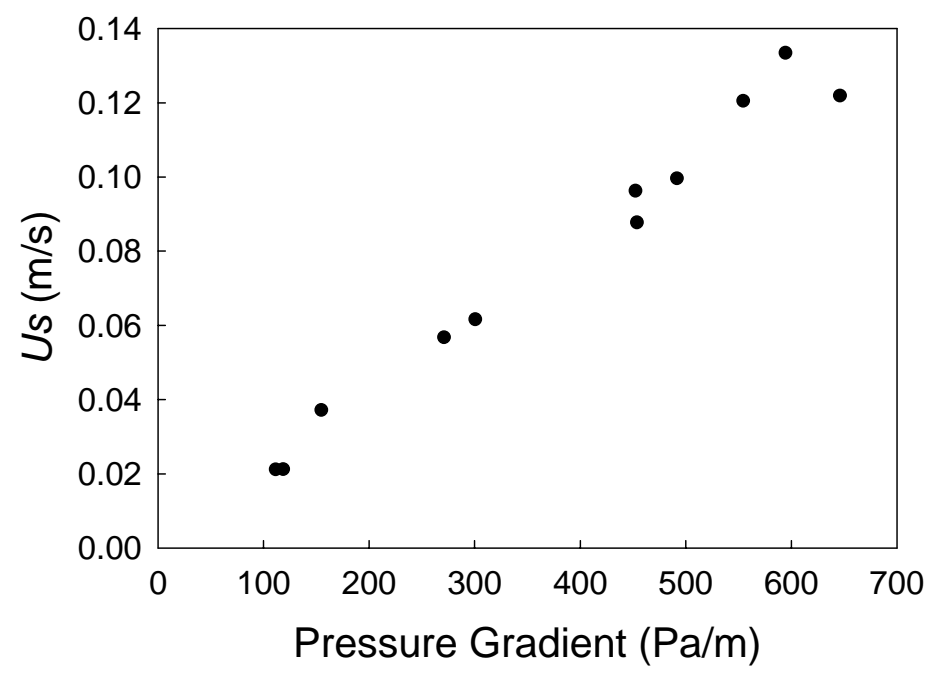

Figure 5.2 Linear relationship between pressure gradient and superficial velocity of solids for the current system

In the current model, the modified Ergun equation is applied as 


$$
\frac{\Delta P}{L}=150 \frac{\mu(1-\varepsilon)^{2}}{\varepsilon^{2}\left(\psi d_{s v}\right)^{2}} U_{s l}+1.75 \frac{\rho_{g}(1-\varepsilon)}{\varepsilon\left(\psi d_{s v}\right)} U_{s l}\left|U_{s l}\right|
$$

where

$$
U_{s l}=u_{g}-u_{s}
$$

Voidage may be expressed as a linear function of slip velocity as given by Knowlton et al. [91]:

$$
\varepsilon=\varepsilon_{p}+\left(\varepsilon_{m f}-\varepsilon_{p}\right) \frac{\left|U_{s l}\right|}{U_{m f} / \varepsilon_{m f}}
$$

Soo and Zhu [92] proposed that satisfactory operation of the cyclone-standpipe system depends on a small leakage flow up the standpipe. Gas interstitial velocity can be estimated from the solids interstitial velocity, which is given by

$$
u_{g}=a u_{s}+b
$$

where

$$
a=1
$$

$$
\begin{aligned}
& b=\frac{A}{2}-\sqrt{\frac{A^{2}}{4}+B} \\
& A=\frac{150 \mu(1-\varepsilon)}{1.75 \varepsilon \rho_{g} \psi d_{s v}} \\
& B=\frac{\varepsilon}{1.75}\left(\frac{\rho_{s} g \psi d_{s v}}{\rho_{g}}\right)
\end{aligned}
$$

The above equations (5.7)-(5.10) are based on fluidized flow and cannot be applied in this study. However for a given system and materials, the coefficients in Eq. (5.6), a and $b$, can be estimated from experimental measurement. If solids flow rate and pressure drop are known, the voidage and gas flow rate can be predicted using equations (5.3)-(5.5). After that, gas flow rates obtained with different solids flow rate can be 
obtained, and the coefficients $a$ and $b$ can calculated by the correlation (Figure 5.3). In the current system, a satisfactory linear relationship between gas and solids interstitial velocities was obtained, and is given by

$$
u_{g}=0.7157 u_{s}-0.0110
$$

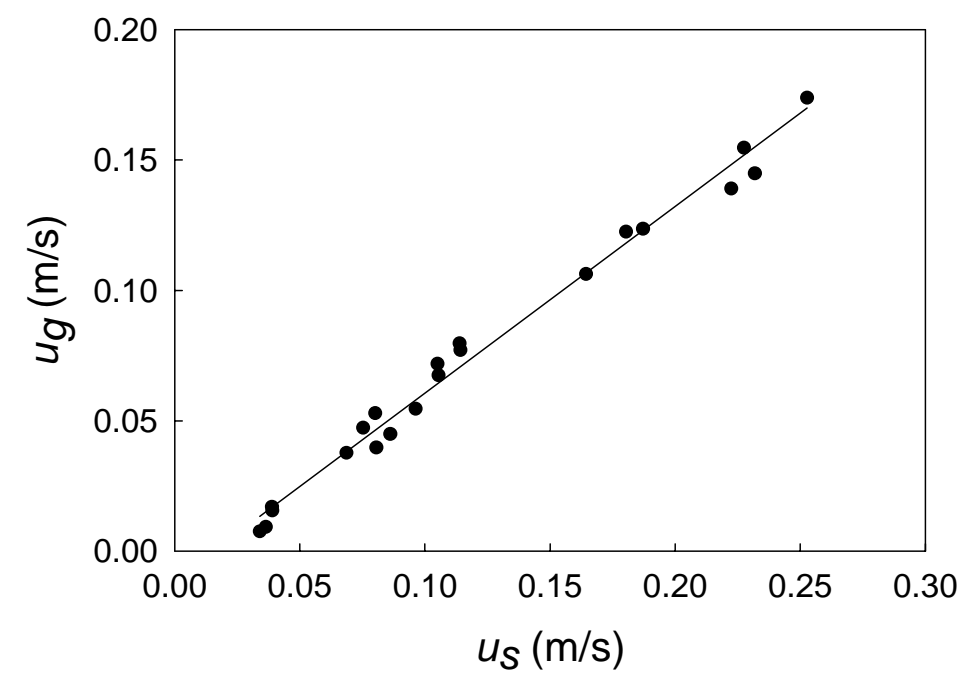

Figure 5.3 Linear relationship between gas and solids interstitial

Based on equations (5.3)-(5.5) and (5.11), the voidage and solids superficial velocity in the dense phase of the standpipe can be predicted from pressure drop measurement. The solids flow rate can be obtained by

$$
M_{s}=A_{s p} \rho_{s} U_{s}
$$

Experimental data and model predictions are shown in Figure 5.4. It is seen that the model fits the experimental data satisfactorily. 

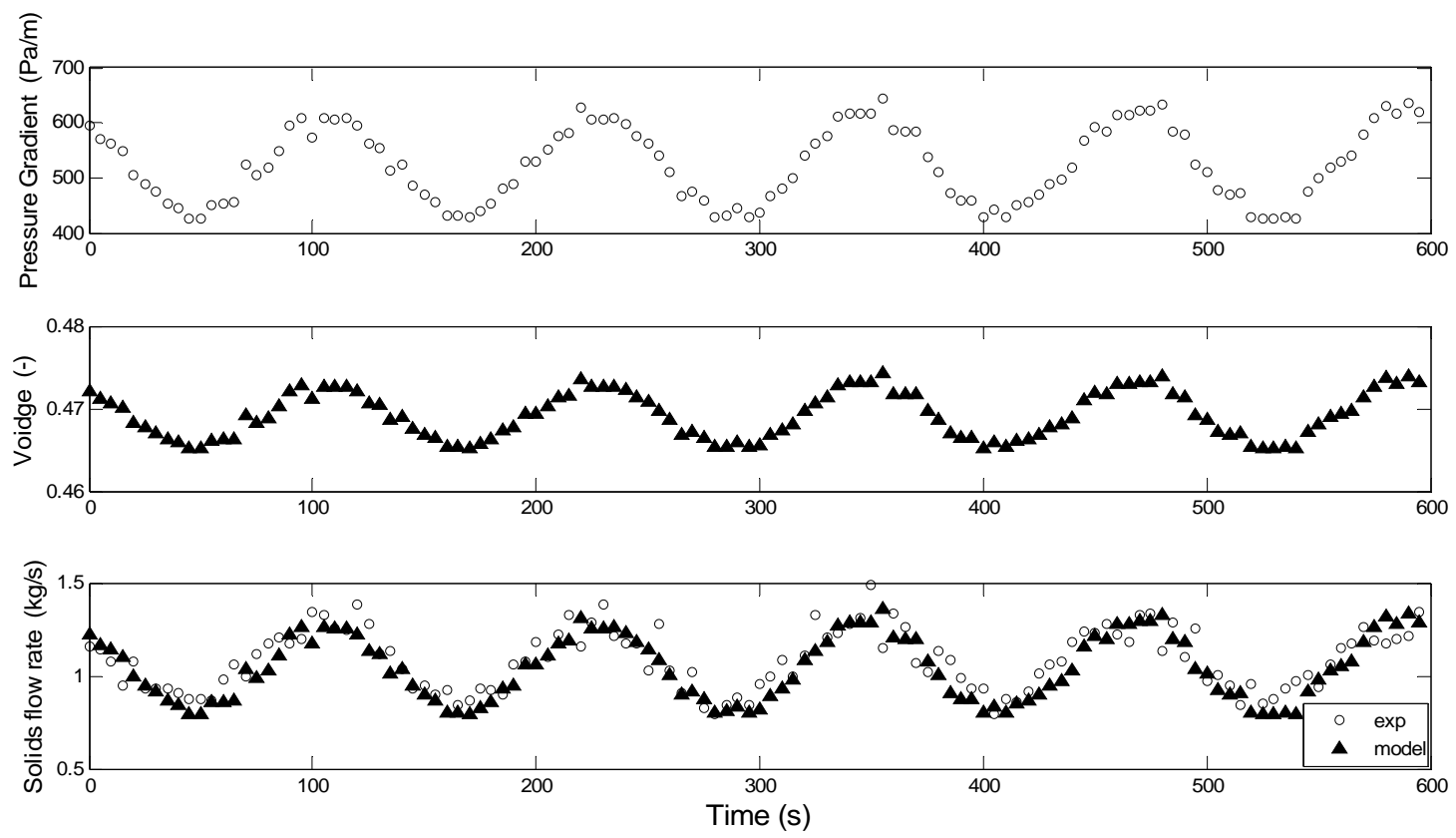

(a)
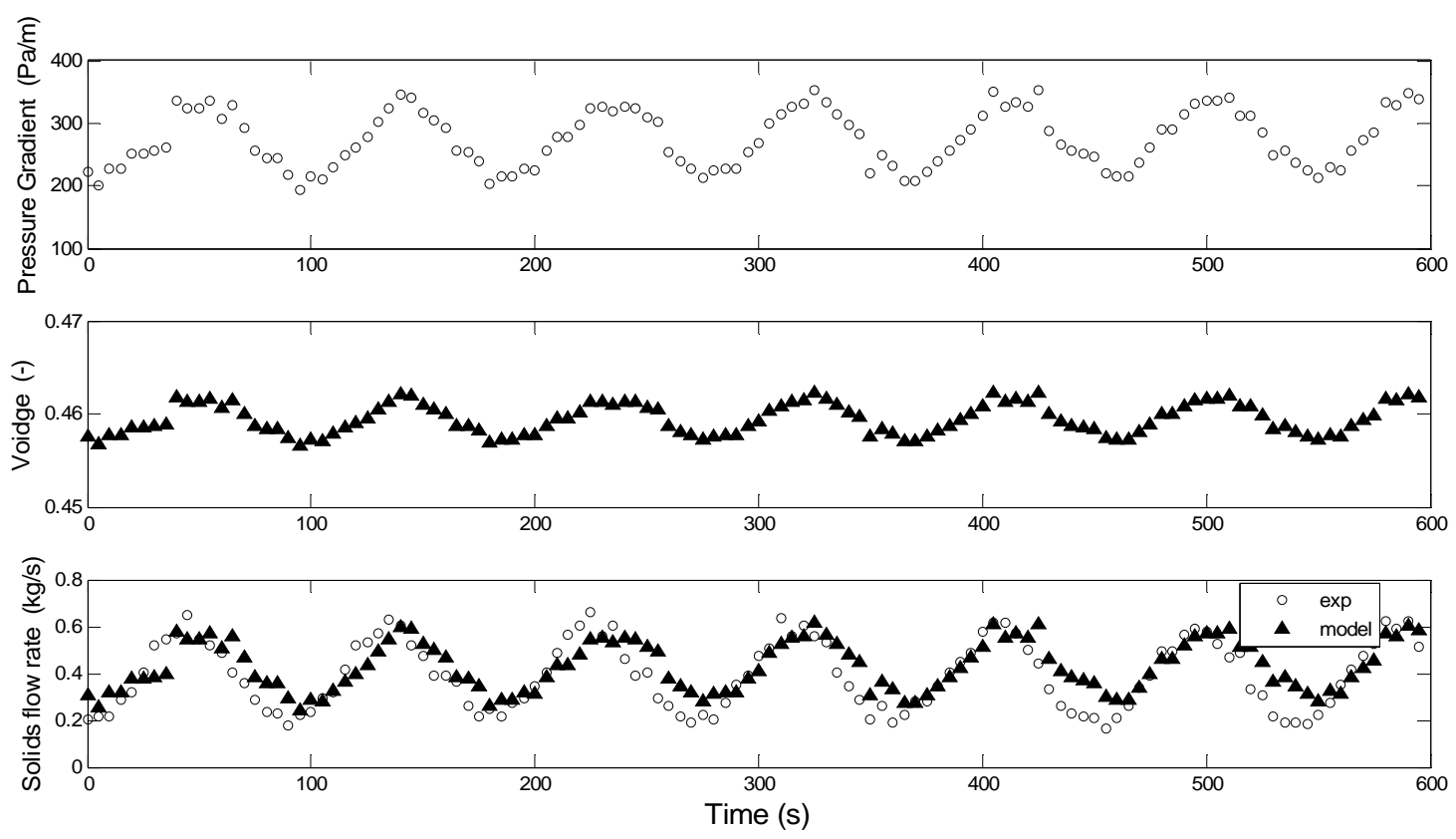

(b)

Figure 5.4 Predictions of solids flow rate in the dense phase of standpipe by pressure drop
(a) $M_{s, \text { ave }}=1.096 \mathrm{~kg} / \mathrm{s} ; T=120 \mathrm{~s}$
(b) $M_{s, a v e}=0.394 \mathrm{~kg} / \mathrm{s} ; T=90 \mathrm{~s}$ 


\subsection{Profile of solids flow rate under unsteady state}

The objectives of this research are not only to predict the solids flow rate from local pressure drop measurements, but also to predict the profile of solids flow rate and wave velocity. The waves of concern are termed continuity or kinematic waves [93].

Based on the above method, a model for a transient process is developed, in which the profile of solids flow rate in the dense phase of a standpipe can be predicted by one pressure drop measurement.

The continuity equation for particle flow in a transient process is as follows:

$$
\frac{\partial \varepsilon}{\partial t}=\frac{\partial U_{s}}{\partial z}
$$

In Eq. 5.13, there are 2 unknowns, $\varepsilon$ and $U_{s}$. Therefore, another equation is required for a solution. It is assumed that solids always move faster than gas so that the gas flow with respect to the downward-flowing solids is in the upward direction. From Eqs. (5.5) and (5.11), we know that

or

$$
\begin{aligned}
& \varepsilon=\varepsilon_{p}+\left(\varepsilon_{m f}-\varepsilon_{p}\right) \frac{u_{s}-u_{g}}{U_{m f} / \varepsilon_{m f}} \\
& \varepsilon=\varepsilon_{p}+\frac{\varepsilon_{m f}-\varepsilon_{p}}{U_{m f} / \varepsilon_{m f}}\left[(1-a) \frac{U_{s}}{1-\varepsilon}-b\right]
\end{aligned}
$$

Replacing the parameters in Eq. (5.15) with the values for the physical properties of cork, gives

or

$$
\begin{aligned}
& \varepsilon^{2}-1.4531 \varepsilon+\left(0.4531+0.0796 U_{s}\right)=0 \\
& U_{s}=18.255 \varepsilon-12.56 \varepsilon^{2}-5.692
\end{aligned}
$$


Using these relationships, $U_{s}$ for the non-fluidized flow regime (i.e. $\varepsilon \in\left[\varepsilon_{p}, \varepsilon_{m f}\right]$ ) is shown in Figure 5.5. The figure indicates that $\varepsilon$ and $U_{s}$ have essentially a linear relationship in the non-fluidized flow regime, even though Eq. (5.17) is non-linear. To simplify the model, Eq. (5.17) can be linearized as follows:

$$
U_{s}=6.446 \varepsilon-2.9185
$$

with a value of $R^{2}=0.9996$.

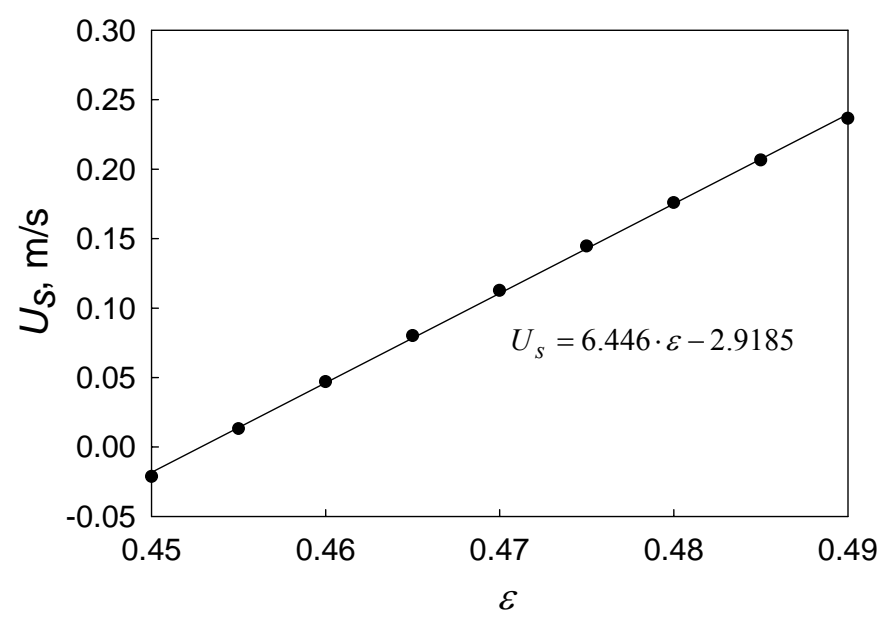

Figure 5.5 Linearization of $U_{s}$ vs. $\varepsilon$ in non-fluidized flow regime

Considering the upward direction as positive and the downward direction as negative, the solids always move downward and $U_{s}$ should be negative (Figure 5.6). So Eq. (5.18) becomes

$$
U_{S}=2.9185-6.446 \varepsilon
$$

Replacing $U_{s}$ in Eq. (5.13), gives

$$
\frac{\partial \varepsilon}{\partial t}=-6.446 \frac{\partial \varepsilon}{\partial z}
$$

where voidage, $\varepsilon$, is a function of position and time, 


$$
\varepsilon=\varepsilon(z, t)
$$

Using the model described in Section 3.2, the boundary condition can be determined from the pressure drop measurements at the bottom of the standpipe, $\Delta p_{o}$, as follows

$$
\varepsilon(0, t)=f\left[\Delta P_{o}(t)\right]
$$

Assuming that the dense phase in the standpipe is initially "homogeneous", so that the initial condition is

$$
\varepsilon(z, 0)=\Delta P_{o}(0)=\text { const }
$$

The boundary condition in one set of experiments is shown in Figure 5.7.

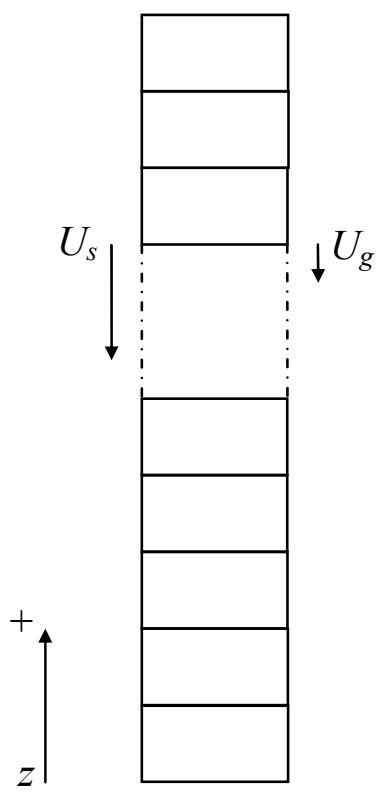

\section{Figure 5.6 Definition of the positive direction of $z$}

The experimental data available in this research are given in terms of pressure drop rather than voidage profiles. Therefore, the results of the model, which are the voidages 
as a function of time for a given position, $z$, can be converted to pressure drops according to Eqns (5.3) and (5.5). By solving above model, the pressure drops at different locations along the standpipe can be predicted, for example, experimental data and model predictions of pressure drop at $z=5 \mathrm{~m}$ are shown in Figure 5.8. It is seen that the model fits the experimental data satisfactorily.

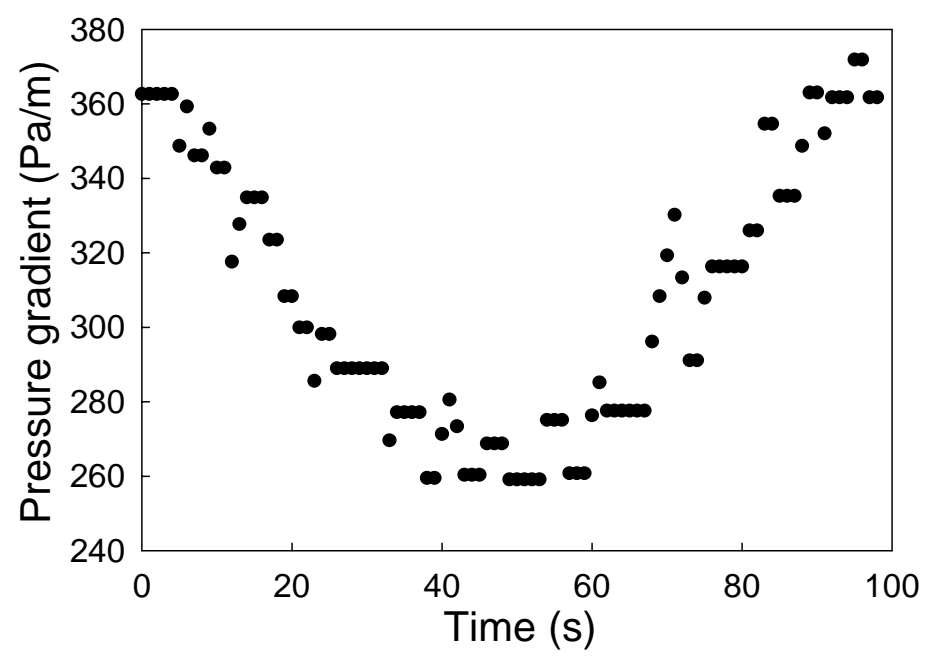

Figure 5.7 Pressure drop measurements used as boundary condition

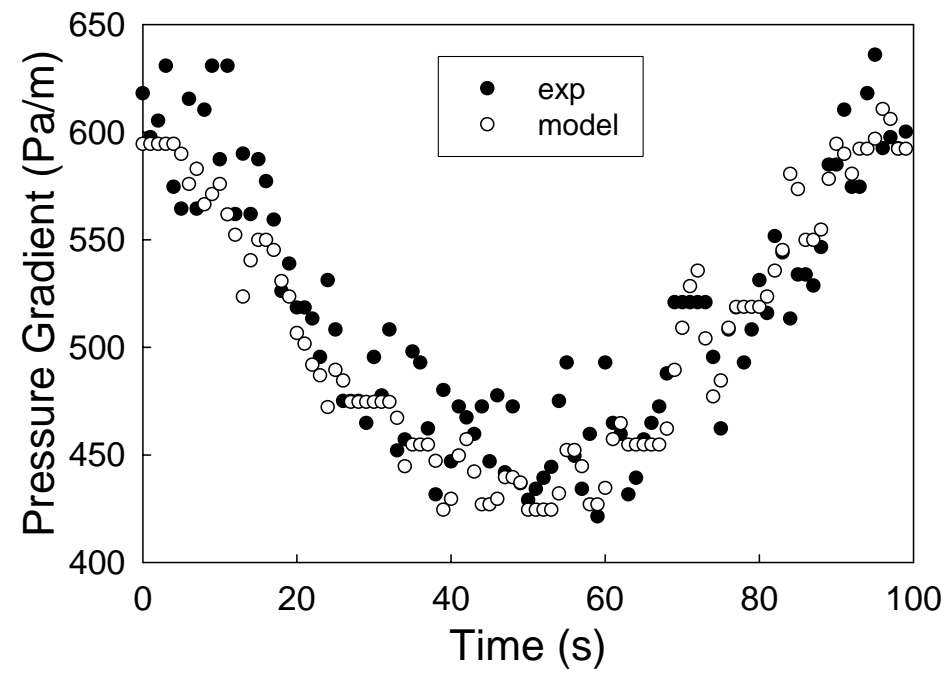

Figure 5.8 Experimental data and model predictions of pressure drop at $\mathrm{z}=5 \mathrm{~m}$ 
The model results for voidage predictions at $z=0.0 \mathrm{~m}$ and $5.0 \mathrm{~m}$ (Figure 5.9) indicate that the amplitudes are similar and the time lag between them is about 0.8 second.

The total CPU time required to run 1 second of simulation in the 5-meter long dense phase region of the standpipe on a $3.0 \mathrm{GHz}$ Intel-Windows $\mathrm{PC}$ is less than 0.2 second, which is fast enough for the model to be used in real-time monitoring of an industrial plant.

In general, for the application of the current model, if the gas leakage correlation (Eq. 5.6) is known or measured for the non-fluidized flow in a given system, only one pressure transducer is required to predict the profile of solids flow rate and voidage in the dense phase of the standpipe. The measurement of the pressure drop is the boundary condition, and the combination of the continuity equation and gas leakage correlation must be solved.

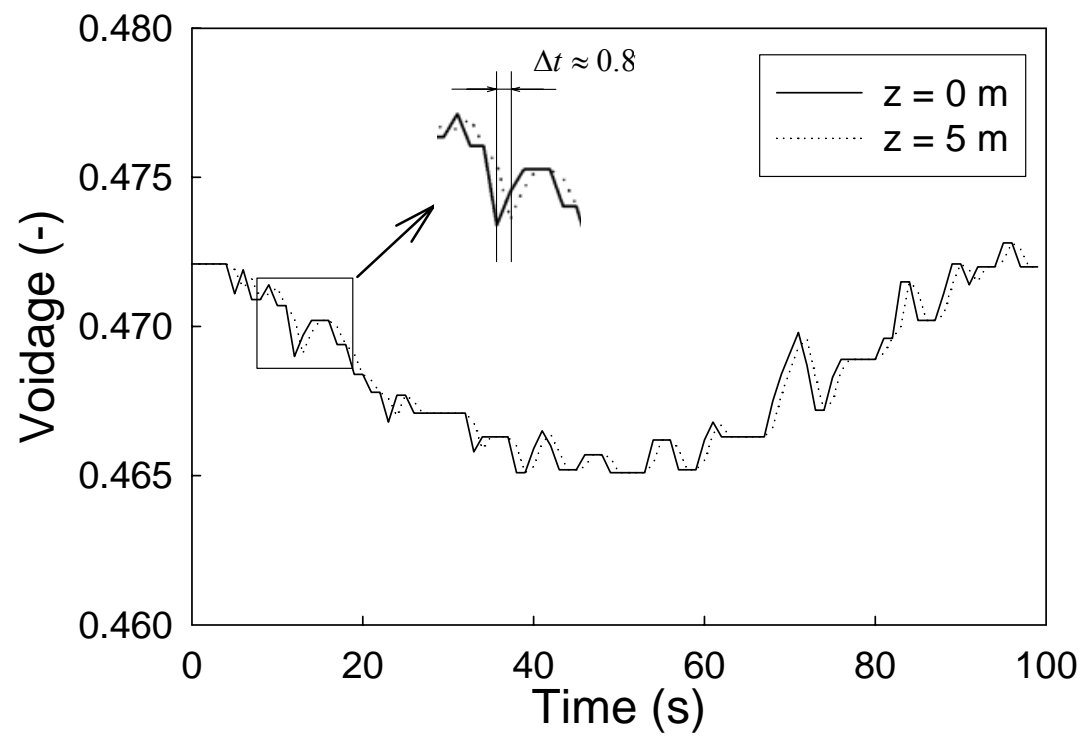

Figure 5.9 Voidage predictions at $z=0.0 \mathrm{~m}$ and $5.0 \mathrm{~m}$ 
Slis et al. [94] have considered the prediction of continuity wave velocity $V_{w}$ for the case when the fluid superficial velocity is raised or lowered slightly (i.e., by a differentially small amount). In the current study, the solids movement will be considered. A control volume is established that encompasses the continuity wave, as seen in Figure 5.10, so that the areas $a-a$ and b-b move with the wave velocity [95]. The volumetric flow rate of the solids crossing unit area a-a is $U_{s}-(1-\varepsilon) V_{w}$, and the volumetric flow rate crossing unit area $\mathrm{b}-\mathrm{b}$ is $U_{s}+\delta U s-[1-(\varepsilon+\delta \varepsilon)] V_{w}$. Assuming the continuity of mass is preserved, so that

$$
\begin{aligned}
& U_{S}-(1-\varepsilon) V_{w}=U_{s}+\delta U_{s}-[1-(\varepsilon+\delta \varepsilon)] \cdot V_{w} \\
& \text { or } \quad V_{w}=-\frac{\delta U_{s}}{\delta \varepsilon}
\end{aligned}
$$

As $\delta \varepsilon$ approaches zero,

$$
V_{w}=-\frac{d U_{s}}{d \varepsilon}
$$

The wave velocity for Eq. (5.19) is

$$
V_{w}=6.446 \mathrm{~m} / \mathrm{s}
$$

where the positive value indicates that the propagation direction is upward. 


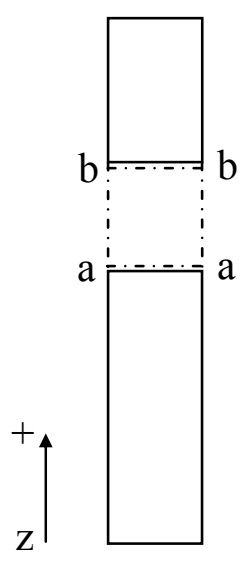

Figure 5.10 Control volume encompassing the continuity wave.

The response time, $\Delta t$, between different locations can be estimated by the continuity wave velocity $V_{w}$, as follows

$$
\Delta t=\frac{\Delta L}{V_{w}}
$$

where $\Delta L$ is the distance between two locations. In the current system, if the distance between two locations is $5 \mathrm{~m}$ (i.e., $\Delta L=5 \mathrm{~m}$ ), the response time $\Delta t$ will be $0.78 \mathrm{~s}$ (i.e., $\Delta t$ $=\Delta L / V_{w}=5 / 6.446 \cong 0.78 \mathrm{~s}$ ). This result is consistent with that obtained in Figure 5.9, namely $\Delta t=0.8 \mathrm{~s}$. 


\subsection{State Model of the standpipe}

This model is developed to analyze the pressure-time data taken from the standpipe section. The development follows a combination of the model of Shim et al. [96] with a simplification that divides the standpipe into two sections.

The assumptions are as follows:

1. The standpipe can be modeled as two homogeneous sections. The upper section has lean phase solids flow and the lower section has dense phase flow.

2. The characteristics of the upper section are

Height $=z_{1}$

Voidage (gas void fraction) $=\varepsilon_{1}$

Solids velocity $=u_{s, 1}$

Pressure Drop $=\Delta P_{1}$

3. The characteristics of the lower section are

Height $=z_{2}$

Voidage $($ gas void fraction $)=\varepsilon_{2}$

Solids velocity $=u_{s, 2}$

Pressure Drop $=\Delta P_{2}$

4. To reduce the number of variables, the superficial gas velocity, $U$, and the solids circulation rate, $M_{\text {circ }}$, are used and are the same for both sections.

With the above formulation there are 10 unknowns, and therefore 10 equations are 
needed to specify completely the system. A schematic diagram illustrating this model is shown in Figure 5.11 below.

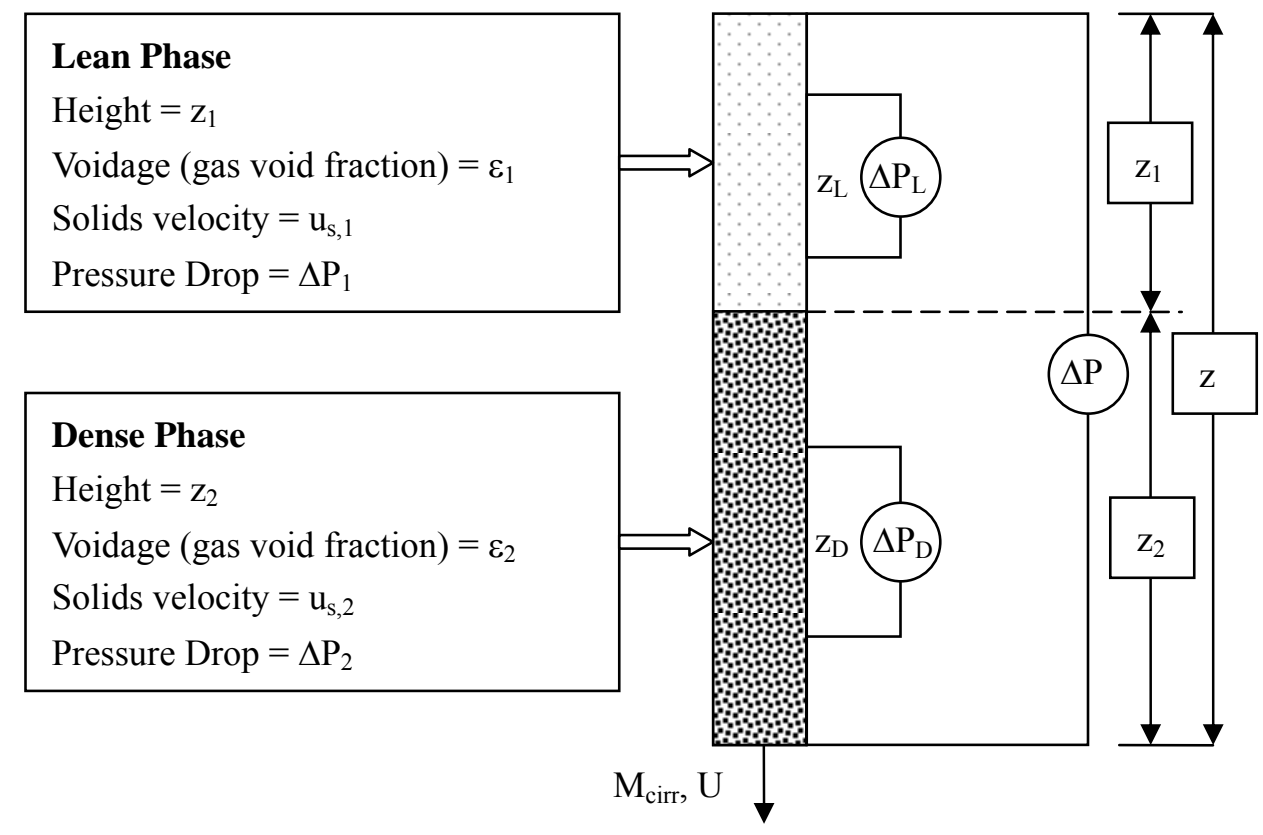

Figure 5.11 Standpipe Model Setup and Variables

5.5.1. Basic equations

For lean phase:

$$
\begin{aligned}
& \Delta P_{1}=\rho_{s} g z_{1}\left(1-\varepsilon_{1}\right) \\
& \Delta P_{1}=\frac{z_{1}}{z_{L}} \Delta P_{L} \\
& M_{\text {circ }}=A \rho_{s}\left(1-\varepsilon_{1}\right) u_{s, 1}
\end{aligned}
$$

For dense phase:

$$
\Delta P_{2}=\frac{150\left(1-\varepsilon_{2}\right)^{2}}{\varepsilon_{2}^{3}} \frac{\mu}{\left(\psi d_{s v}\right)^{2}}\left(U-\varepsilon_{2} u_{s, 2}\right) z_{2}+\frac{1.75\left(1-\varepsilon_{2}\right)}{\varepsilon_{2}^{3}} \frac{\rho_{g}}{\psi d_{s v}}\left(U-\varepsilon_{2} u_{s, 2}\right)\left|U-\varepsilon_{2} u_{s, 2}\right| z_{2}
$$




$$
\begin{aligned}
& \Delta P_{2}=\frac{z_{2}}{z_{D}} \Delta P_{D} \\
& \varepsilon=\varepsilon_{p}+\left(\varepsilon_{m f}-\varepsilon_{p}\right) \frac{\left|U-\varepsilon_{2} u_{s, 2}\right|}{U_{m f} / \varepsilon_{m f}} \\
& \frac{U}{\varepsilon_{2}}=0.7157 u_{s}-0.0110 \\
& M_{\text {circ }}=A \rho_{s}\left(1-\varepsilon_{2}\right) u_{s, 2}
\end{aligned}
$$

For the whole standpipe:

$$
\begin{aligned}
& \Delta P=\Delta P_{1}+\Delta P_{2} \\
& z=z_{1}+z_{2}
\end{aligned}
$$

So the known and unknown variables can be presented by Figure 5.12.

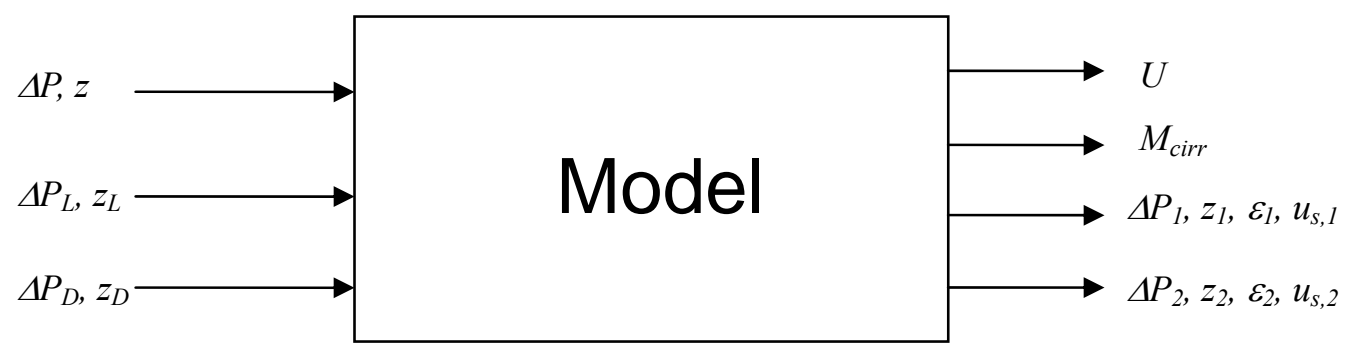

Figure 5.12 The known and unknown variables in standpipe model

\subsubsection{Prediction of standpipe bed height}

Using Equations (5.30), (5.33), (5.37) and (5.38), $z_{1}, z_{2}, P_{1}$, and $P_{2}$ can be solved yielding $z_{2}$ which is the length of dense phase, or bed height (Figure 5.11). This principle is illustrated in Figure 5.13.

The standpipe bed height is a very important control variable which can be used to 
monitor the inventory of solids in standpipe or riser.

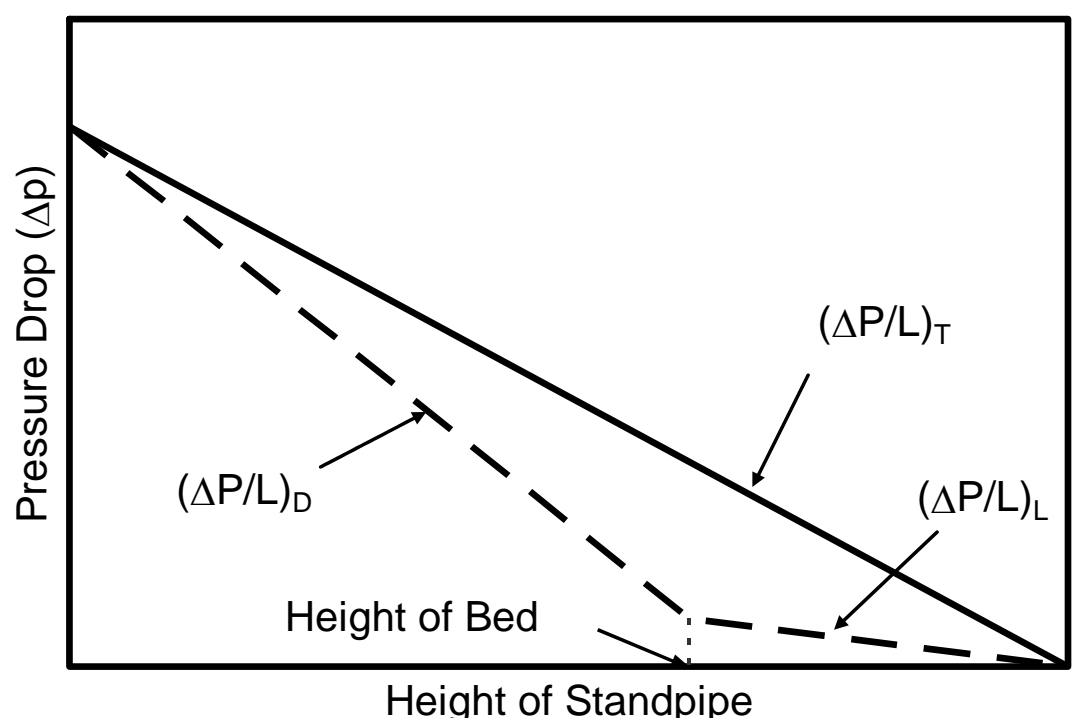

Figure 5.13 Diagram showing relationship between lean region, dense region, and overall bed pressure drops and the bed height of standpipe

There are two examples (Figure 5.14 (a), (b)) of predicting the standpipe bed height using the above method for Experiments K39 and K40.

Based on the above results, it can be seen that Eqns 5.30, 5.33, 5.37 and 5.38 are an easy and quick way to monitor the inventory of solids in the standpipe using pressure measurements. 


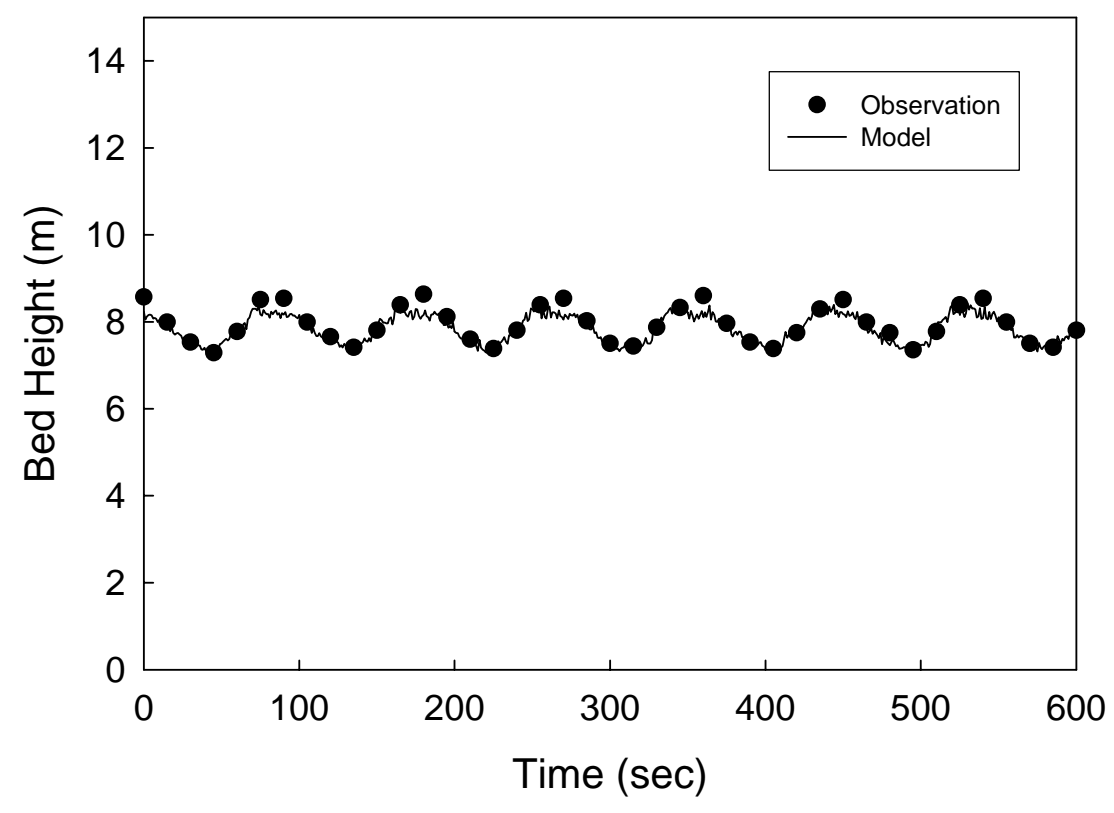

(a) Experiment K39

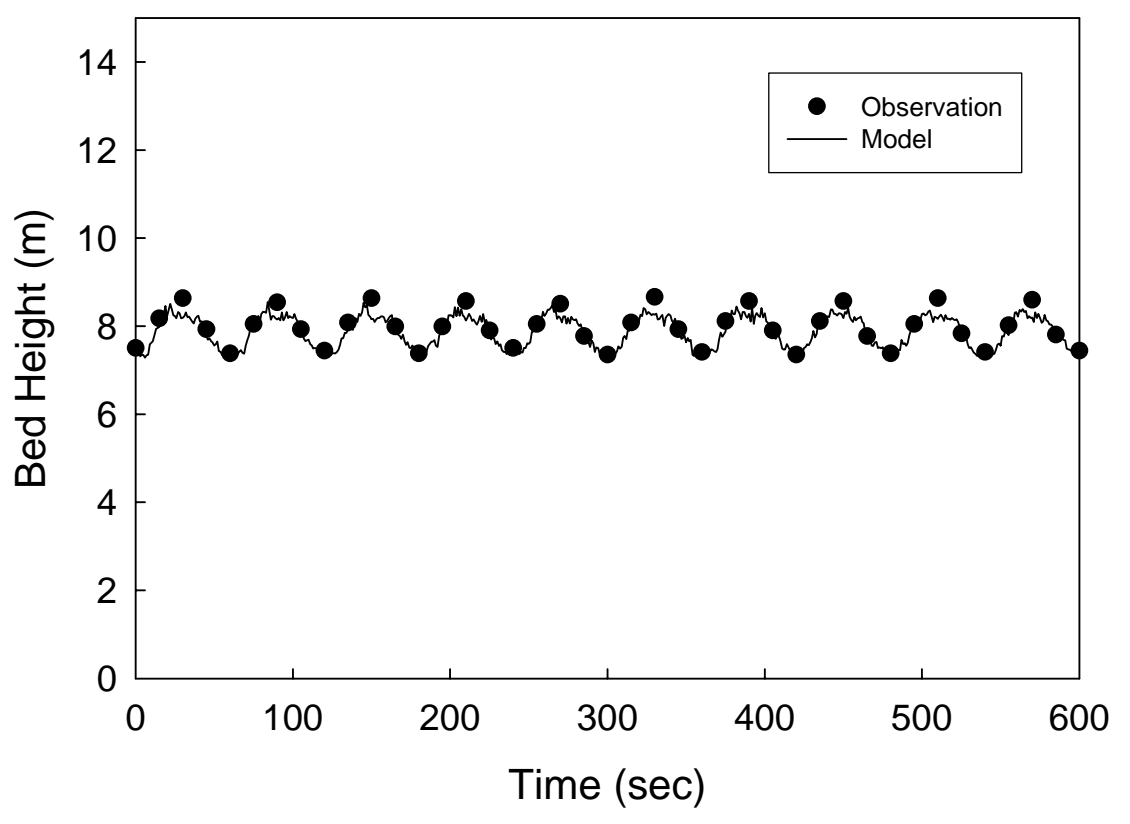

(b) Experiment K40

Figure 5.14 Prediction of the standpipe bed height using pressure measurements and Eqns 5.30, 5.33, 5.37 and 5.38 


\subsubsection{Prediction of phase voidages}

In this state model, the standpipe is modeled as two homogeneous sections. It assumes that the properties in the same section are identical. The voidages in the lean and dense phases can also be estimated by the above model. The voidage in the lean phase is obtained through its pressure drop measurement, so that

$$
\varepsilon_{1}=1-\frac{\Delta P_{1}}{\rho_{s} g z_{1}}
$$

The voidage in the dense phase is also obtained through its pressure drop measurement, but it is calculated by solving the non-linear algebraic equations 5.32, 5.34 and 5.35.

Two examples are shown in Figure 5.15 (a), (b).

Based on the combination of bed height and voidage estimations, voidage profile along the standpipe can be obtained. Hence, the inventory of solids can be calculated. 


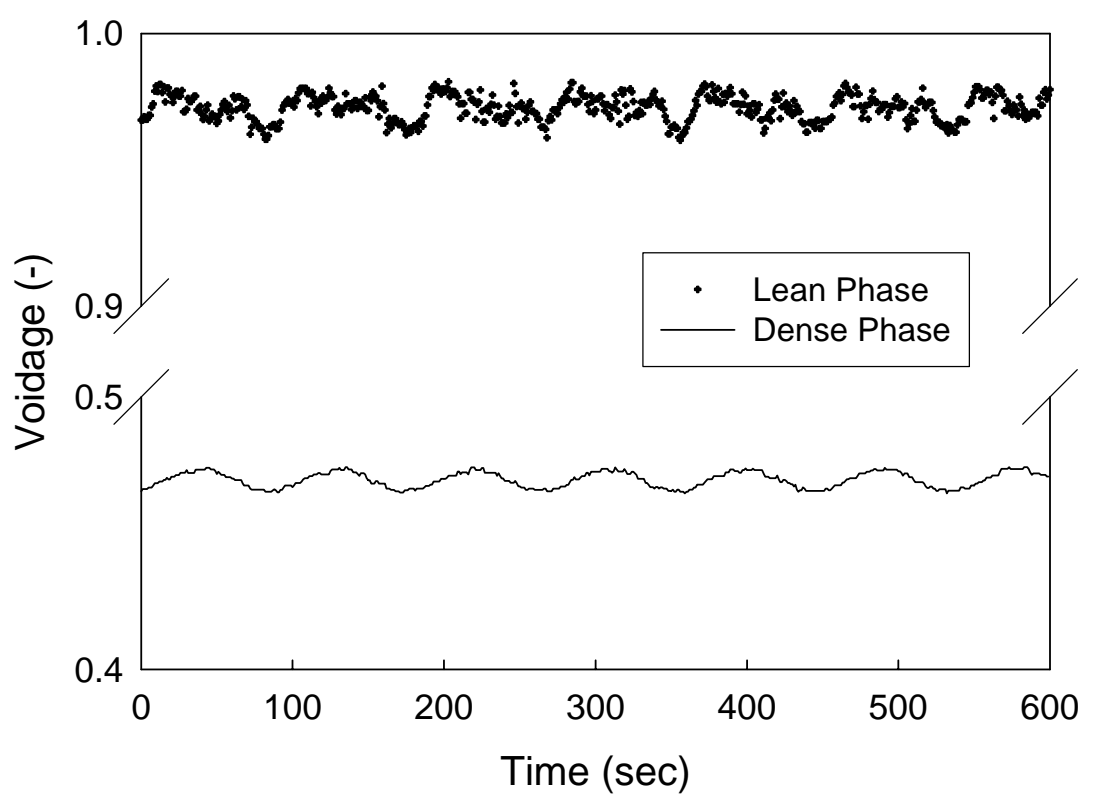

(a) Experiment K39

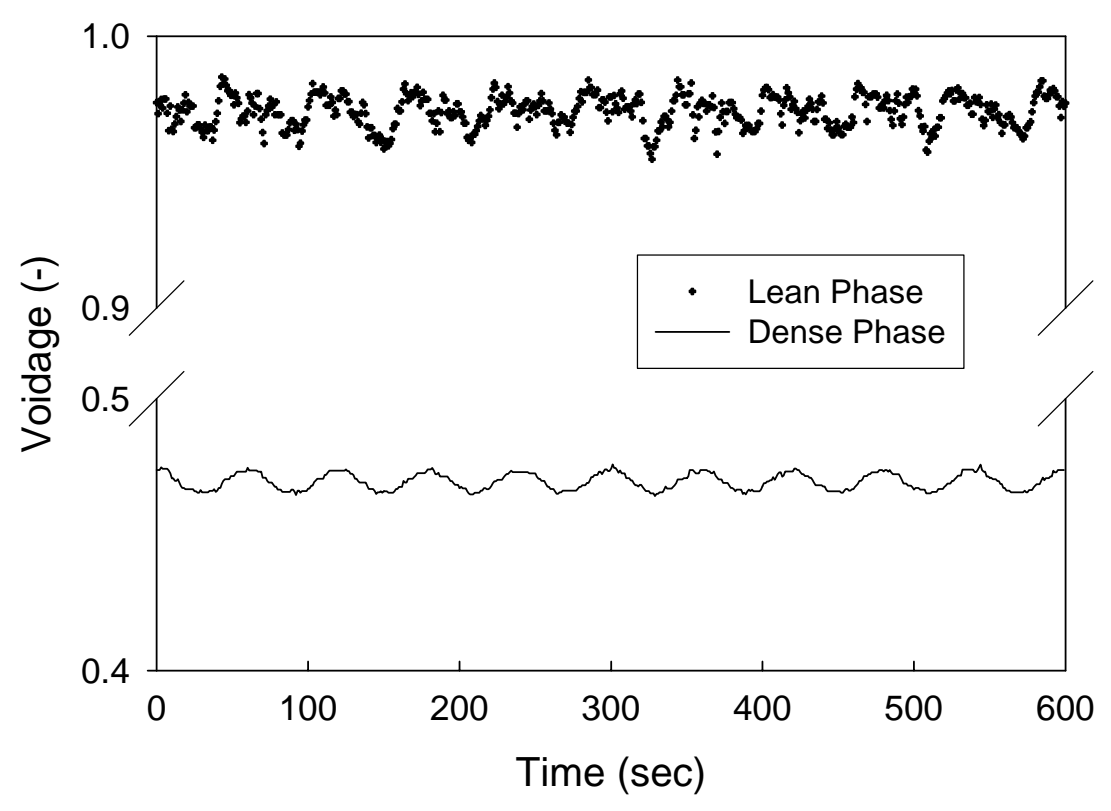

(b) Experiment K40

Figure 5.15 Prediction of voidages in the standpipe 


\section{Chapter 6 Integration of the CFB model}

\subsection{Introduction}

CFB technology is relatively mature, and most likely will play an important role in future processes such as combustors, coal gasifiers and catalytic reactors. Its optimization and control for CFB systems is very important. Advanced control methods have been applied to CFB systems, but for chemical engineers, some essential information for chemical reaction and mass or heat transport process can not be provided in these control models.

The current research work discusses the development of a phenomenological model for the transient process of circulating fluidized bed. Based on models in Chapters 4 and 5, an integrated model is developed to simulate the entire loop of a pilot-scale CFB.

\subsection{Pressure balance}

In a CFB system, solids and gas flow behavior is strongly dependent on the pressure drops of different sections, including loopseal, riser, crossover and standpipe. The pressure balance over the whole system (shown in Figure 6.1) is written as

$$
\Delta P_{\text {loopseal }}+\Delta P_{\text {riser }}+\Delta P_{\text {crossover }}=\Delta P_{\text {standpipe }}
$$

where $\Delta P_{\text {loopseal }}=P_{l}-P_{2}, \Delta P_{\text {riser }}=P_{2}-P_{3}, \Delta P_{\text {crossover }}=P_{3}-P_{4}$ and $\Delta P_{\text {standpipe }}=P_{1}-P_{4}$. 


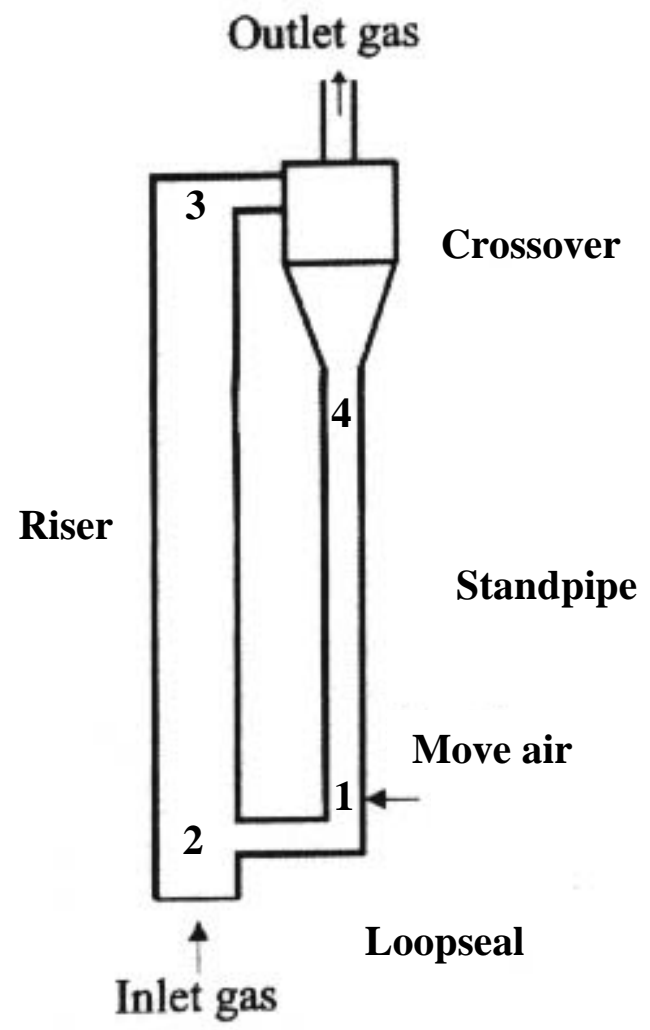

Figure 6.1 Schematic diagram for pressure balance of a CFB system

In our experiments, the move air generated sinusoidal flow rate of solids, and inlet gas flow rate was held constant. Figure 6.2 indicates the pressure drops along the CFB loop in the transient process. The pressure drops across the standpipe, riser and crossover change sinusoidally. Compared with other components, the loopseal has a relative irregular pressure drop profile with smaller amplitude. At the same time, the pressure drops obey the pressure balance equation 6.1, which are shown in Figure 6.3. 


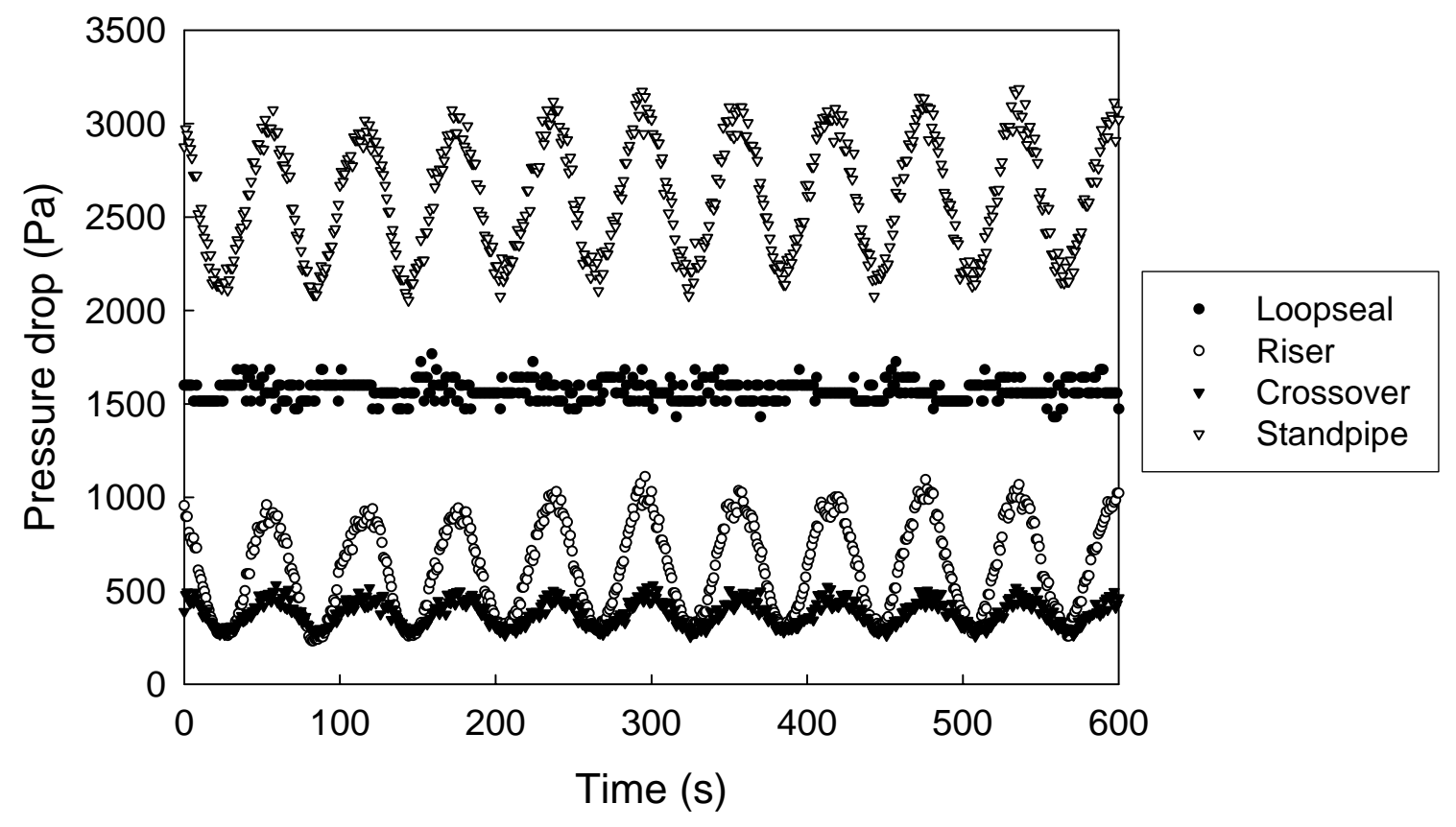

Figure 6.2 Pressure drops along the CFB loop under a transient process

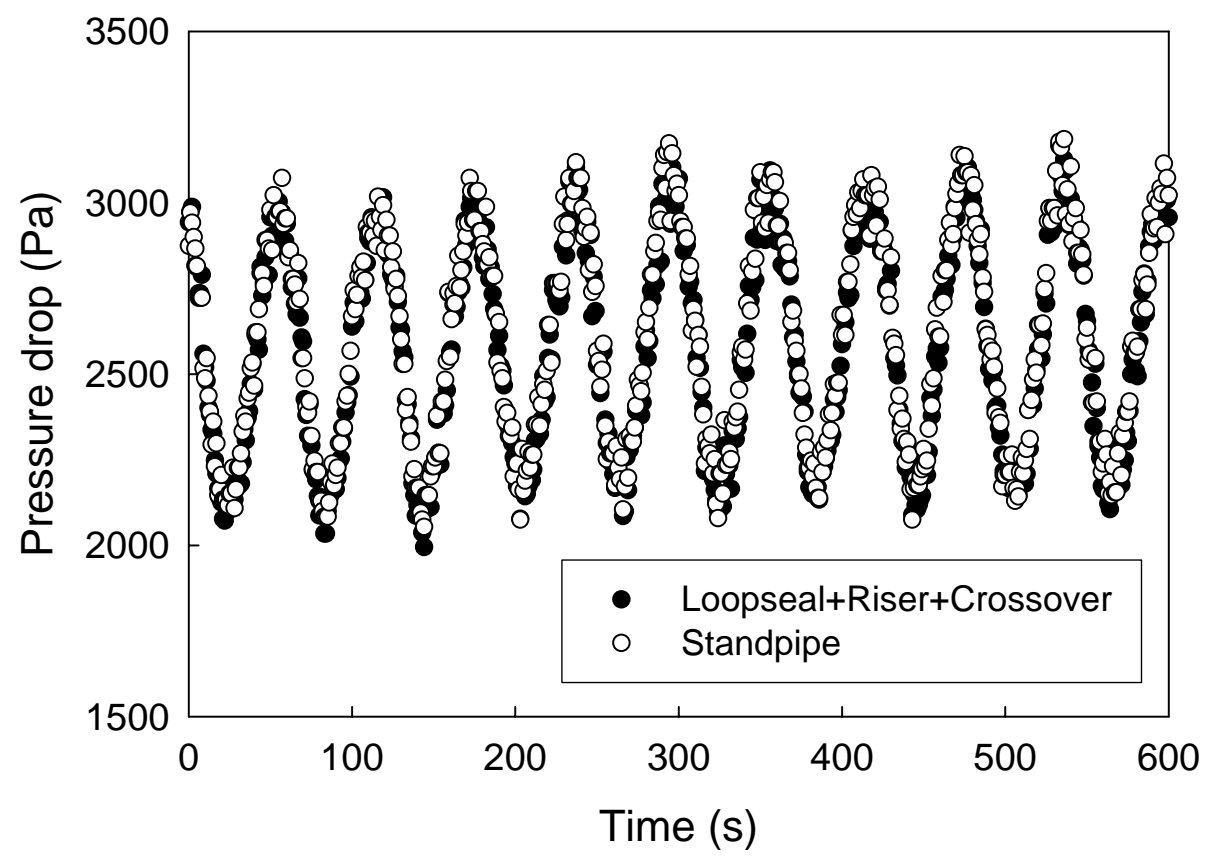

Figure 6.3 Pressure balance from experimental measurements 
In the previous chapters, the phase shifts within the riser and standpipe were discussed respectively. The measurements of the overall pressure drops along the riser and the standpipe, shown in Figure 6.2, can be also analyzed. Figure 6.4 indicates the pressure drops for the four components along the loop in a period of 100 seconds. No significant phase shift is observed between the loopseal, riser or standpipe.

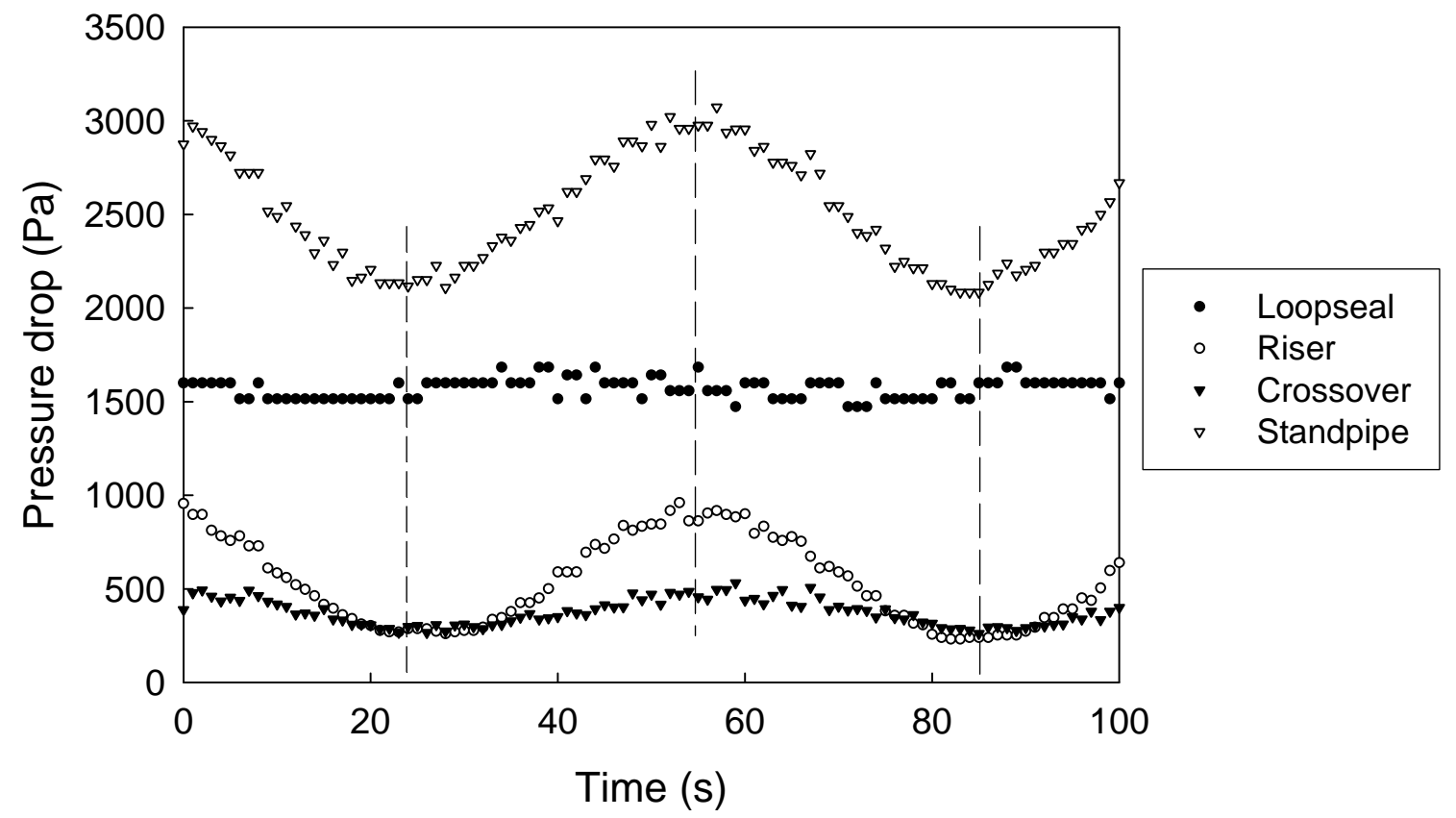

Figure 6.4 Pressure balance of a CFB system

Based on the pressure balance around the CFB loop, an increase in the move air causes an increase in the pressure drop across the standpipe. The system responds immediately with an increase in solids flow rate resulting in an increase in riser solids inventory and an increase in riser pressure drop. That is the reason why the overall pressure drop in 
the riser varies by following the change of the pressure drop in the standpipe without a significant time lag. Hence, the flow rate of solids entering the riser from the loopseal can be considered to be as same as the flow rate at the bottom of the standpipe.

\subsection{Integrated CFB model}

From the above analysis, the dynamic models of the riser and the standpipe can be combined easily. The variables in the integrated CFB model are shown in Figure 6.5.

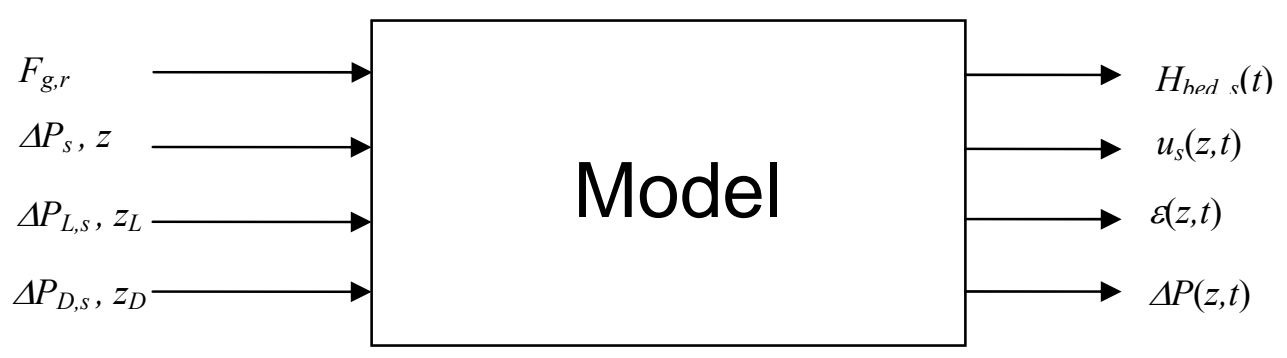

Figure 6.5 The known and unknown variables in the integrated CFB model

In this model, the required measurements as model inputs are follows:

1. $F_{g, r}$ or $U_{g, r}$ : inlet gas flow rate or superficial velocity at the bottom of the riser;

2. $\Delta P_{s}$ : the overall pressure drop along the standpipe;

3. $\Delta P_{L, S}:$ the pressure drop in the lean phase of the standpipe;

4. $\Delta P_{D, s}$ : the pressure drop in the dense phase of the standpipe.

And the model outputs would be pressure drop profile, voidage profile, solids flow rate profile and so on. This is the information which chemical engineers would be interested in. 
A code written under the Matlab 7.0 environment was developed for the integrated CFB model (See Appendix 3). An example is given and its results are shown in Figure 6.6. In principle, if above three pressure drops $\left(\Delta P_{s}, \Delta P_{L, s}, \Delta P_{D, s}\right)$ and flow rate of main fluidizing air $\left(F_{g, r}\right)$ are measured, the standpipe bed height and solids flow rate can be predicted (shown in Figure 6.6 (a)), and also the pressure and voidage profiles in the riser and the standpipe can be obtained ( shown in Figure $6.6(\mathrm{~b})$ ). 


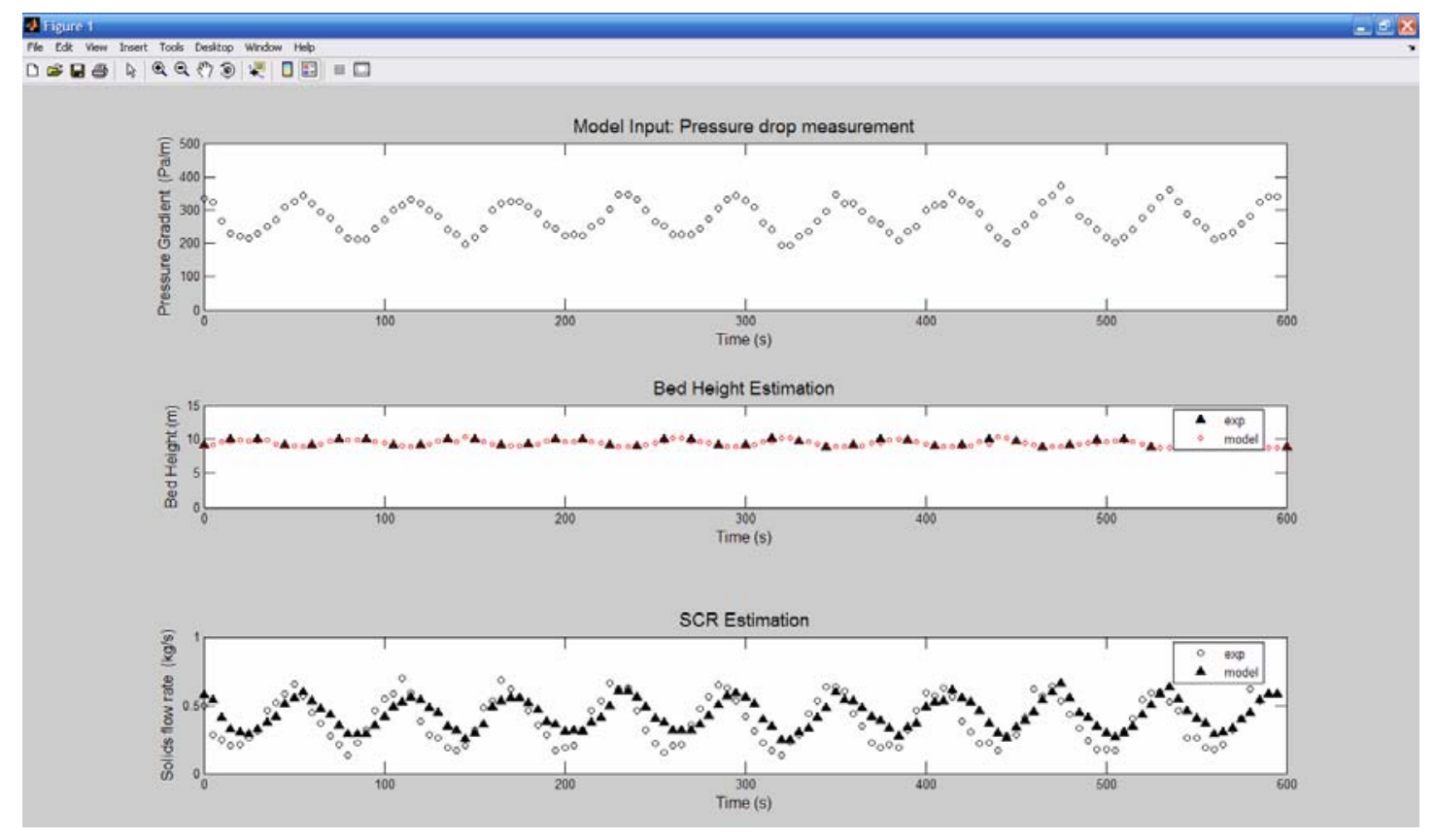

(a)

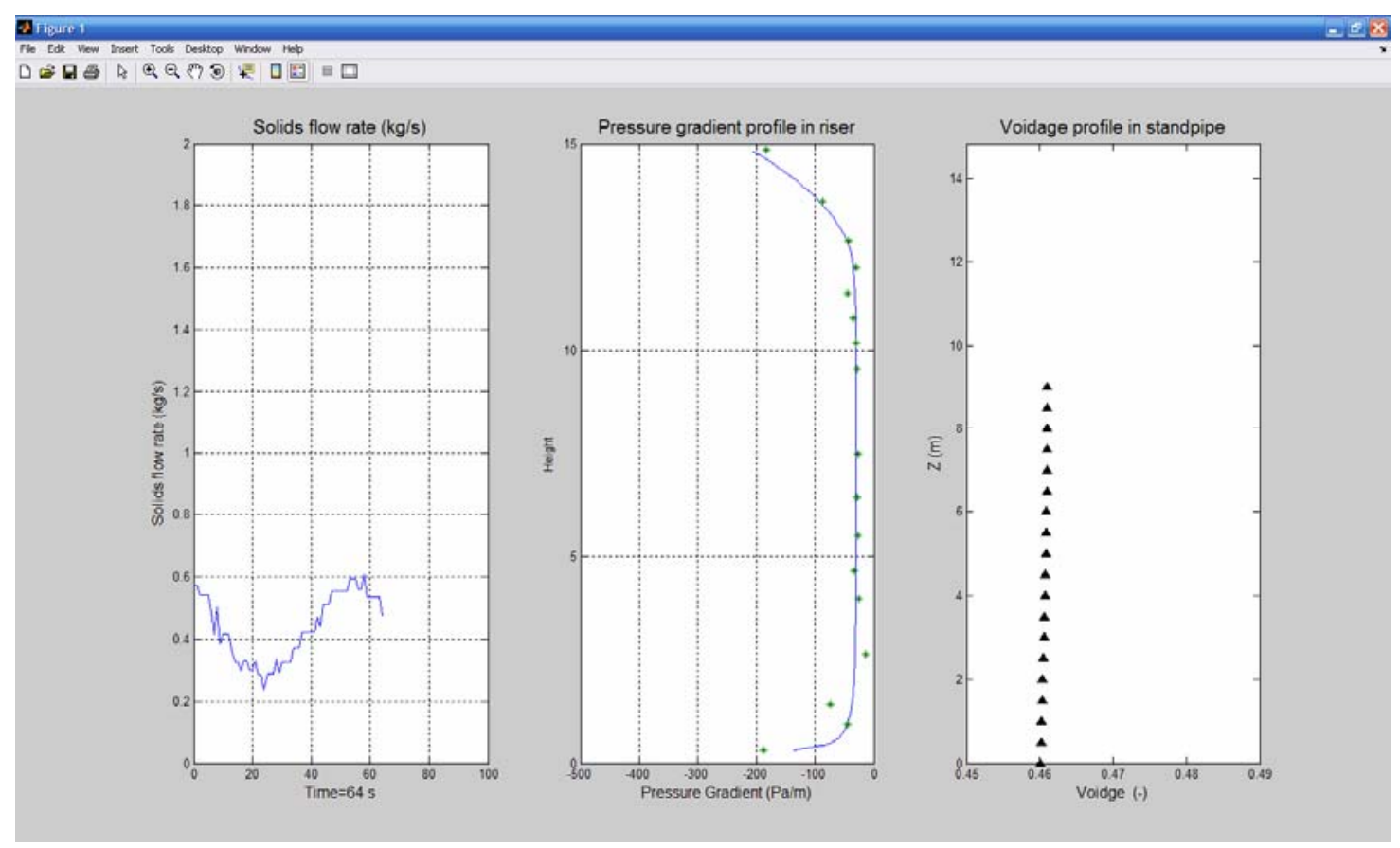

(b)

Figure 6.6 Results of the integrated CFB model under Matlab 7.0 environment 


\section{Chapter 7 Conclusions and Future Work}

\subsection{Conclusions}

Real time controlling and monitoring CFB systems are important in industrial practices, but the real-time, phenomenological model of large-scale CFB units has not been reported in recent literatures. The present work successfully developed the model to predict the steady and transient behaviors of large CFBs so that some essential information of the processes can be obtained.

Dynamic models were developed for the riser and the standpipe. The riser is modeled as a set of well-mixed tanks or 1-D axisymetric cluster flow. The smooth changes of solids inventory and the dynamic response time of the riser were estimated successfully. These models can be applied to the entire riser which includes acceleration region, developed flow region and exit region. It can also be extended to a reacting system. The state model of the standpipe estimates the solids flow rate and bed height, so that the voidage profile and solids velocities along the standpipe can be obtained. A dynamic model to describe the transient process in the standpipe is also developed, and it can be applied to predict the amplitude and phase shift of the voidages at different locations in the standpipe.

The above models are combined into an integrated CFB model through the analysis of system pressure balance. For given materials and CFB plant, the required measurements for the model inputs are three pressure drops in the standpipe and the inlet 
gas flow rate at the bottom of the riser. The model outputs would be pressure drop profile, voidage profile, solids flow profile, etc. This is the information in which chemical engineers would be interested.

Therefore, in the current research work, a real-time phenomenological model for large scale CFB system is developed to describe and quantify its transient processes. Through a few hands-on measurements, the inventory and flow characteristics can be estimated by this model. It provides an effective method for the purpose of on-line control and monitoring of pilot or industrial scale units.

\subsection{Future Work}

Current models are based on cold flow CFB plant. Even though the riser model can be applied to a reacting system, further research is required for a reacting process for the validation of the reaction model.

The integrated CFB model is developed according to the analysis of the riser and standpipe. For more information of the entire system, the models for the crossover, cyclone and loop seal may be considered respectively in the future. 


\section{Nomenclature}

\begin{tabular}{|c|c|c|}
\hline$A_{r}$ & Archimedes number & - \\
\hline$A_{r i}$ & Inside section area of riser & $\mathrm{m}^{2}$ \\
\hline$A_{s}$ & Inside section area of standpipe & $\mathrm{m}^{2}$ \\
\hline$D$ & Diffusion coefficient of solids & $\mathrm{m}^{2} / \mathrm{s}$ \\
\hline$d$ & Diameter of particles & $\mathrm{m}$ \\
\hline$d_{s v}$ & Surface-volume diameter of particles & $\mathrm{m}$ \\
\hline$F_{m}$ & Volumetric flow rate of move air & $\mathrm{SCFH}$ \\
\hline$G_{S}$ & Solids flow rate & $\mathrm{kg} / \mathrm{s}$ \\
\hline$g$ & Gravity's acceleration & $\mathrm{m} / \mathrm{s}^{2}$ \\
\hline$J_{s}$ & Solids flux & $\mathrm{kg} / \mathrm{m}^{2} \cdot \mathrm{s}$ \\
\hline$K$ & Spring constant & $\mathrm{kg} / \mathrm{m}^{2}$ \\
\hline$M_{\text {circ }}$ & Mass flow rate of solids & $\mathrm{kg} / \mathrm{s}$ \\
\hline$n$ & Richardson-Zaki constant & - \\
\hline$R$ & Ratio of gas to solids & $(\mathrm{m} / \mathrm{s}):(\mathrm{kg} / \mathrm{s})$ \\
\hline $\operatorname{Re}$ & Reynolds number & - \\
\hline$R e_{t}$ & Reynolds number of particle under terminal velocity & - \\
\hline$U_{f d}$ & Maximum gas velocity for a given solids circulation rate & $\mathrm{m} / \mathrm{s}$ \\
\hline$U_{t}$ & Particle terminal velocity & $\mathrm{m} / \mathrm{s}$ \\
\hline$U_{t f}$ & Minimum gas velocity for a given solids circulation rate & $\mathrm{m} / \mathrm{s}$ \\
\hline$U_{g}$ & Superficial velocity & $\mathrm{m} / \mathrm{s}$ \\
\hline
\end{tabular}


$\begin{array}{lll}u_{s, 1} & \text { Solids velocity in lean phase of standpipe } & \mathrm{m} / \mathrm{s} \\ u_{s, 2} & \text { Solids velocity in dense phase of standpipe } & \mathrm{m} / \mathrm{s} \\ Z_{o} & \text { Length of the transition region between the dilute and dense regions }\end{array}$

$\mathrm{m}$

$z_{i} \quad$ Location of the inflection point $\mathrm{m}$

Greek Symbols

$\triangle P \quad$ Pressure drop $\quad P$

$\bar{\varepsilon} \quad$ Cross-sectional averaged voidage

$\varepsilon^{*} \quad$ Asymptotic voidage in the top dilute region -

$\varepsilon_{1} \quad$ Voidage of lean phase in standpipe

$\varepsilon_{2} \quad$ Voidage of dense phase in standpipe -

$\varepsilon_{a} \quad$ Asymptotic voidage in the bottom dense region -

$\varepsilon_{\max } \quad$ Maximal voidage at lean phase of riser

$\varepsilon_{o b} \quad$ Voidage at the bottom of riser -

$\varepsilon_{o t} \quad$ Voidage at the top of riser -

$\varepsilon_{w} \quad$ Local voidage at the wall -

$\mu \quad$ Viscosity of gas $\quad \mathrm{Pa} \cdot \mathrm{s}$

$\rho_{g} \quad$ Density of gas $\quad \mathrm{kg} / \mathrm{m}^{3}$

$\rho_{s} \quad$ Density of solids $\quad \mathrm{kg} / \mathrm{m}^{3}$

$\tau_{c} \quad$ Impact time of perfectly elastic collision with linear elements 


\section{References}

[1] Grace, J. R. and Bi, H., Introduction to circulating fluidized beds, In Circulating fluidized beds, Ed. Grace, Avidan and Knowlton, Blackie Academic and Professional, London, 1996

[2] King, D., Fluidized catalytic cracker: an engineering review, In Fluidization VII. Ed. Potter and Nicklin. Engineering Foundation, New York, 1992

[3] Basu, P. and Fraser, S. A., Circulating fluidized bed boilers: design and operations, Butterworths, Boston, 1991

[4] Fujimura, H., Oshita, T. and Naruse K., Fluidized-bed gasification and slagging combustion system, IT3 Conference, Philadelphia, USA, May 14-18, 2001

[5] Avidan, A.A., Fluid catalytic cracking, In Circulating fluidized beds, Ed. Grace, Avidan and Knowlton, Blackie Academic and Professional, London, 1996

[6] Kavidass, S., Anderson, G.L. and Norton G.S. Jr., Why build a circulating fluidized bed boiler to generate steam and electric power, POWER-GEN Asia 2000, Bangkok, Thailand, Sept. 20-22, 2000

[7] Karppanen, E., Advanced control of an industrial circulating fluidized bed boiler using fuzzy logic, Academic dissertation, University of Oulu, Finland, 2000

[8] Grace J. R., Contacting modes and behaviour classification of gas-solid and other-phase suspensions, Can. J. Chem. Eng., 64, 353-363, 1986

[9] Bai, D., Jin, Y. and Yu, Z., Flow regimes in circulating fluidized beds, Chem. Eng. Technol., 16, 307 
[10]Fan, L.-S. and Zhu, C., Principles of Gas-Solids Flows, Cambridge University Press, 1998

[11]Bi, H. T. and Fan, L.-S., Regime transition in gas-solid circulating fluidized beds, AIChE Annual Meeting, Los Angeles, USA, Nov. 17-22, 1991

[12]Clift, R., Grace, J.R. and Weber M.E., Bubbles, drops and particles, Academic Press, New York, 1978

[13]Khan, A.R. and Richardson, J.F., Fluid-particle interactions and flow characteristics of fluidized beds and setting suspensions of spherical particles, Chem. Eng. Commun. $78,111-130,1989$

[14]Flemmer, R. LC, and Banks, C. L., On the drag coefficient of a sphere, Powder Technol., 48(3), 217-221, 1986

[15]Turton, R.; and Levenspiel, O., A short note on the drag correlation for spheres, Powder Technol., 47, 83-86, 1986

[16]Clift, R. and Gauvin, W.H, Proc. CHEMECA '70, Butterworth, Melbourne, 1, 14-28. 1970

[17] Geldart, D., Gas fluidization technology, John Wiley \& Sons, 1986

[18] Turton, R. and Clark, N., An explicit relationship to predict spherical particle terminal velocity, Powder Technol., 53, 127-129, 1987

[19]Haider, A. and Levenspiel, O., Drag coefficient and terminal velocity of spherical and nonspherical particles, Powder Technol., 58, 63-70, 1989 
[20]Li, Y. and Kwauk, M., The dynamics of fast fluidization, In Fluidization, Ed. Grace and Matsen, Plenum, New York, 1980

[21]Bai, D. R., Jin Y., Yu Z. Q. and Zhu, J. X. The axial distribution of the cross-sectionally averaged voidage in fast fluidized bed, Powder Technol., 71, 51-58, 1992

[22]Zhang, W., Tung, Y. and Johnsson, F., Radial voidage profiles in the fast fluidized beds of different diameters. Chem. Eng. Sci., 46, 3045, 1991

[23] Geldart D., Types of gas fluidization, Powder Technol., 7, 285-292, 1973

[24]Kwauk M., Fluidization: idealized and bubbleless, with applications. Science Press, Beijing, 1992

[25]Brereton C. and Stromberg L., Circulating fluidized bed technology, Ed. Basu, New York, 133, 1986

[26]Rhodes, M. J. and Geldart, D., A model for the circulating fluidized bed, Powder Technol., 53, 155-162 , 1987

[27] Werther J., Fluid mechanics of large-scale CFB units, In Circulating fluidized beds technology IV, Ed. Avidan, AIChE Publications, New York, 1993

[28]Rhodes M.J., Zhou S. and Benkreira H., Flow of dilute gas-particle suspensions, AIChE J. 38, 1913-1915, 1992

[29] Goedicke, F. and Reh, L., Particle induced heat transfer between walls and gas-solid fluidized bed, AIChE symp. Ser 89, No 296, 123-136 
[30] Yang, W.-C., A model for the dynamics of a circulating fluidized bed loop, Circulating Fluidized Bed Technology II, 1988

[31] Monazam, R.E., Shadle L.J. and Lawson L.O., A transient method for determination of saturation carrying capacity, Powder Technol., 121, 205-212, 2001

[32]Pallares, D.J. and Johnsson. F., Fluid dynamic modeling of large CFB units, Proceedings of the 7th international conference on circulating fluidized beds (CFB7), Ed. Grace, Zhu, de Lasa, Niagara Falls, Ontario, Canada, 387-394, May 5-8, 2002

[33] Secchi, A.R., Santos, M.G., Neumann, G.A. and Trierweiler, J.O., A dynamic model for a FCC UOP stacked converter unit, Computers and Chemical Engineering, $25,851-858,2001$

[34] Mathiesen, V., Solberg, T., Arastoopour, H. and B. H. Hjertager, Experimental and computational study of multiphase gas/ particle flow in a CFB riser, AIChE Journal, 45(12), 2503-2518, 1999

[35]Rong D. and Horio M., DEM Simulation of char combustion in a fluidized bed, $2^{\text {nd }}$ international conference on CFD in the mineral and process industries, Melbourne, Australia, Dec. 6-8, 1999

[36]Li, J. and Kuipers J.A.M., Effect of pressure on gas-solid flow behavior in dense gas-fluidized beds: a discrete particle simulation study, Powder Technol., 127, $173-184,2002$ 
[37]Di Maio F.P. and Di Renzo A., A numerical tool for the simulation of fluidized bed hydrodynamics based on a combined DEM-CFD approach, Chem Eng. Trans., 3, 985-990, 2003

[38] Sinclair, J.L. and Jackson, R., Gas-particle flow in a vertical pipe with particle-particle interactions. AIChE J., 35, 1473-1486, 1989

[39] Anderson, T. and Jackson, R., Fluid mechanical description of fluidized beds, Ind. Eng. Chem. Fundam, 6, 527-539, 1967

[40]Burkell, J.J., Grace, J.R., Zhao, J. and Lim, C. J., Measurement of solids circulation rates in fluidized beds, Proceedings of 2nd International Conference on Circulating Fluidized Beds, Ed. Basu and Large, Pergamon, New York, 501-509, 1988

[41]Lui, J., and Huan, B. Turbine meter for the measurement of bulk solids flowrate, Powder Technol., 82, 145-151, 1995

[42]Davis, C. E. and Harris B. J., A device for measuring solids flowrates: characteristics, and application in a circulating fluidized bed, Fluidization VII, Ed. Potter and Nicklin, Engineering Foundation, New York, 741-745, 1992,

[43] Christopher Ludlow J., Lawson, L., Shadle, L., Syamlal, M., Development of a spiral device for measuring the solids flow in a circulating fluidized bed, In Proceedings of the 7th International Conference on Circulating Fluidized Beds (CFB7), Ed. Grace, Zhu, de Lasa, Niagara Falls, Ontario, Canada, May 5-8, 513-520, 2002

[44] Patience, G.S., Chaouki, J. and Grandjean, B.P.A., Solids flow metering from pressure drop measurement in circulating fluidized beds. Powder Technol., 61 95-99, 1990 
[45]Lim, K. S., Peeler, P., Close, R. and Joyce, T., Estimation of solids circulationrate in CFB from pressure loop profile, In Circulating Fluidized Beds VI, Ed Werther, Frankfurt, Germany, 819-824, 1999

[46]Rhodes, M. J. and Laussman, P. A., Study of the pressure balance around the loop of a CFB, Can. J. Chem. Eng. 70, 625-630, 1992

[47] Ergun S., Fluid flow through packed columns, Chem. Eng. Prog., 48, 89-94, 1952

[48] Macdonald, I. F., El-Sayed, M. S., Mow, K. and Dullien, F.A., Flow through porous media - the Ergun equation revisited, Ind. Eng. Chem. Fundam, 8 (3) 199-208, 1979 [49]Paterson, W. R., Crawshaw, J. P., Hart, G., Parker, S. R. Scott, D. M. and Young, J. P., Pressure drop in countercurrent gas flow through moving particulate beds, Trsns IChemE, 70, Part A, 252-254, May 1992

[50]Davari, A., Patankar A., Koduru, P., Shadle, L. and Lawson, L., Modeling and control of circulating fluidized bed using neural networks, Annual project report, University/NETL Partnership Program, 2001

[51]Zadeh, L., A fuzzy sets, Information and control, 8: 338-353, 1965

[52] Ostergaard, J.-J., High level control of industrial processes. In: Proceedings of TOOLMET'96- Tool Environments and Development Methods for Intelligent Systems, Ed. Yliniemi and Juuso, 1-12, University of Oulu, Control Engineering Laboratory, Finland, 1996

[53]Kalman, R. E., A new approach to linear filtering and prediction problems, Transaction of the ASME, Journal of Basic Engineering, 3, 35-45, 1960 
[54] Shim, H., Famouri, P., Sams, W. N., and Boyle, E. J., A state estimation of the standpipe of a circulating fluidized bed using an extended kalman filter, Proceedings of the 16th International Conference on Fluidized Bed Combustion, 130-140, May 2001

[55] Shadle, L. J., Monazam E. R., Mei J. S., Circulating Fluidized Bed Operation, Proceedings of the 7th International Conference on Circulating Fluidized Beds (CFB7), Ed. Grace, Zhu and de Lasa, Niagara Falls, Ontario, Canada, May 5-8, $255-262,2002$

[56]Richardson, J.F. and Zaki, W.N., Sedimentation and fluidization. Transactions of the Institution of Chemical Engineers 32, 35-53. 1954

[57]Harris, B.J. and Davidson, J. F., Modeling options for circulating fluidized beds: a core-annulus deposition model, in: Circulating Fluidized Bed Technology IV, Ed. Avidan, AIChE, New York, 32-39, 1993

[58]Ishii, H., Nakajima, T. and Horio, M., The clustering annular flow model of circulating fluidized beds, J. Chem. Eng. Japan, 22, 484-490, 1989

[59] Sinclair, J.L. and Jackson, R., Gas-particle flow in a vertical pipe with particle-particle interactions, AlChE J., , 35, 1473-1486, 1989

[60] Dasgupta, S., Jackson R. and Sundaresan, S., Turbulent gas-particle flow in vertical risers, AIChE J., 40, 215-227, 1994 
[61]Fligner, M., Schipper, P.H., Sapre, A.V. and Krambeck, F.J., Two phase cluster model in riser reactors: impact of radial density distribution on yields, Chem. Eng. Sci., 49, 5813-5818, 1994

[62]Lough, M., Lischer, D.J. and Chang H., Measurements of voidage near the wall of a circulating fluidized bed riser, Powder Technology, 62, 269-276, 1990

[63]Rhodes, M., Mineo H. and Hirama, T., Particle motion at the wall of a circulating fluidized bed, Powder Technol., 70, 207-214, 1992

[64]Zhou, J., Grace J.R., Lim, C.J. and Brereton, C.M.H., Particle velocity profiles in a circulating fluidized bed riser of square cross-section, Chem. Eng. Sci., 50, 237-244, 1995

[65] Sharma, A.K., Tuzla, K., Matsen, J. and Chen, J.C., Parametric effects of particle size and gas velocity on cluster characteristics in fast fluidized beds, Powder Technol., $111,114-122,2000$

[66]Lints, M., Particle-to-wall heat transfer in circulating fluidized beds, Doctoral Thesis, Massachusetts Institute of Technology, Cambridge, MA, 1992

[67]Harris, A.T., Davidson, J.F. and Thorpe, R. B., The prediction of particle cluster properties in the near wall region of a vertical riser, Powder Technol., 127, 128-143, 2002

[68] Xu, G. and Kato, K., Hydrodynamic equivalent diameter for clusters in heterogeneous gas-solid flow, Chem. Eng. Sci., 54, 1837-1847, 1999 
[69]Pandey, P., Turton, R., Yue, P. and Shadle, L.J, Nonintrusive particle motion studies in the near-wall region of a pilot-scale circulating fluidized bed, Ind. Eng. Chem. Res., $43,5582-5592,2004$

[70]Bi, H.T., Some issues on core-annulus and cluster models of circulating fluidized bed reactors, Can. J. Chem. Eng., 80, 809-817, 2002

[71]Wen, C.-Y. and Yu, Y. H., Mechanics of fluidization, Chem. Eng. Prog. Symp. Series, $62,100-111,1966$

[72]Day, J. Y., Littman, H. and Morgan, M. H., A new choking velocity correlation for vertical pneumatic conveying, Chem. Eng. Sci., 45, 355-360, 1990

[73] Sabbaghan, H., Sotudeh-Gharebagh, R., and Mostoufi, N., Modeling the acceleration zone in the riser of circulating fluidized beds, Powder Technol., 142, 129-135, 2004

[74] Ouyang, S.; Li, X.G.; and Potter, O.E., Circulating fluidized bed as a catalytic reactor: experimental study, AIChE J., 41,1534-1542, 1995

[75]Lei, H.; and Horio, M., A comprehensive pressure balance model of circulating fluidized beds, Journal of Chemical Engineering of Japan, 31, 83-94, 1998

[76] Harris, A. T., Davidson, J. F. and Thorpe, R. B., The influence of the riser exit on the particle residence time distribution in a circulating fluidised bed riser, Chemical Engineering Science, 58 (16), 3669-3680, 2003

[77]Harris, A. T., Davidson, J. F. and Thorpe, R. B., Influence of exit geometry in circulating fluidized-bed risers, AIChE J., 49(1), 52-64, 2003 
[78]Horio, M., Hydrodynamics, in Circulating fluidized beds, Chap. 2, Ed. Grace, Avidan and Knowlton, Chapman \& Hall, London, 1997

[79] Werther, J. and Hirschberg, B., Solids motion and mixing, Circulating fluidized beds, Chap. 4, Ed. Grace, Avidan and Knowlton, Chapman \& Hall, London, 1997

[80] Lim, K. S., Zhu, J. X. and Grace, J. R., Hydrodynamics of gas-solid fluidization, Int. J. Multiphase Flow, 21 Suppl., 141-193, 1995

[81]Martin, M. P., Derouin, C., Turlier, P., Forissier, M., Wild, G. and Bernard, J. R., Catalytic cracking in riser reactors: core-annulus and elbow effects, Chem. Eng. Sci., 47, 2319-2324, 1992

[82] Martin, M. P., Turlier, P., Wild, G. and Bernard, J. R., Gas and solid behaviour in cracking circulating fluidized beds, Powder Technol., 70, 249-258, 1992

[83]Rudnick, C. and Werther, J., The discrimination of cluster characteristics from fiber-optical probe signals in circulating fluidized beds, in Fluidization IX, Ed. Fan and Knowlton, Engineering Foundation, New York, 573-580, 1998

[84]Li, Y., Lu, Y., Wang F., Han, K., Mi, W., Chen., X. and Wang, P., Behavior of gas-solid flow in the downcomer of a circulating fluidized bed reactor with a V-valve, Powder Technol., 91, 11-16, 1997

[85]Couch, K.A., Seibert, K.D. and Van Opdorp P.J., Controlling FCC yields and emissions: UOP technology for a changing environment, Annual Meeting of National Petrochemical \& Refiners Association, San Antonio, Texas, 2003 
[86] Leung, L. S., Design of fluidized gas-solids flow in standpipes, Powder Technol., 16, $1-6,1977$

[87] Leung, L. S., Wiles, R. J. and Nicklin, D. J., Transition from fluidized to packed bed flow in vertical hydraulic convey, Tans. Inst. Chem. Eng., 47: T271-T278, 1969

[88] Yang, W. C. and Knowlton, T. M., L-valve Equation, Powder Technology, 77, 49-54 1993

[89] Kim, S.W., Namkung, W. and Kim, S.D., Solids flow characteristic in loop-seal of a circulating fluidized bed, Korean, J. Chem. Eng., 16(1), 82-88, 1999

[90] Park, J., Huang, Y., Turton, R., Famouri, P. and Boyle, E. J., The control of bed height and solids circulation rate in the standpipe of a cold flow circulating fluidized bed, Powder Technol., 150 176-184, 2005

[91]Knowlton, T. M.; Hirsan, I. and Leung, L. S., The effect of aeration tap location on the performance of a J-valve, In: Fluidization, Ed. Davidson and Keairns, Cambridge University Press, 128-133, 1978

[92] Soo S. L. and Zhu C., Unsteady motion of dense suspensions and rheological behavior, In: Particulate Two-Phase Flow, Ed. Roco, Butterworth-Heinemann, 265-297, 1993

[93] Wallis, G. B., One-dimensional two-phase flow, McGraw-Hill, New York, 1969

[94] Slis, P.L., Willemse, T.W. and Kramers, H. The response of the level of a liquid fluidized bed to sudden change in the fluidizing velocity, Appl. Sci. Res., A8, 209-218, 1958 
[95]Cox, J.D., and Clark, N.N., The effect of particle drag relationships on prediction of kinematic wave velocity in fluidized beds, Powder Technol., 66, 177-189, 1991

[96] Shim, H., Famouri, P., Sams, W. N. and Boyle, E.J., A state estimation of the standpipe of a circulating fluidized bed using an extended kalman filter, Proceedings of the $16^{\text {th }}$ International Conference on Fluidized Bed Combustion, 130-140, May 2001. 


\section{Appendix}

\section{Matlab code for Cluster Model}

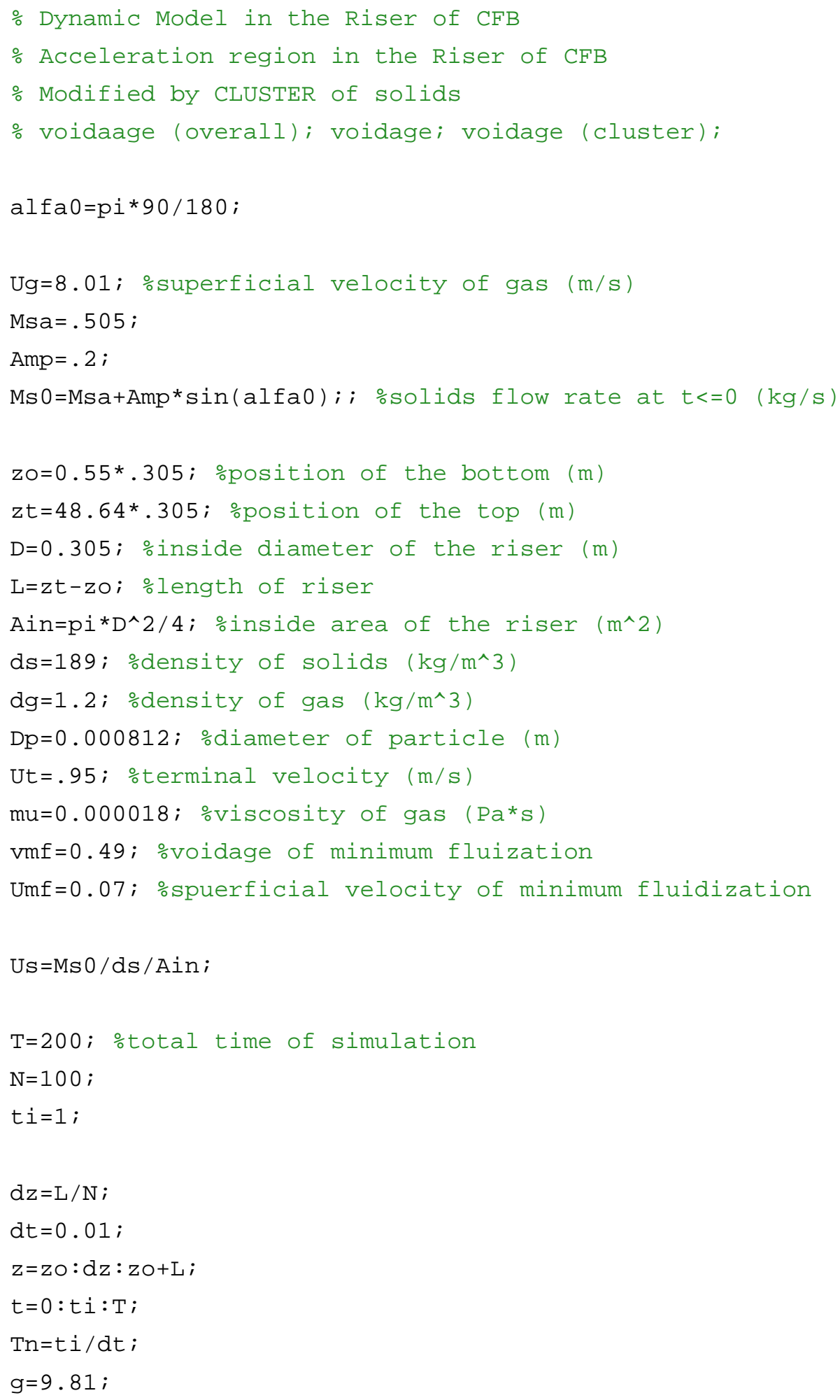




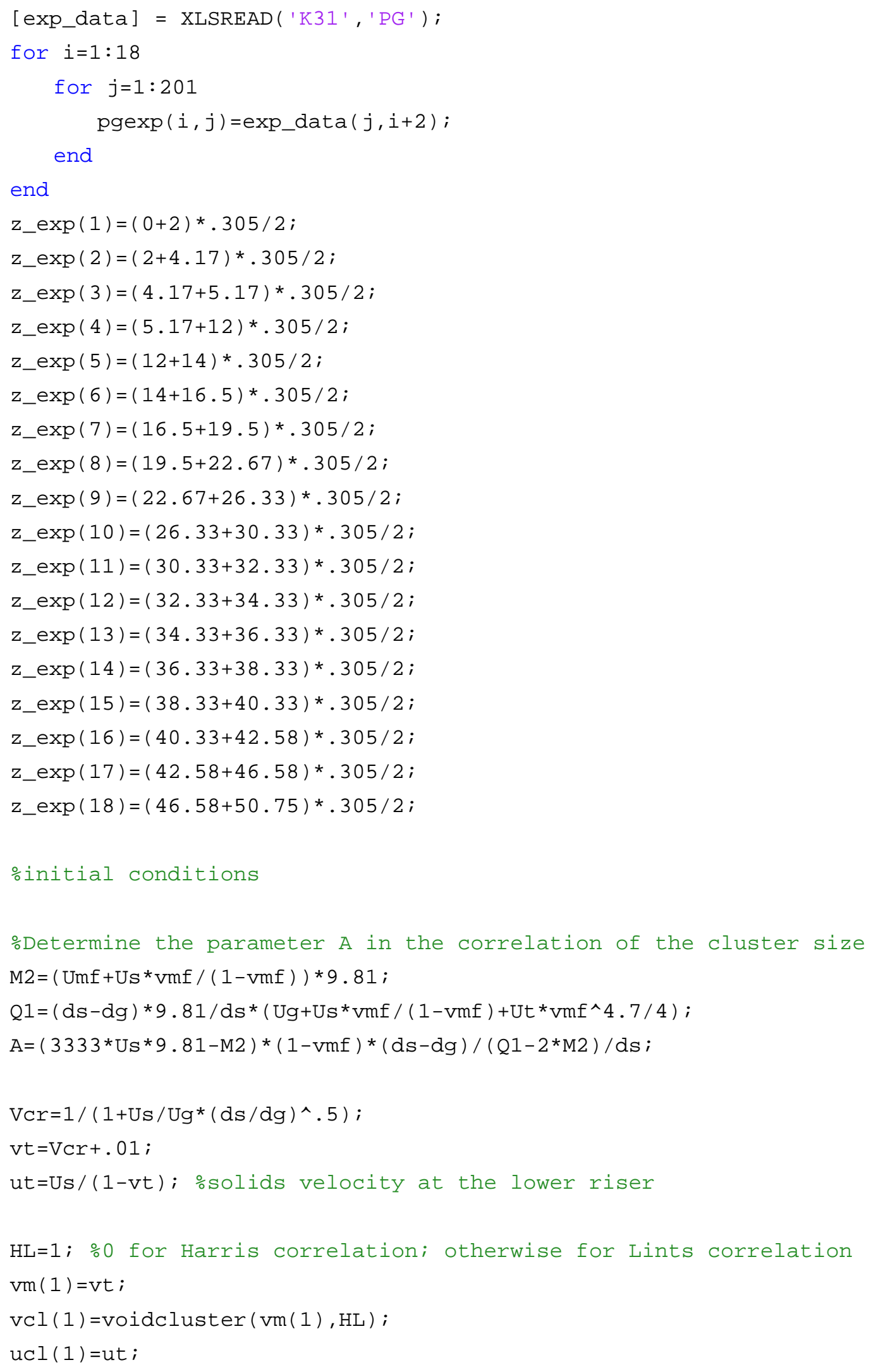

\%initial conditions

\%Determine the parameter $A$ in the correlation of the cluster size $\mathrm{M} 2=\left(\mathrm{Umf}+U \mathrm{~s}^{*} \mathrm{vmf} /(1-\mathrm{vmf})\right) * 9.81$;

$\mathrm{Q} 1=(\mathrm{ds}-\mathrm{dg}) * 9.81 / \mathrm{ds} *\left(U \mathrm{U}+U \mathrm{~s}^{*} \mathrm{vmf} /(1-\mathrm{vmf})+U \mathrm{U}{ }^{*} \mathrm{vmf} \wedge 4.7 / 4\right)$;

$A=\left(3333^{*} U s^{*} 9.81-M 2\right) *(1-v m f) *(d s-d g) /(Q 1-2 * M 2) / d s$;

$\operatorname{Vcr}=1 /\left(1+\mathrm{Us} / \mathrm{Ug}^{*}(\mathrm{ds} / \mathrm{dg})^{\wedge} .5\right)$;

$\mathrm{vt}=\mathrm{Vcr}+.01$;

ut=Us/(1-vt); \%solids velocity at the lower riser

HL=1; \%० for Harris correlation; otherwise for Lints correlation $\mathrm{vm}(1)=\mathrm{vt}$;

$\operatorname{vcl}(1)=\operatorname{voidcluster}(\mathrm{vm}(1), \mathrm{HL})$;

$\operatorname{ucl}(1)=u t$; 


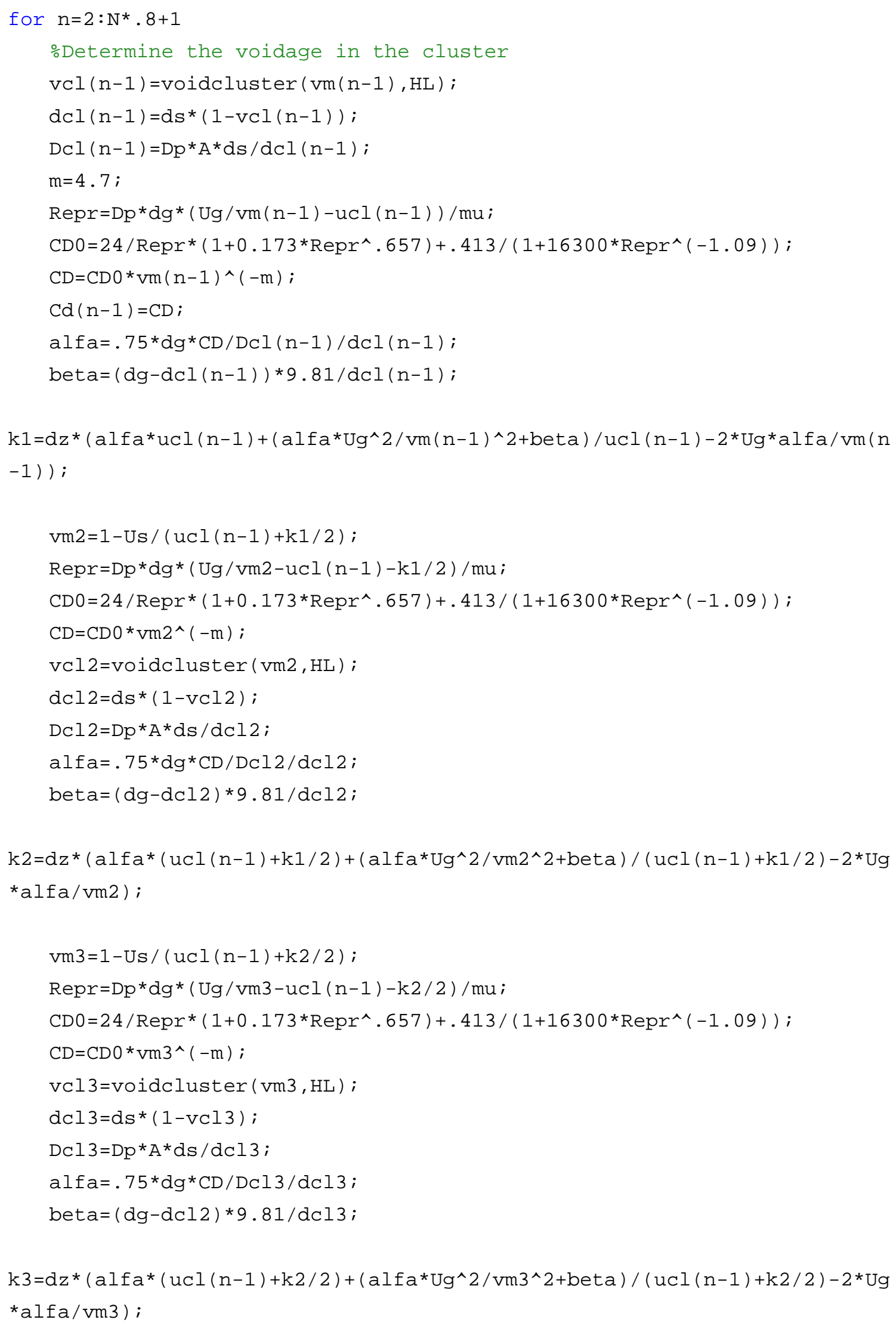




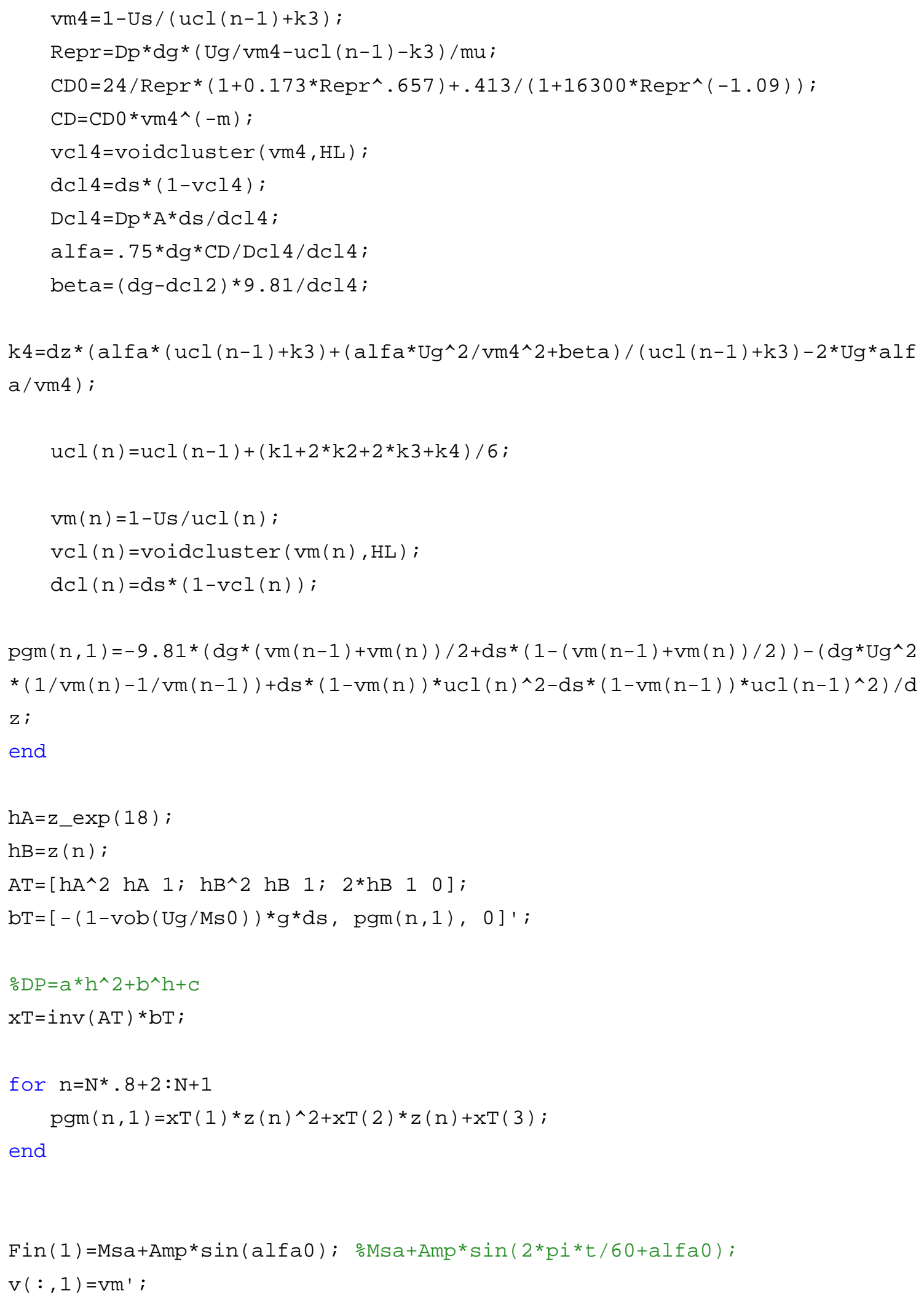




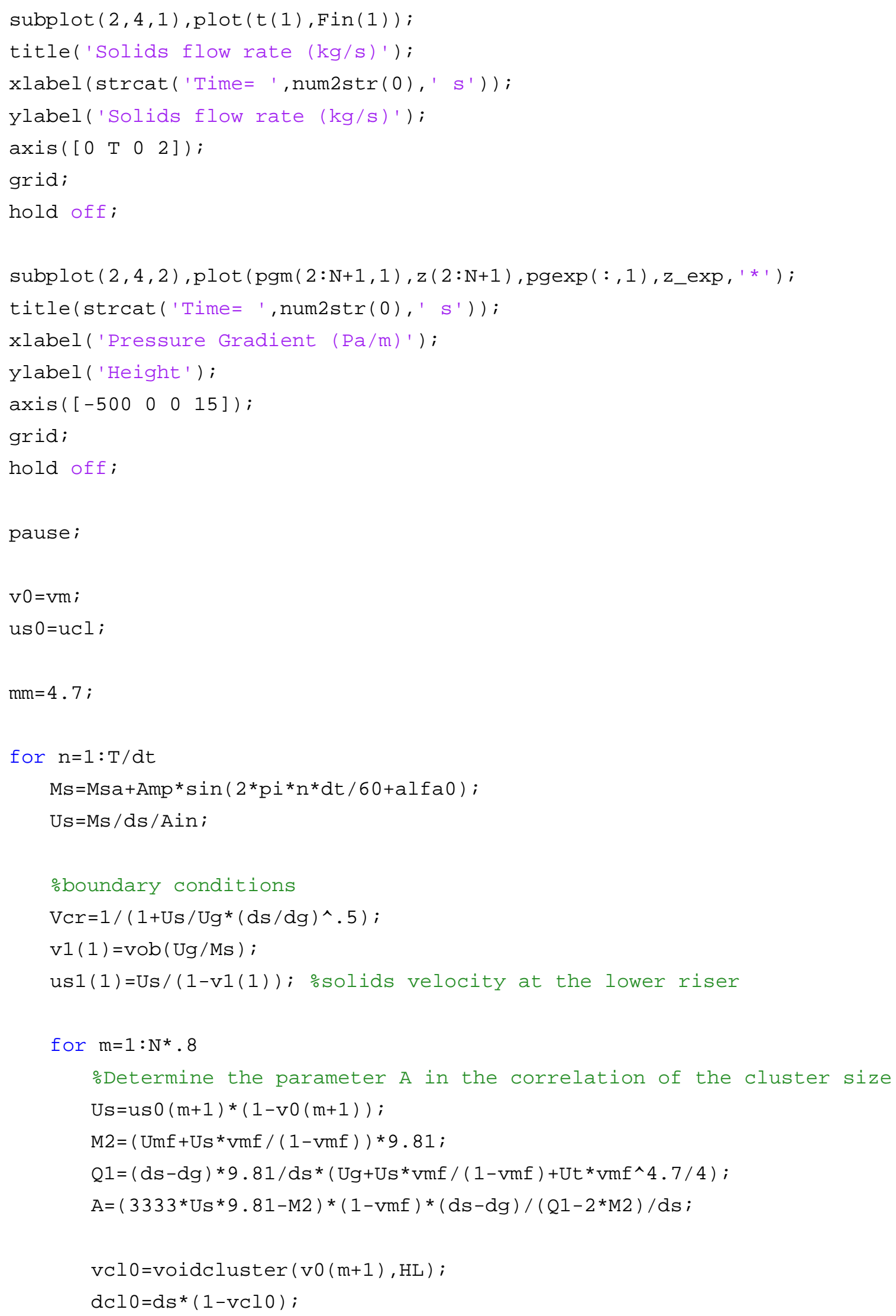




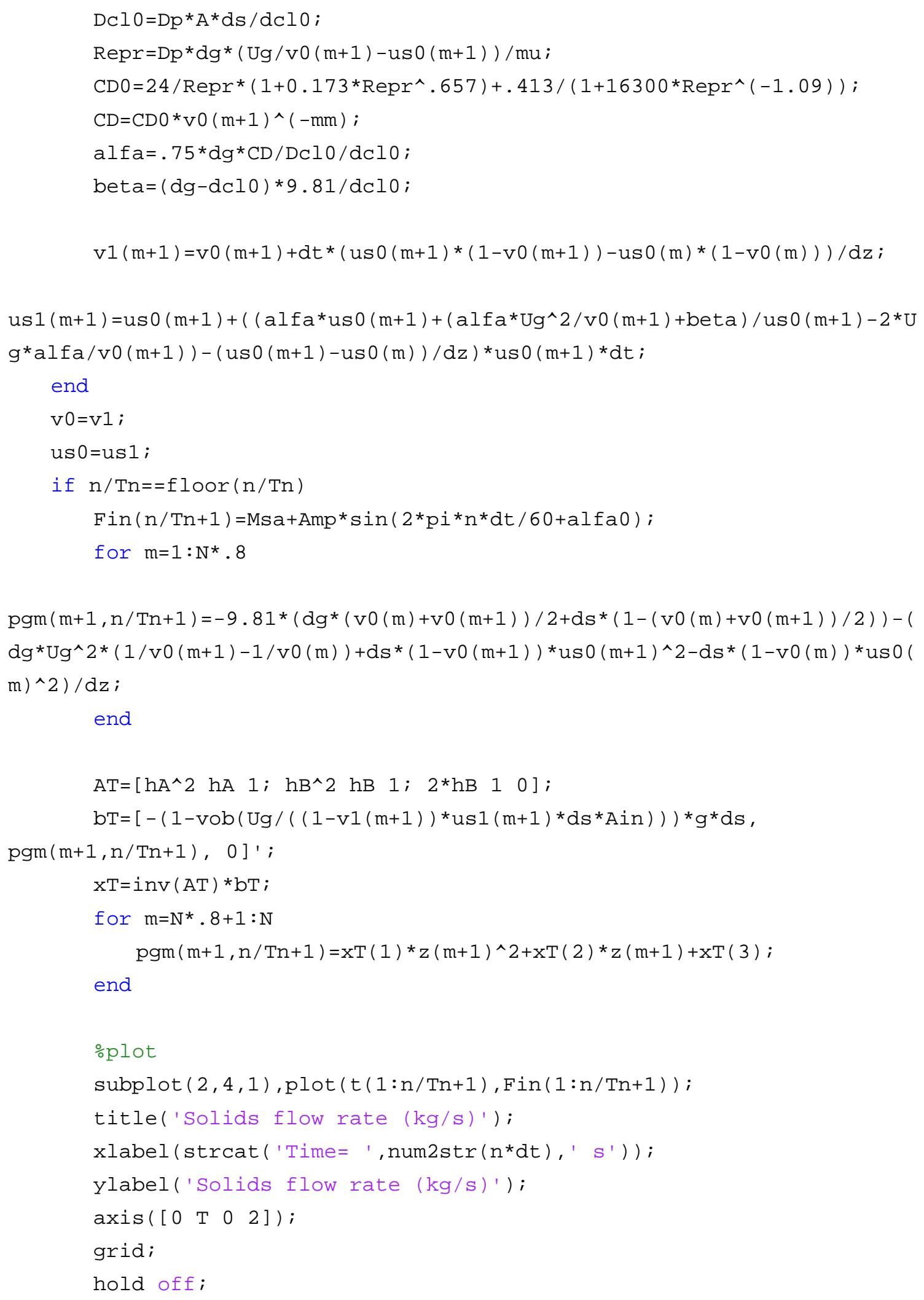




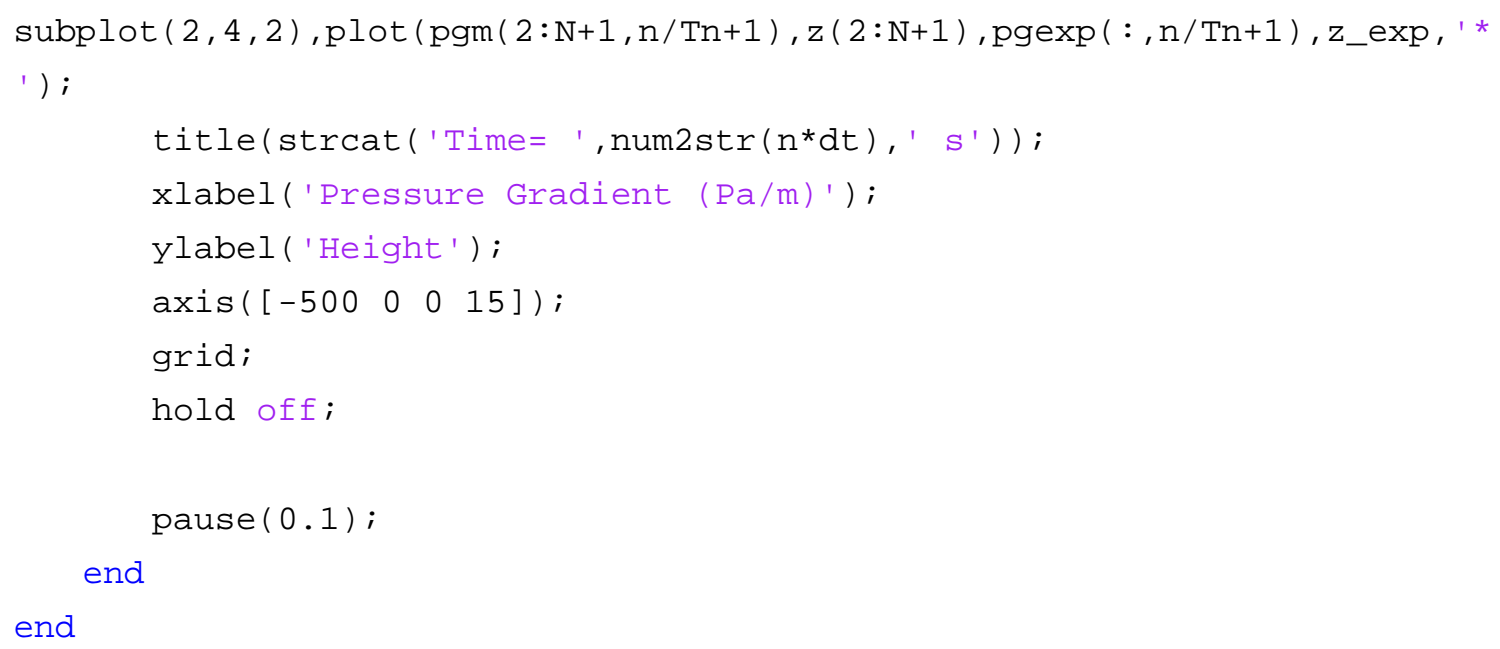




\section{Matlab code for Standpipe Model}

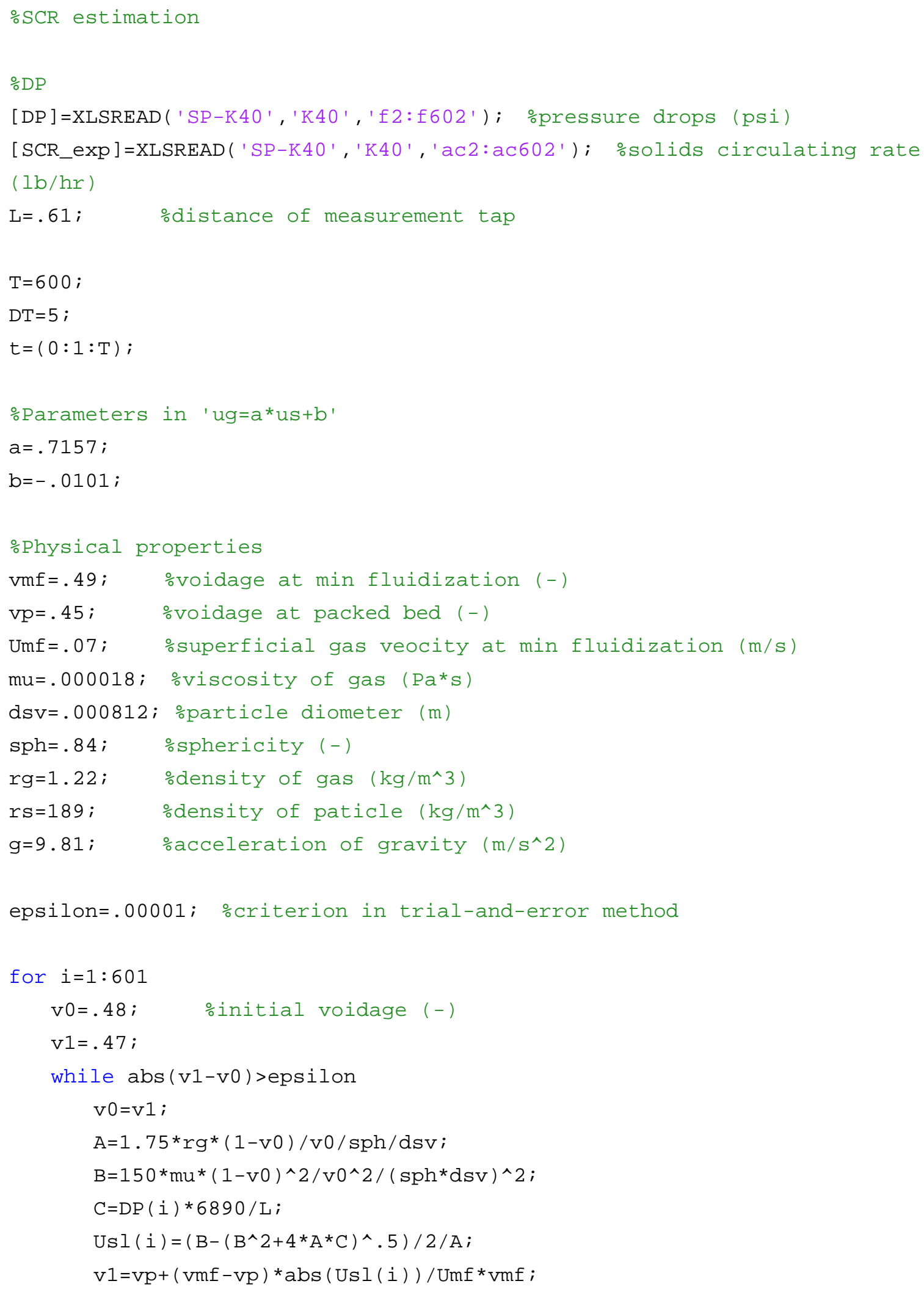




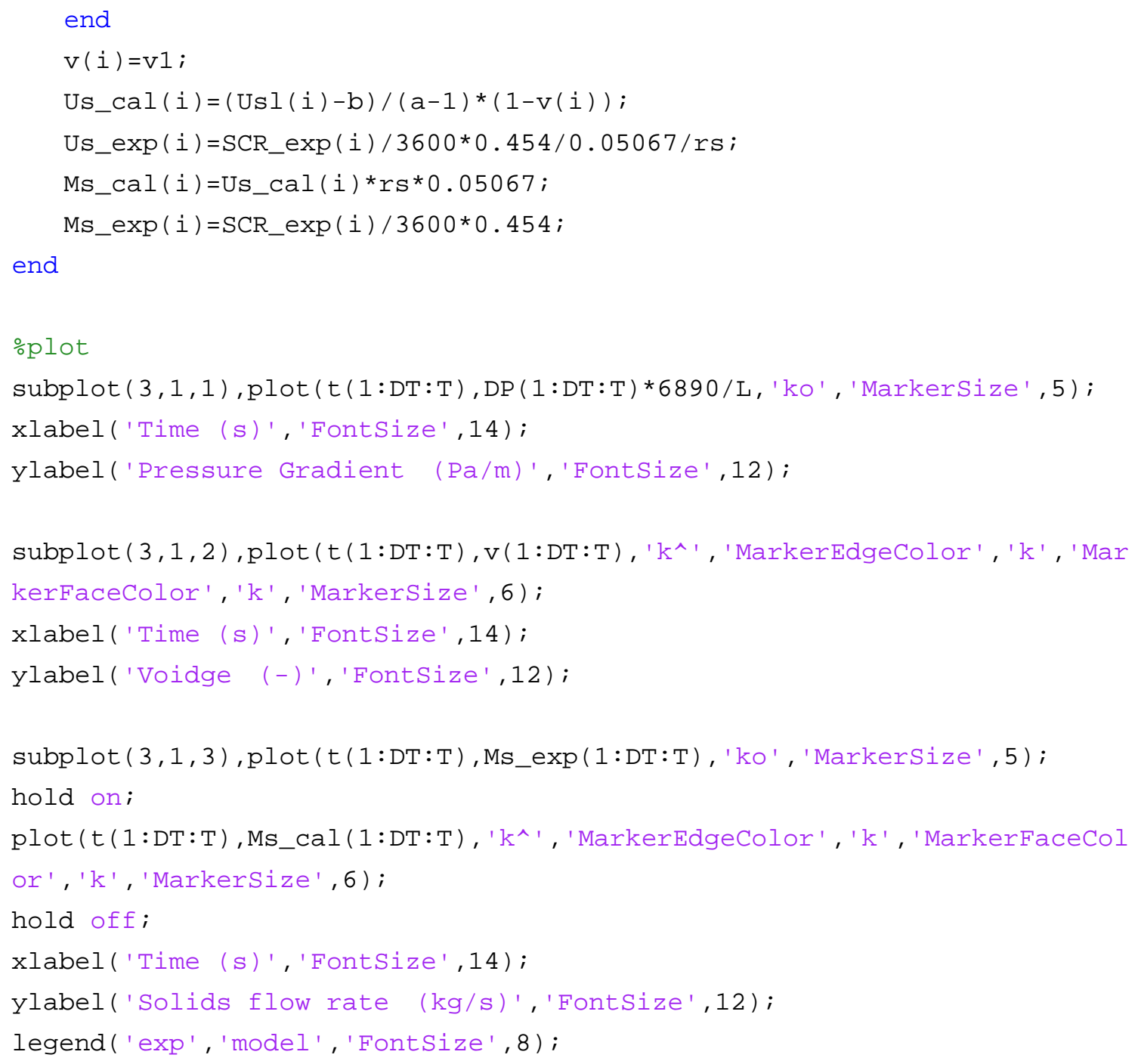




\section{Matlab code for Integrated CFB Model}

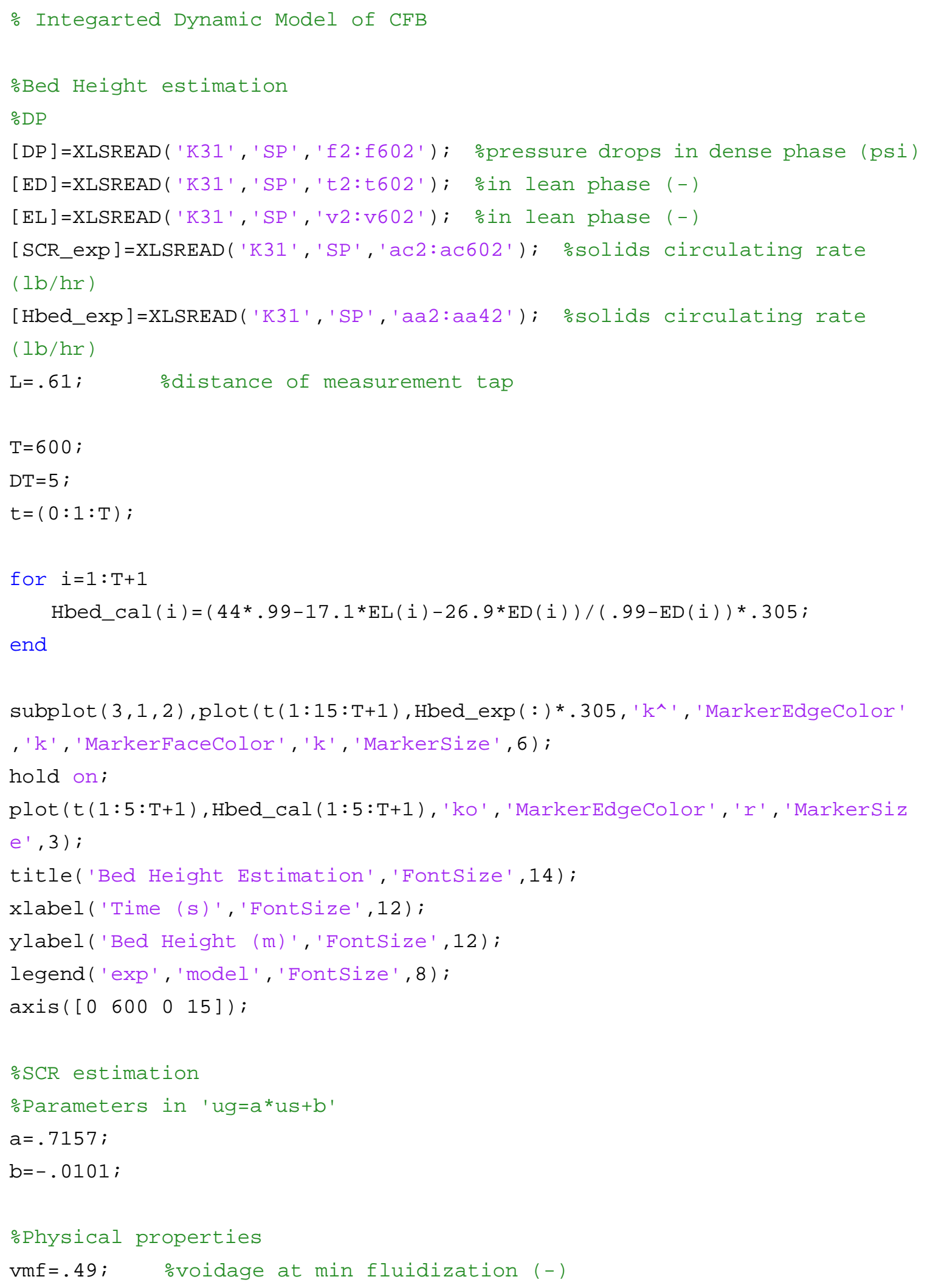




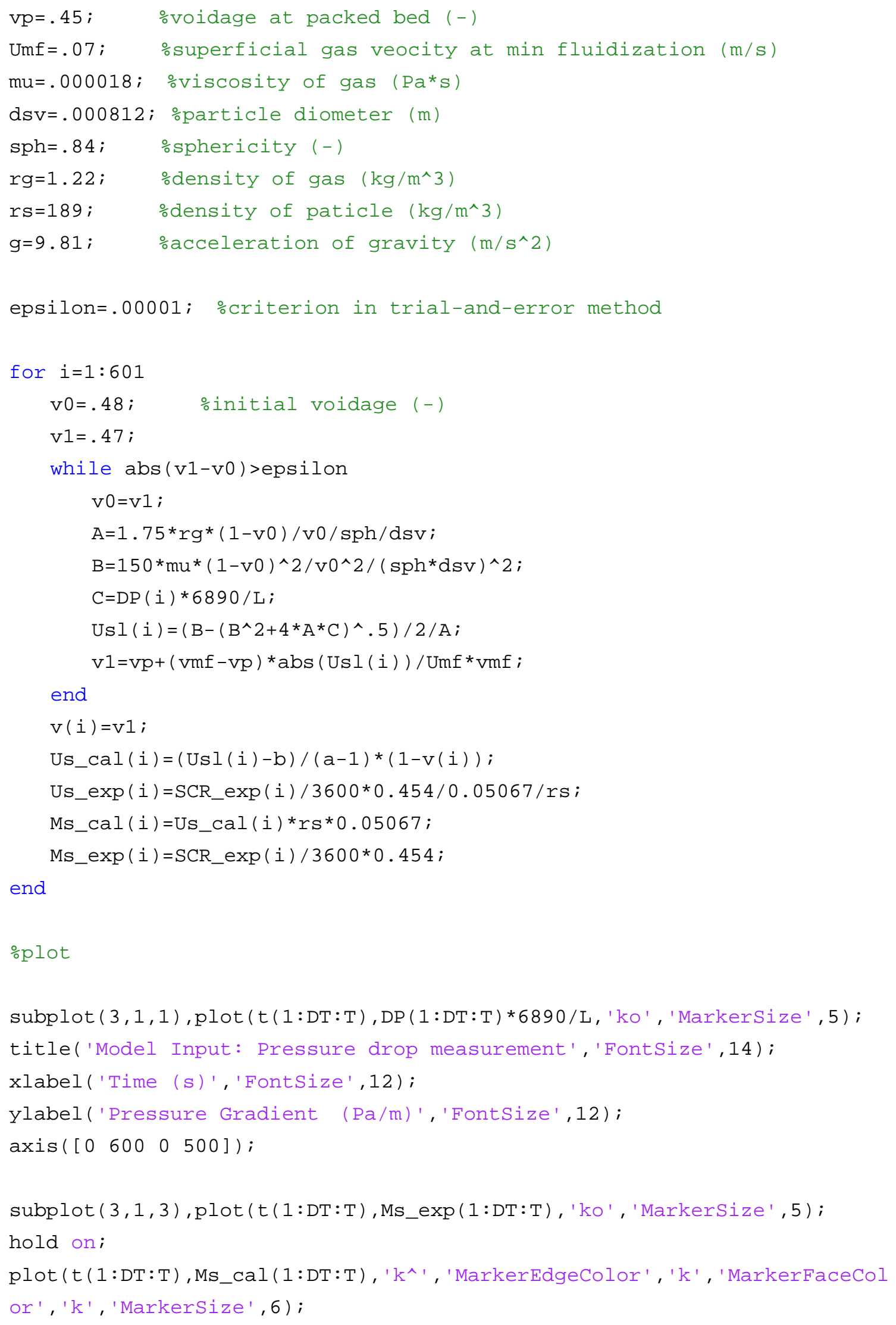




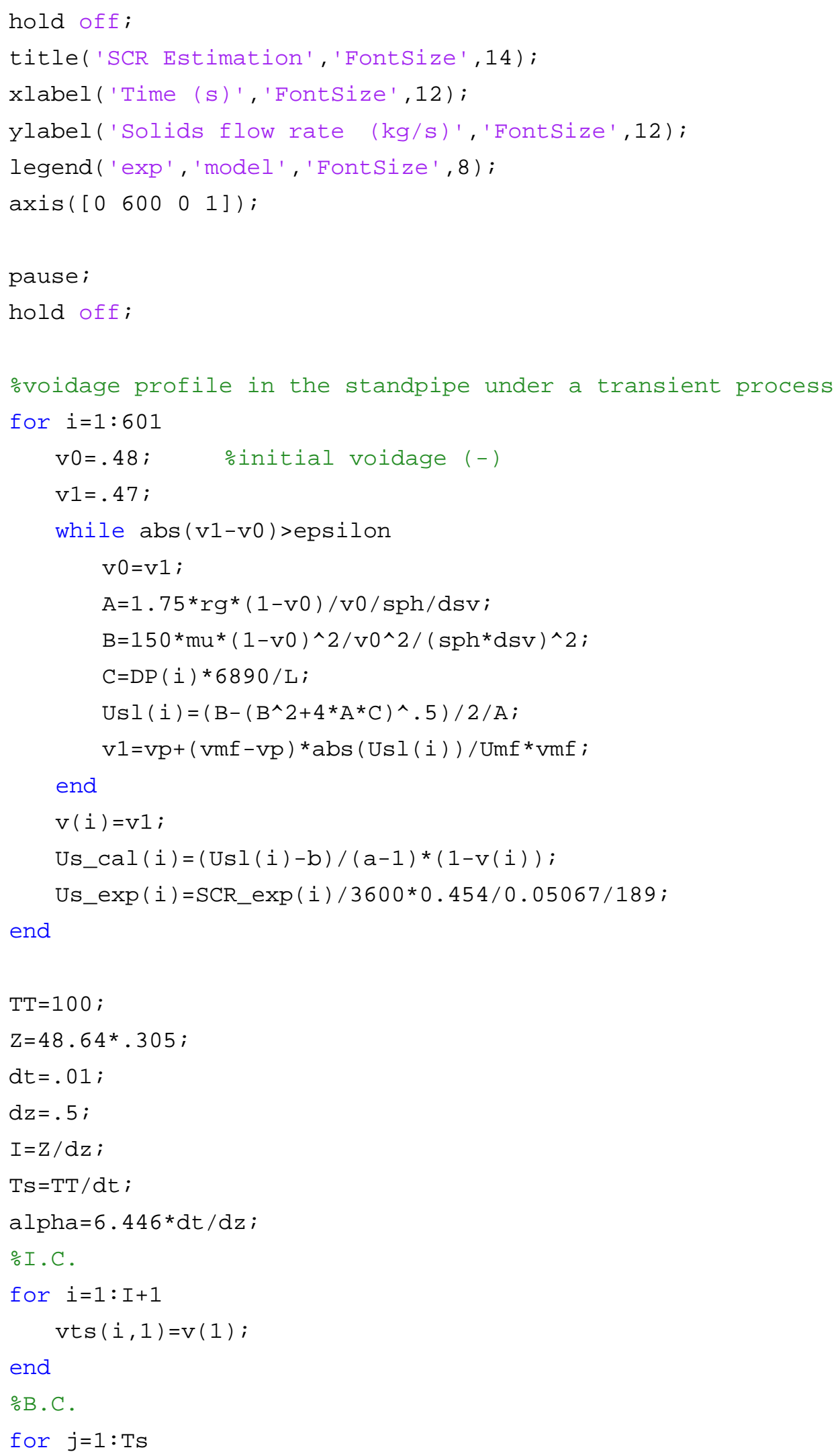




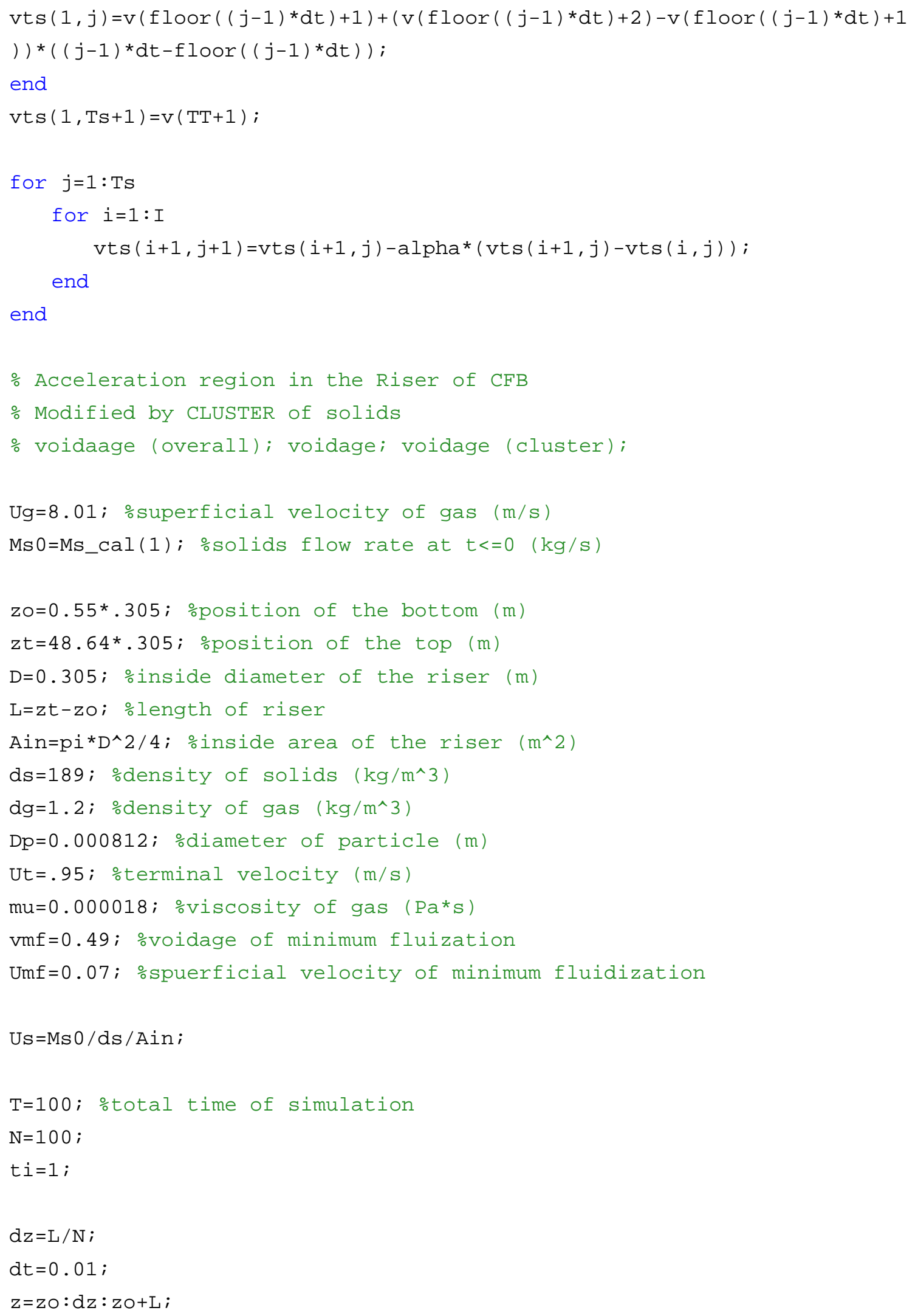


$\mathrm{t}=0: \mathrm{ti}: \mathrm{T} ;$

$\mathrm{Tn}=\mathrm{ti} / \mathrm{dt}$;

$g=9.81$;

[exp_data $]=\operatorname{XLSREAD}\left({ }^{\prime} K 31\right.$ ', 'PG' $)$;

for $i=1: 18$

for $j=1: 201$

$\operatorname{pgexp}(i, j)=\exp \_\operatorname{data}(j, i+2)$;

end

end

z_exp $(1)=(0+2) *$. 305/2;

$z \_\exp (2)=(2+4.17) * .305 / 2$;

$z \_\exp (3)=(4.17+5.17) * .305 / 2$;

$z \_\exp (4)=(5.17+12) * .305 / 2$;

$z \_\exp (5)=(12+14) * 305 / 2$;

$z_{-} \exp (6)=(14+16.5) * 305 / 2$;

$z_{-} \exp (7)=(16.5+19.5) * .305 / 2$;

$z_{-} \exp (8)=(19.5+22.67) * 305 / 2$;

$z \_\exp (9)=(22.67+26.33) * .305 / 2$;

$z_{-} \exp (10)=(26.33+30.33) * .305 / 2$;

$z_{-} \exp (11)=(30.33+32.33) * .305 / 2$;

$z_{-} \exp (12)=(32.33+34.33) * .305 / 2$;

$z_{-} \exp (13)=(34.33+36.33) * .305 / 2$;

$z_{-} \exp (14)=(36.33+38.33) * .305 / 2$;

$z_{-} \exp (15)=(38.33+40.33) * 305 / 2$;

$z_{-} \exp (16)=(40.33+42.58) * .305 / 2$;

$z_{\_} \exp (17)=(42.58+46.58) * .305 / 2$;

z_exp $(18)=(46.58+50.75) * .305 / 2$;

\%initial conditions

\%Determine the parameter $A$ in the correlation of the cluster size $\mathrm{M} 2=\left(\mathrm{Umf}+\mathrm{Us}^{*} \mathrm{vmf} /(1-\mathrm{vmf})\right){ }^{*} 9.81$;

$\mathrm{Q} 1=(\mathrm{ds}-\mathrm{dg}) * 9.81 / \mathrm{ds} *\left(\mathrm{Ug}+\mathrm{Us}{ }^{*} \mathrm{vmf} /(1-\mathrm{vmf})+\mathrm{Ut}{ }^{*} \mathrm{vmf} \wedge 4.7 / 4\right)$;

$A=\left(3333^{*} U s^{*} 9.81-M 2\right) *(1-v m f) *(d s-d g) /(Q 1-2 * M 2) / d s$;

$\mathrm{Vcr}=1 /\left(1+\mathrm{Us} / \mathrm{Ug}^{*}(\mathrm{ds} / \mathrm{dg})^{\wedge} .5\right)$;

$\mathrm{vt}=\mathrm{Vcr}+.01$;

ut=Us/(1-vt); \%solids velocity at the lower riser

$\mathrm{HL}=1 ; \% \odot$ for Harris correlation; otherwise for Lints correlation 


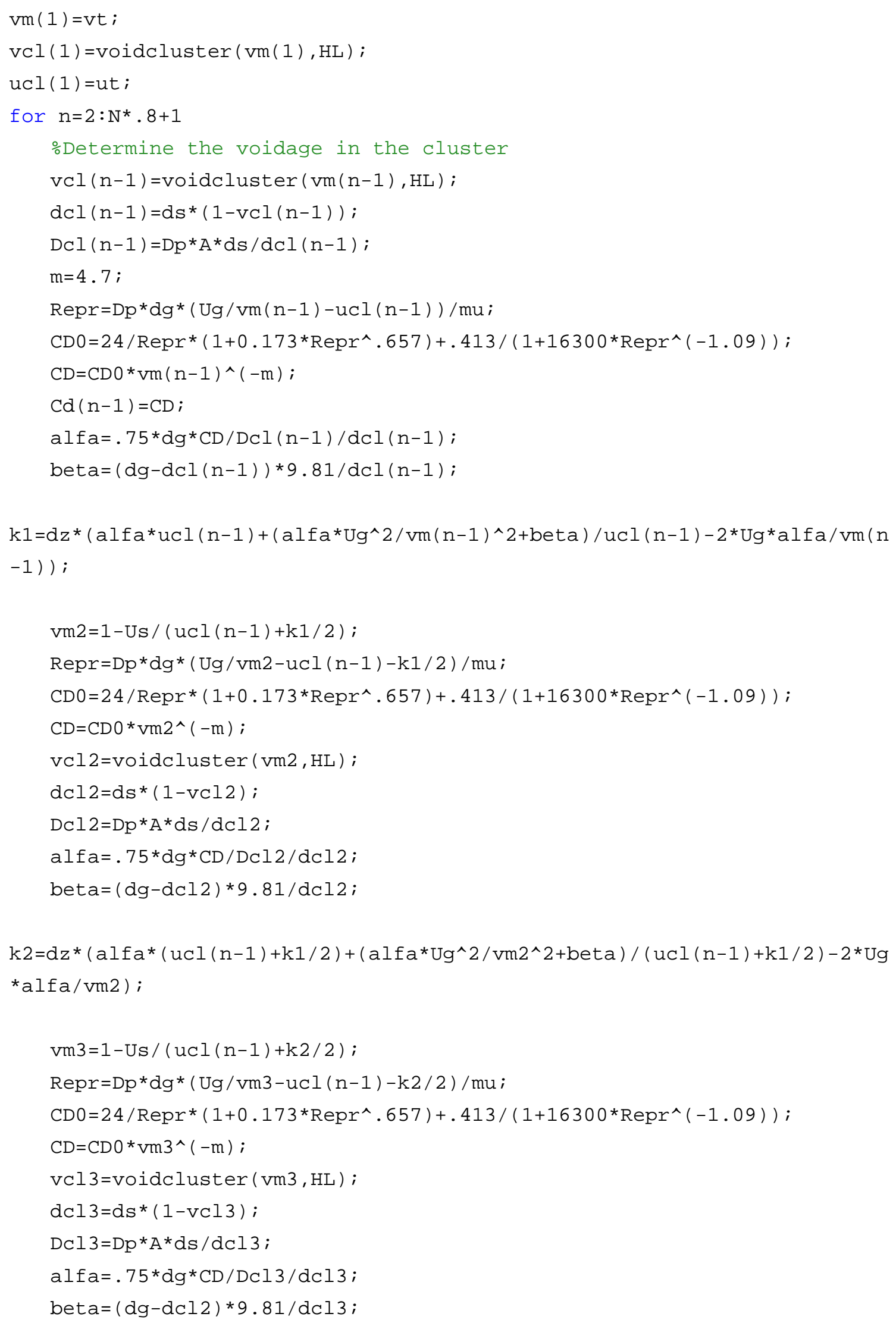




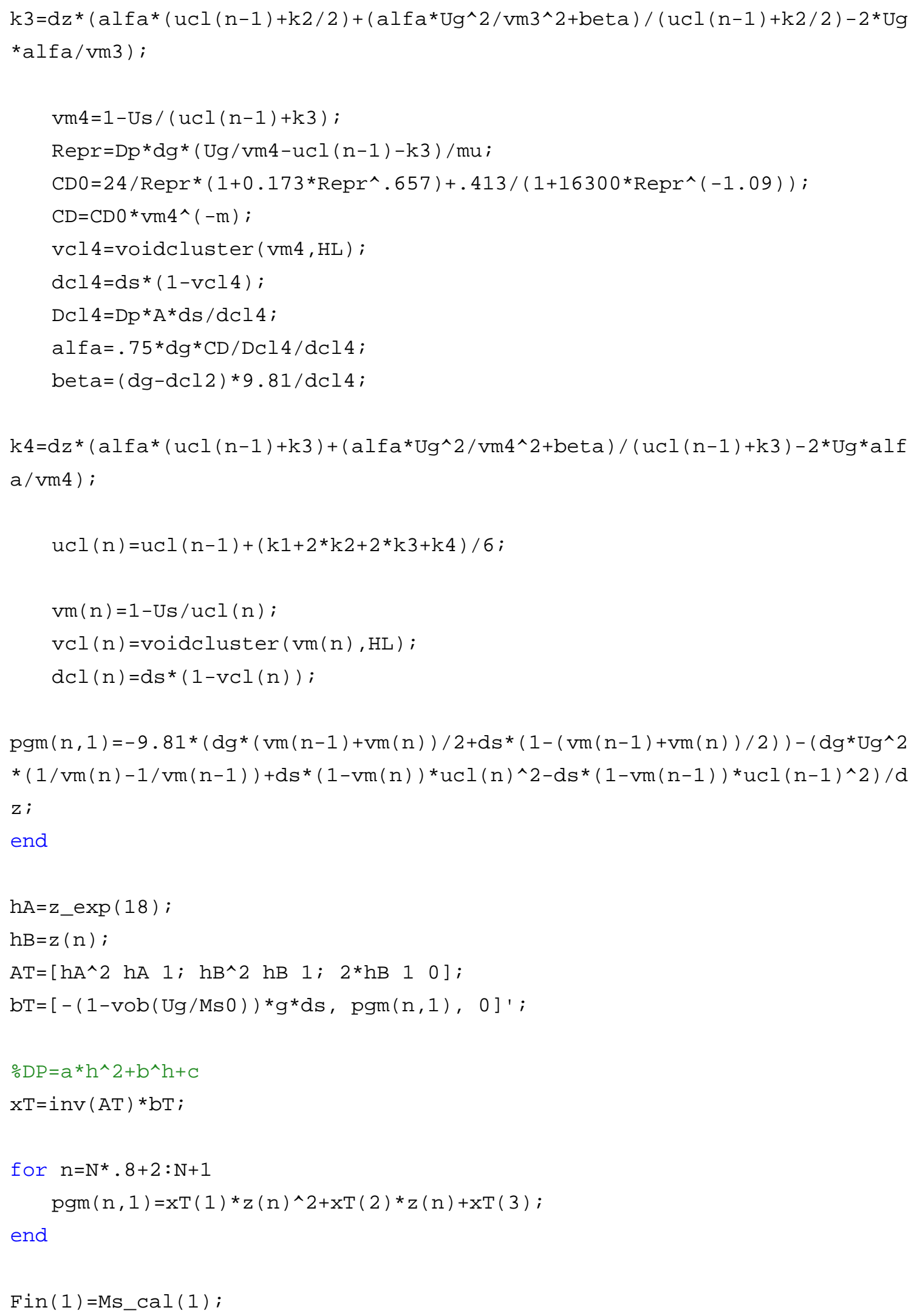




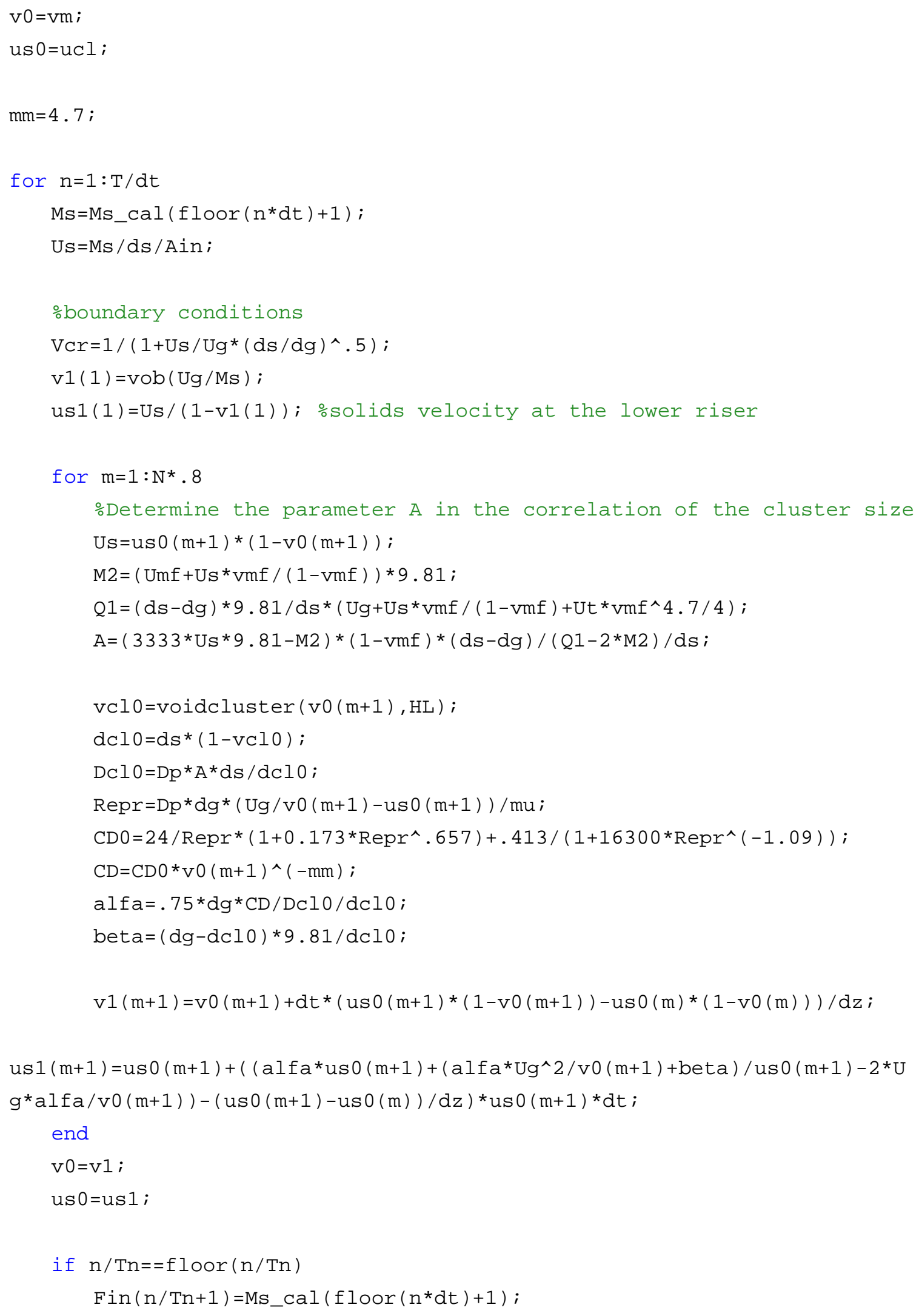


for $m=1: N^{*} .8$

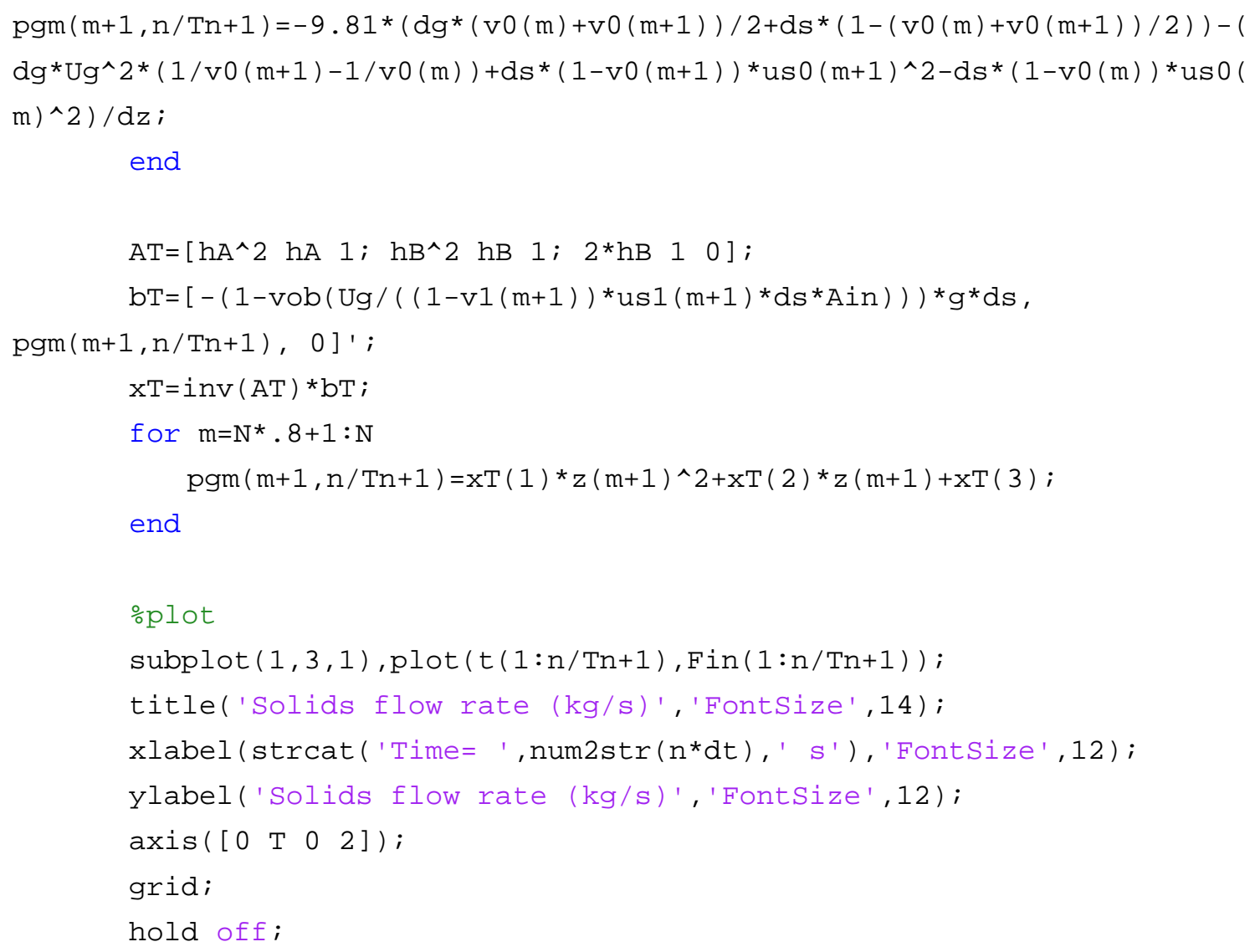

subplot $(1,3,2), \operatorname{plot}\left(\operatorname{pgm}(2: N+1, n / T n+1), z(2: N+1), \operatorname{pgexp}(:, n / T n+1), z \_e x p, '\right.$ * ');

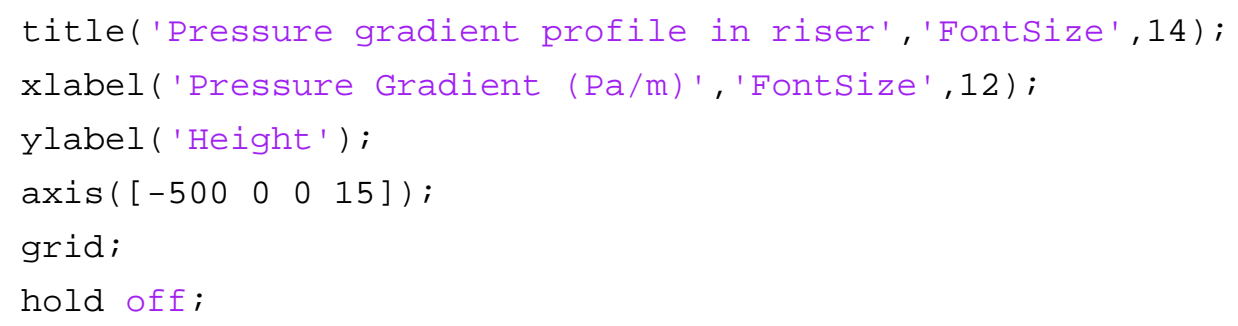

subplot $(1,3,3), \operatorname{plot}\left(\operatorname{vts}\left(1:\right.\right.$ floor $\left(\right.$ Hbed_cal $\left.\left.\left(n^{*} d t\right) / .5\right)+1, n+1\right),(0: .5:$ floor $(H$ bed_cal $\left.\left.\left(\mathrm{n}^{*} \mathrm{dt}\right) / .5\right)^{*} .5\right)$, 'k^ ', 'MarkerEdgeColor ', 'k' , 'MarkerFaceColor' , 'k', 'MarkerSize', 6$)$;

title('Voidage profile in standpipe', 'FontSize',14);

xlabel('Voidge (-)', 'FontSize', 12);

ylabel('z (m)', 'FontSize', 12); 


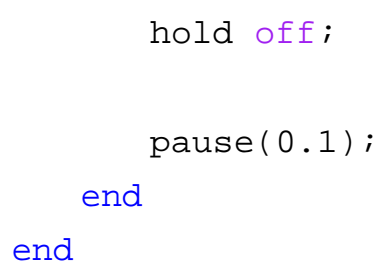

